AUTARQUIA ASSOCIADA À UNIVERSIDADE DE SÃO PAULO

\title{
ESTUDO DO PIOR CASO NA VALIDAÇÃO DE LIMPEZA DE EQUIPAMENTOS DE PRODUÇÃO DE RADIOFÁRMACOS DE REAGENTES LIOFILIZADOS. VALIDAÇÃO DE METODOLOGIA DE CARBONO ORGÂNICO TOTAL.
}

\author{
Luciana Valéria Ferrari Machado Porto
}

Dissertação apresentada como parte dos requisitos para obtenção do Grau de Mestre em Ciências na Área de Tecnologia Nuclear - Aplicações

Orientadora:

Profa. Dra. Margareth Mie Nakamura Matsuda 
INSTITUTO DE PESQUISAS ENERGÉTICAS E NUCLEARES

Autarquia associada à Universidade de São Paulo

ESTUDO DO PIOR CASO NA VALIDAÇÃO DE LIMPEZA DE EQUIPAMENTOS DE PRODUÇÃO DE RADIOFÁRMACOS DE REAGENTES LIOFILIZADOS. VALIDAÇÃO DE METODOLOGIA DE CARBONO ORGÂNICO TOTAL.

Luciana Valéria Ferrari Machado Porto

Dissertação apresentada como parte dos requisitos para obtenção do Grau de Mestre em Ciências na Área de Tecnologia Nuclear - Aplicações

Orientadora:

Profa. Dra. Margareth Mie Nakamura Matsuda

Versão Corrigida

Versão Original disponível no IPEN

São Paulo

2015 


\section{DEDICATÓRIA}

A Deus por me conceder o dom da vida e a oportunidade de aprender com meus erros a tornar-me uma pessoa melhor, e, principalmente, por carregar-me em seus braços em todos os momentos difíceis, mostrando-me sempre o melhor caminho a seguir.

Aos meus pais, Demósthenes Garcia Machado (in memorian) e Maria Aparecida Ferrari Machado, por todo amor, dedicação e abnegação em minha criação. Obrigada por todos os ensinamentos transmitidos e por sempre primarem pela minha educação, e, principalmente, pelos exemplos de caráter, hombridade e respeito para com as pessoas.

Ao meu esposo José Marcelo de Moraes Porto, meu grande e eterno amor, companheiro de todos os momentos, meu maior incentivador e melhor amigo, o meu muito obrigado por toda compreensão durante os momentos de crise e estresse, que não foram raros nestes últimos meses. Apesar da distância, você esteve presente me apoiando incondicionalmente com suas palavras de incentivo e sabedoria, acalmando-me e aliviando minhas angústias, sempre me fazendo acreditar que chegaria ao final desta difícil etapa e que conseguiria alcançar este sonho, que por muitas vezes considerei impossível para mim. Sou imensamente grata por cada gesto de carinho, cada telefonema, cada mensagem, cada poema a mim dedicados. Você fez e faz por mim muito mais do que eu poderia merecer. É como sempre digo e não me canso de repetir: EU TE AMO, VOCÊ É MEU SOL!

Aos meus filhos Felipe Machado Porto e Lucas Machado Porto, pelas palavras de incentivo, por suportarem os meus desabafos nos momentos difíceis e por todas as privações passadas pela minha ausência. Vocês são a minha maior realização na vida e agradeço todos os dias a Deus pela benção e privilégio de tê-los como filhos. Faço minhas as palavras de E. E. Cummings em seu poema:

\section{“Eu carrego seu coração comigo}

\section{Eu o carrego em meu coração}

Eu nunca estou sem ele

Aonde quer que eu vá, você vai comigo, querido...

Aqui está o segredo mais profundo que ninguém sabe

Aqui está a raiz da raiz

E o botão do botão

E o céu do céu 
De uma árvore chamada vida

A qual fica mais alta do que a alma pode esperar

Ou que a mente pode esconder

E esta é a maravilha que mantêm as estrelas separadas

Eu carrego seu coração

Eu o carrego em meu coração." 


\section{AGRADECIMENTOS}

À Agência Nacional de Vigilância Sanitária - ANVISA, por possibilitar o meu afastamento para cursar o Mestrado.

À Universidade de São Paulo pelo oferecimento do curso de pós-graduação e ao Instituto de Pesquisas Energéticas e Nucleares juntamente com o Centro de Radiofarmácia pela infraestrutura proporcionada e oportunidade para o desenvolvimento deste trabalho.

Ao MSc. Jair Mengatti pela colaboração proporcionada para a realização deste estudo.

À Dra. Margareth Mie Nakamura Matsuda pela orientação, dedicação, paciência e conselhos a mim dispensados. O meu muito obrigado por compartilhar seus conhecimentos e sabedoria, me incentivando a buscar cada vez mais o meu crescimento e amadurecimento profissional.

À querida amiga e mestranda Cássia Yumi Furukawa, minha eterna gratidão por todo carinho demonstrado, pelas conversas, trocas de experiências, toda ajuda e apoio na realização deste estudo.

Ao querido amigo e "filho postiço" Rafael Puga, o meu eterno agradecimento pelos conselhos, pelas palavras de incentivo, pelas piadas trocadas, por tornar os dias mais leves e alegres, e por suportar muitas vezes os meus desabafos.

Ao farmacêutico e amigo Marcelo Pucci (vulgo "Molanguinho Malando") e a querida Vivian Mendonça, meu eterno carinho e gratidão por todo apoio prestado para a realização das análises laboratoriais e por sempre me socorrerem em minhas deficiências tecnológicas.

À querida Stella Benedetti, por todas as orientações e esclarecimentos prestados para realização da validação de metodologia, e pela paciência com meus esquecimentos.

Às queridas Dra. Patrícia de Andrade Martins e Dra. Dulcila Maria Lessa Bernardes, pela maneira carinhosa com que me receberam no Centro de Radiofarmácia, proporcionando um clima de amizade e coleguismo do qual jamais me esquecerei.

À minha querida amiga e colega de trabalho Alessandra Paixão Dias, por toda ajuda prestada durante o período de afastamento de minhas funções na ANVISA.

Aos demais Pesquisadores, Funcionários e Colegas de Trabalho do Centro de Radiofarmácia que contribuíram direta ou indiretamente para a consolidação deste trabalho. 


\section{AGRADECIMENTO ESPECIAL}

Ao meu querido filho, Felipe Machado Porto, meu especial agradecimento por toda ajuda prestada na confecção desta dissertação. Obrigada por toda paciência, pelas horas de sono perdidas, por levantar o meu moral nos momentos de tristeza e angústia pelo afastamento, por todos os cuidados a mim dispensados. Não tenho palavras para descrever o quanto me sinto abençoada por tê-lo em minha vida! Você é, com certeza, um anjo que Deus colocou em meu caminho. TE AMO FILHOTE! 
"Talvez não tenha conseguido fazer o melhor, mas lutei para que o melhor fosse feito. Não sou o que deveria ser, mas Graças a Deus, não sou o que era antes."

(Marthin Luther King)

"A tarefa não é ver aquilo que ninguém viu, mas pensar o que ninguém ainda pensou sobre aquilo que todo mundo vê."

(Arthur Schopenhauer) 


\section{ESTUDO DO PIOR CASO NA VALIDAÇÃO DE LIMPEZA DE EQUIPAMENTOS DE PRODUÇÃO DE RADIOFÁRMACOS DE REAGENTES LIOFILIZADOS. VALIDAÇÃO DE METODOLOGIA DE CARBONO ORGÂNICO TOTAL.}

\section{Luciana Valéria Ferrari Machado Porto}

\section{RESUMO}

Os radiofármacos são definidos como preparações farmacêuticas contendo um radionuclídeo em sua composição, são administrados intravenosamente em sua maioria, e, portanto, o cumprimento dos princípios de Boas Práticas de Fabricação (BPF) é essencial e indispensável à tais produtos. A validação de limpeza é um requisito das BPF e consiste na evidência documentada que demonstra que os procedimentos de limpeza removem os resíduos a níveis pré-determinados de aceitação, garantindo que não haja contaminação cruzada. Uma simplificação da validação dos processos de limpeza é admitida, e consiste na escolha de um produto, denominado de "pior caso" ou worst case, para representar a limpeza de todos os equipamentos da mesma linha de produção. Uma das etapas da validação de limpeza é o estabelecimento e validação do método analítico para quantificação do resíduo. O objetivo deste estudo foi estabelecer o pior caso para a validação de limpeza dos equipamentos de produção de reagentes liofilizados-RL para marcação com ${ }^{99 \mathrm{~m}} \mathrm{Tc}$, avaliar a utilização do teor de carbono orgânico total (COT) como indicador de limpeza dos equipamentos utilizados na fabricação dos RL, validar o método para determinação de CONP (carbono orgânico não purgável/volátil) e realizar testes de recuperação com o produto escolhido como pior caso. A escolha do produto pior caso baseou-se no cálculo de um índice denominado "índice para pior caso - Worst Case Index (WCI) ”, utilizando informações de solubilidade dos fármacos, dificuldade de limpeza dos equipamentos e taxa de ocupação dos produtos na linha de produção. O produto indicado como pior caso entre os RL foi o MIBI-TEC. Os ensaios de validação do método foram realizados utilizando-se um analisador de carbono modelo TOC-Vwp acoplado a um amostrador automático modelo ASI-V, ambos da marca Shimadzu ${ }^{\circledR}$ e controlados por software TOC Control-V Shimadzu ${ }^{\circledR}$. Foi utilizado o método direto de quantificação do CONP. Os parâmetros avaliados na validação do método foram: conformidade do sistema, robustez, linearidade, limites de detecção (LD) e de quantificação (LQ), precisão (repetibilidade e precisão 
intermediária), e exatidão (recuperação) e foram definidos como: $4 \%$ acidificante, $2,5 \mathrm{~mL}$ de oxidante, tempo de integração da curva de 4,5 minutos, tempo de sparge de 3,0 minutos e linearidade na faixa de 40-1000 $\mu \mathrm{gL}^{-1}$, com coeficiente de correlação (r) e soma residual dos mínimos quadrados $\left(\mathrm{r}^{2}\right)>0,99$ respectivamente. LD e LQ para CONP foram 14,25 ppb e 47,52 ppb, respectivamente, repetibilidade entre $0,11-4,47 \%$; a precisão intermediária entre 0,59 a $3,80 \%$ e exatidão entre $97,05-102,90 \%$. A curva analítica para Mibi mostrou-se linear na faixa de 100-800 $\mu \mathrm{gL}^{-1}$, com r e ${ }^{2}>0,99$, apresentando parâmetros similares aos das curvas analíticas de CONP. Os resultados obtidos neste estudo demonstraram que a abordagem do pior caso para validação de limpeza é um meio simples e eficaz para diminuir a complexidade e morosidade do processo de validação, além de proporcionar uma redução nos custos envolvidos nestas atividades. Todos os resultados obtidos nos ensaios de validação de método CONP atenderam as exigências e especificações preconizadas pela norma RE 899/2003 da ANVISA para considerar a metodologia validada. 


\title{
WORST-CASE STUDY FOR CLEANING VALIDATION OF EQUIPMENTS IN THE RADIOPHARMACEUTICAL PRODUCTION OF LYOPHILIZED REAGENTS. METODOLOGY VALIDATION OF TOTAL ORGANIC CARBON.
}

\author{
Luciana Valéria Ferrari Machado Porto
}

\begin{abstract}
Radiopharmaceuticals are defined as pharmaceutical preparations containing a radionuclide in their composition, mostly intravenously administered, and therefore compliance with the principles of Good Manufacturing Practices (GMP) is essential and indispensable. Cleaning validation is a requirement of the current GMP, and consists of documented evidence, which demonstrates that the cleaning procedures are able to remove residues to pre-determined acceptance levels, ensuring that no cross contamination occurs. A simplification of cleaning processes validation is accepted, and consists in choosing a product, called "worst case", to represent the cleaning processes of all equipment of the same production area. One of the steps of cleaning validation is the establishment and validation of the analytical method to quantify the residue. The aim of this study was to establish the worst case for cleaning validation of equipment in the radiopharmaceutical production of lyophilized reagent (LR) for labeling with ${ }^{99 \mathrm{~m}} \mathrm{Tc}$, evaluate the use of Total Organic Carbon (TOC) content as indicator of equipment cleaning used in the LR manufacture, validate the method of Non-Purgeable Organic Carbon (NPOC), and perform recovery tests with the product chosen as worst case. Worst case product's choice was based on the calculation of an index called "Worst Case Index" (WCI), using information about drug solubility, difficulty of cleaning the equipment and occupancy rate of the products in line production. The products indicated as "worst case" was the LR MIBI-TEC. The method validation assays were performed using carbon analyser model TOC-Vwp coupled to an autosampler model ASI-V, both from Shimadzu ${ }^{\circledR}$, controlled by TOC Control-V software. It was used the direct method for NPOC quantification. The parameters evaluated in the validation method were: system suitability, robustness, linearity, detection limit (DL) and quantification limit (QL), precision (repeatability and intermediate precision), and accuracy (recovery) and they were defined as follows: 4\% acidifying reagent, $2.5 \mathrm{ml}$ oxidizing reagent, 4.5 minutes integration curve time, 3 minutes sparge time and linearity in 40-1000 $\mu \mathrm{gL}^{-1}$ range,
\end{abstract}


with correlation coefficient $(r)$ and residual sum of minimum squares $\left(\mathrm{r}^{2}\right)$ greater than 0.99 respectively. DL and QL for NPOC were $14.25 \mathrm{ppb}$ e $47.52 \mathrm{ppb}$ respectively, repeatability between 0.11 and $4.47 \%$; the intermediate precision between 0.59 and $3.80 \%$ and accuracy between 97.05 and $102.90 \%$. The analytical curve for Mibi was linear in $100-800 \mu \mathrm{gL}^{-1}$ range with $r$ and $r^{2}$ greater than 0.99 , presenting similar parameters to NPOC analytical curves. The results obtained in this study demonstrated that the worst-case approach to cleaning validation is a simple and effective way to reduce the complexity and slowness of the validation process, and provide a costs reduction involved in these activities. All results obtained in NPOC method validation assays met the requirements and specifications recommended by the RE 899/2003 Resolution from ANVISA to consider the method validated. 


\section{SUMÁRIO}

\section{Página}

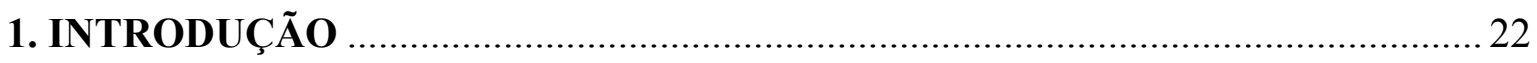

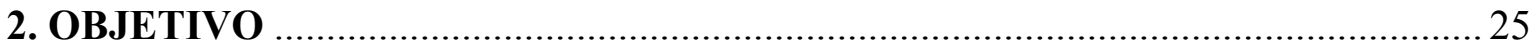

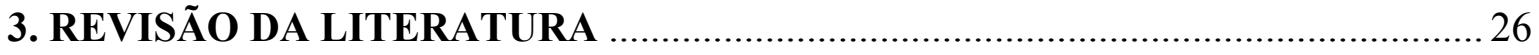

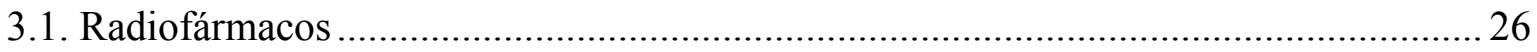

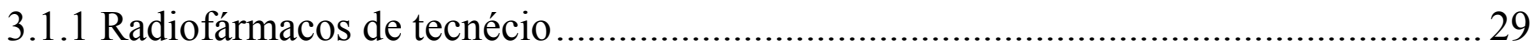

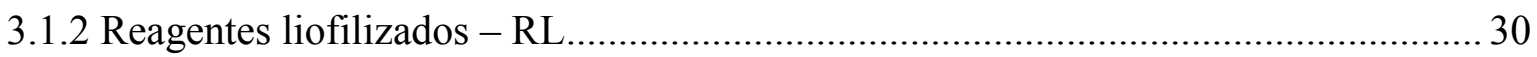

3.2 Garantia da Qualidade, Boas Práticas de Fabricação e Controle de Qualidade de

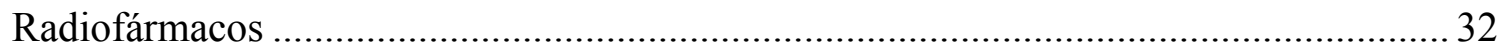

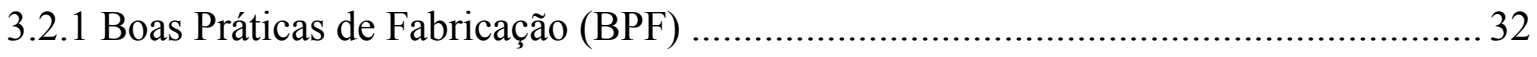

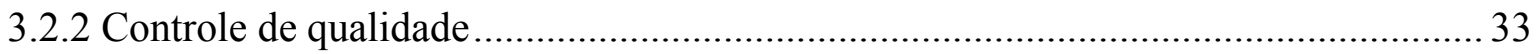

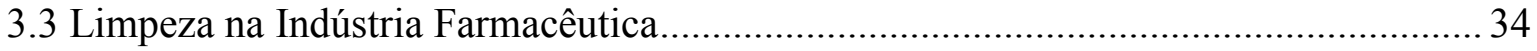

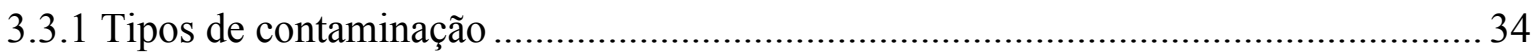

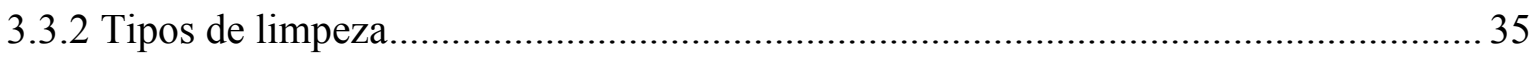

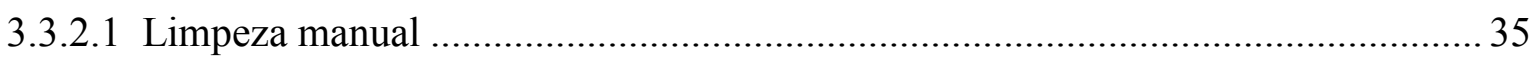

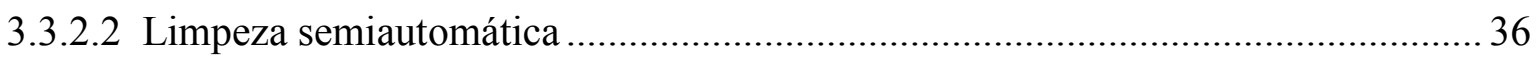

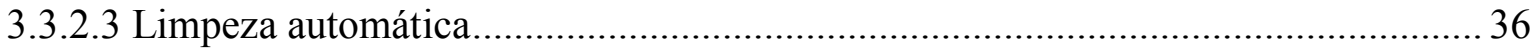

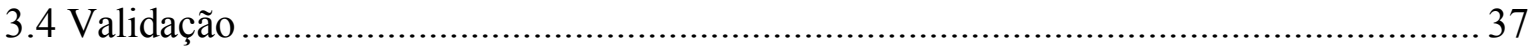

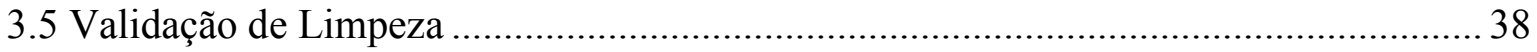

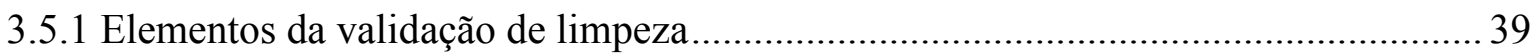

3.5.1.1 Estabelecimento de critérios de aceitação .............................................................. 39

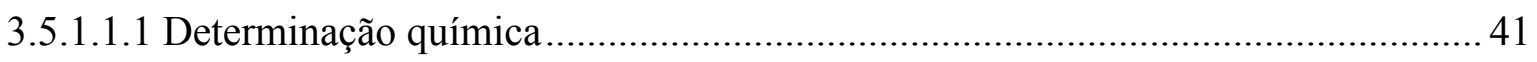

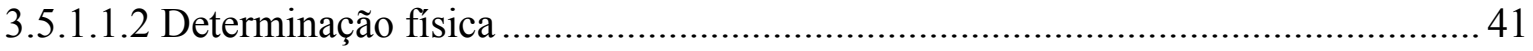

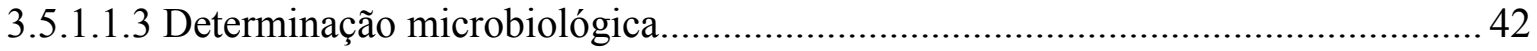

3.5.1.1.4 Fórmulas para cálculo dos critérios de aceitação .................................................. 43

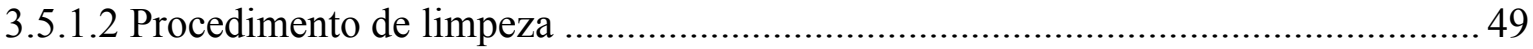

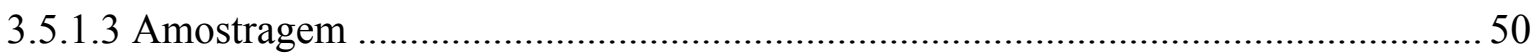

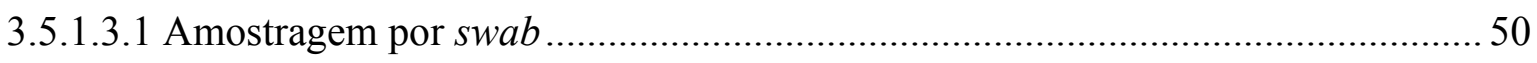

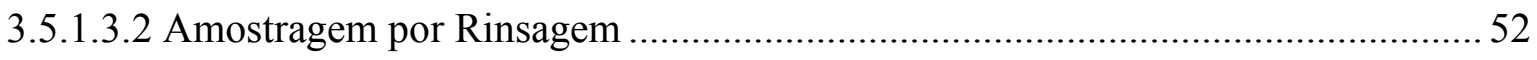

3.5.1.4 Métodos analíticos utilizados em validação de limpeza........................................... 53

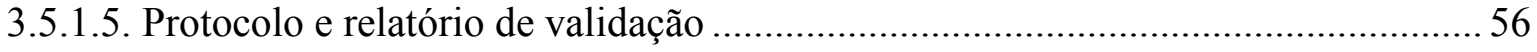


3.6 Carbono Orgânico Total (COT, ou do inglês, TOC) ..................................................... 58

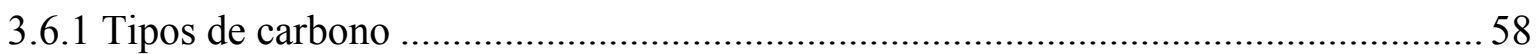

3.6.2. Métodos analíticos para determinação de carbono orgânico total (COT) .................. 59

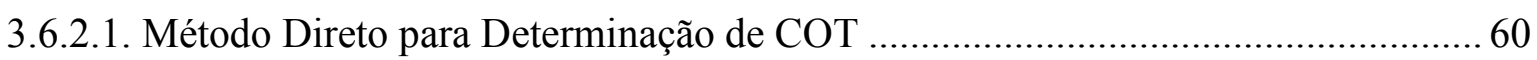

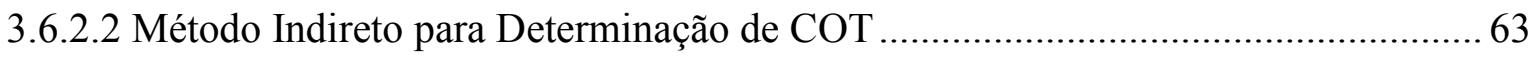

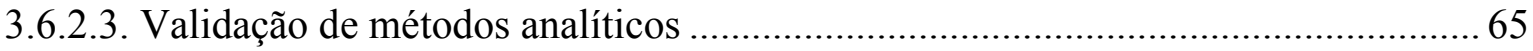

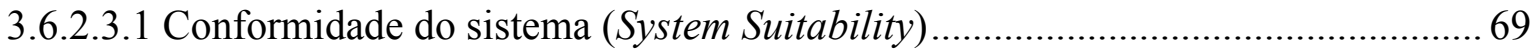

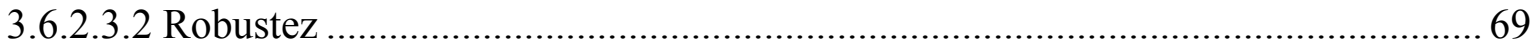

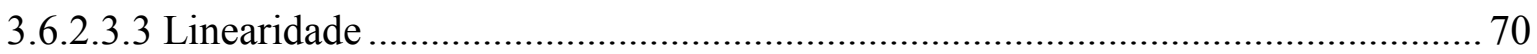

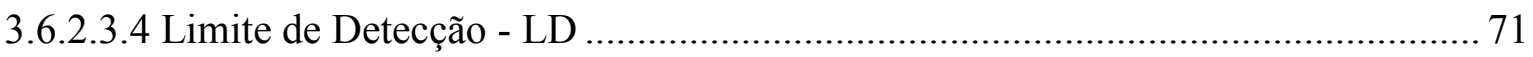

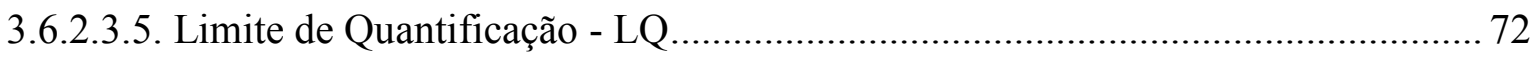

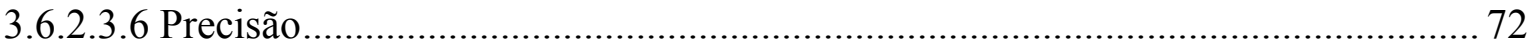

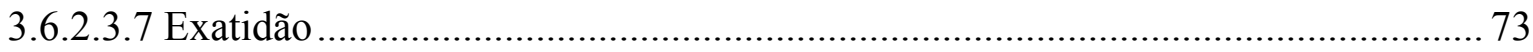

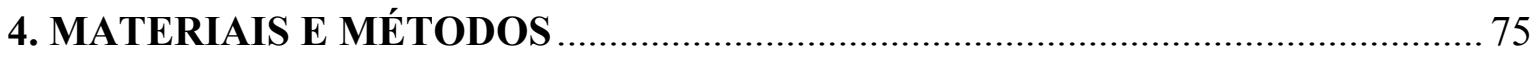

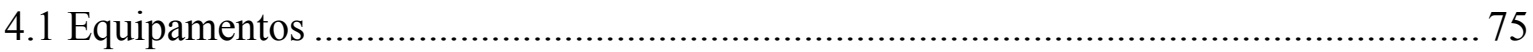

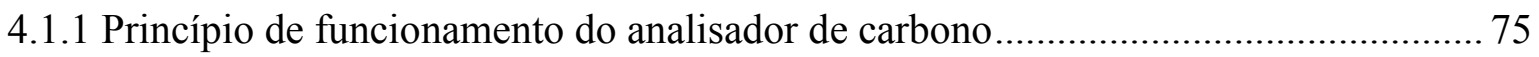

4.1.1.1 Descrição das etapas para determinação de CONP ................................................. 75

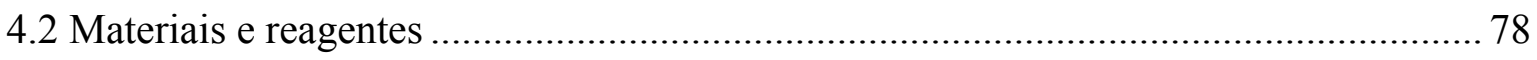

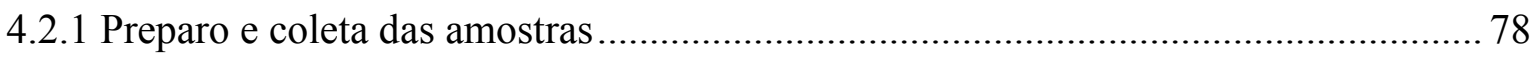

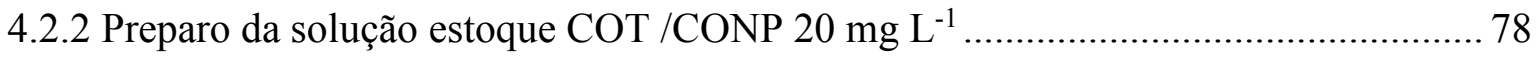

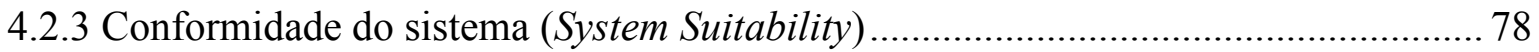

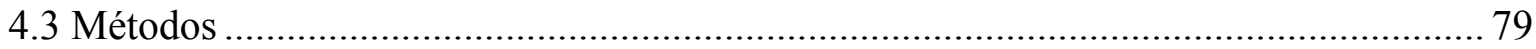

4.3.1 Análise do teor de COT nos equipamentos de produção de RL................................ 79

4.3.1.1 Análise do teor de COT antes da limpeza dos equipamentos de produção de RL .. 79

4.3.1.2 Análise do teor COT após limpeza dos equipamentos de produção de RL ............ 79

4.3.2 Cálculo do Pior Caso para Validação de Limpeza ....................................................... 80

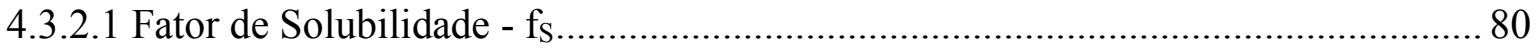

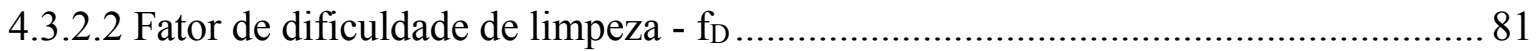

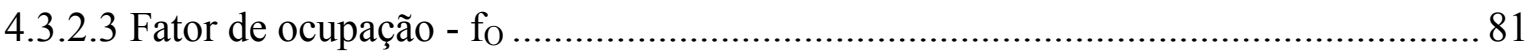

4.3.3 Validação de Método Analítico para Determinação de COT - CONP ....................... 81

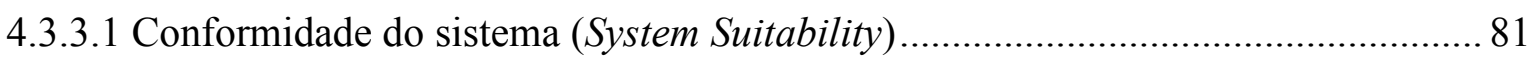

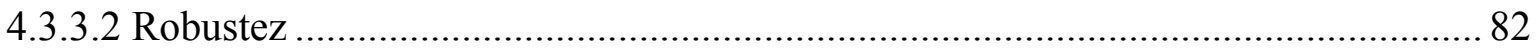

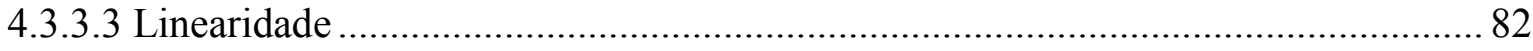

4.3.3.4 Limite de detecção (LD) e limite de quantificação (LQ) ........................................ 83 


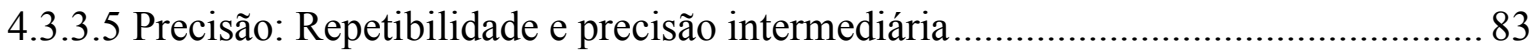

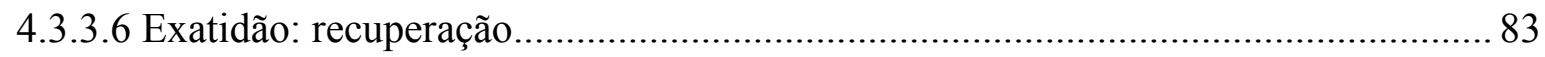

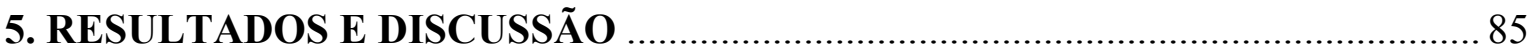

5.1 Recuperação de COT em vidraria utilizada na produção de RL: prévia e posteriormente

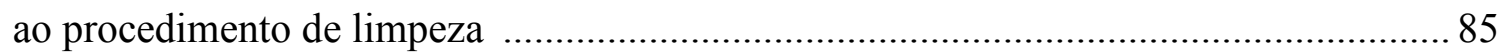

5.2 Estabelecimento do pior caso para validação de limpeza dos equipamentos................ 95

5.3 Validação de Método Analítico para Determinação de COT/CONP ........................... 104

5.3.1 Conformidade do sistema (System Suitability) ..................................................... 104

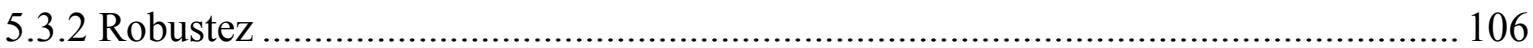

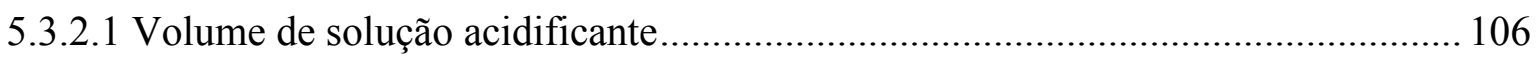

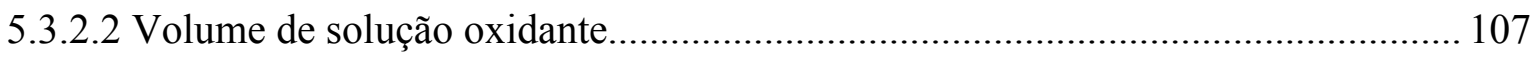

5.3.2.3 Tempo de integração da área da curva de COT/CONP ......................................... 108

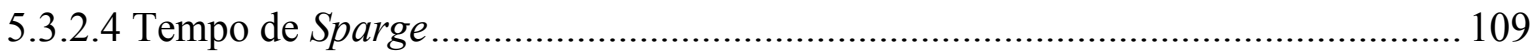

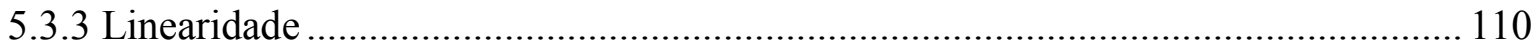

5.3.4 Limite de detecção (LD) e limite de quantificação (LQ) ......................................... 111

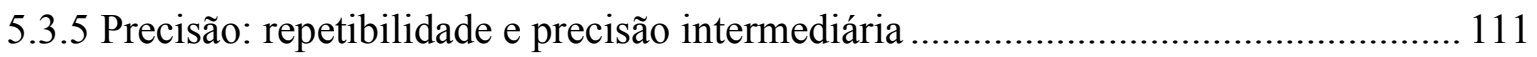

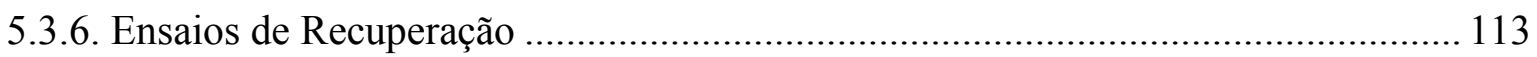

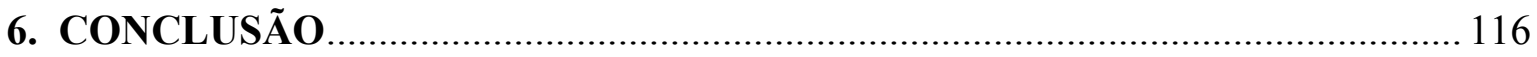

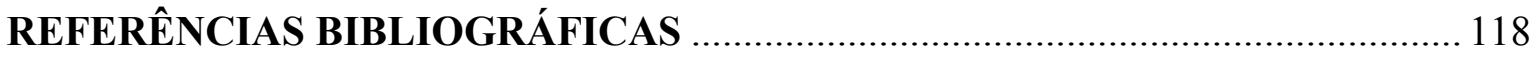




\section{LISTA DE TABELAS}

TABELA 1 - Fator de Segurança segundo rota de administração .................................... 48

TABELA 2 - Técnicas analíticas usadas na Validação de Limpeza..................................... 54

TABELA 3 - Métodos comumente utilizados para diferentes analitos ............................. 54

TABELA 4 - Comparação da capacidade de detecção das técnicas analíticas.................... 55

TABELA 5 - Fases do Processo de Validação de Limpeza.................................................. 57

TABELA 6 - Classificação do Carbono Orgânico conforme características físico-químicas.......59

TABELA 7 - Critério para escolha e aplicação dos ácidos utilizados na determinação de COT 61

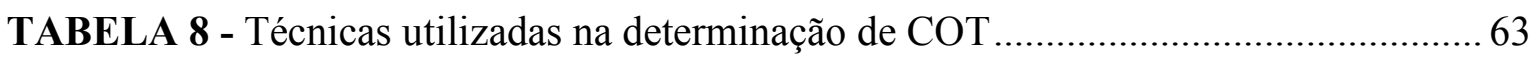

TABELA 9 - Técnicas de deteç̧ão/quantificação de $\mathrm{CO}_{2}$............................................... 65

TABELA 10 - Parâmetros de desempenho previstos no guia harmonizado pela AOAC Internacional, ISO e IUPAC, no documento orientativo do INMETRO e no guia da ANVISA

TABELA 11 - Parâmetros de desempenho e definições apresentados na RE nº $899 / 2003$

TABELA 12 - Dados da análise do teor de COT antes da execução dos procedimentos de limpeza dos equipamentos utilizados na produção dos RL .85

TABELA 13 - Dados da análise do teor de COT após execução dos procedimentos de limpeza dos equipamentos utilizados na produção dos RL

TABELA 14 - Dados da análise de CONP após execução dos procedimentos de limpeza dos equipamentos utilizados na produção dos RL............................................................ 93

TABELA 15 - Dados de Solubilidade dos RL produzidos no IPEN-CNEN/SP 97

TABELA 16 -Tabela de Referência com respectivo Fator de Solubilidade em água - $\mathrm{f}_{\mathrm{S} . . . . . .98}$

TABELA 17 - Fator de dificuldade de limpeza - $f_{D}$

TABELA 18 - Número de lotes de RL produzidos no IPEN - CNEN/SP em 2013 ........ 100

TABELA 19 - Fator de Ocupação - fo. 100

TABELA 20 - Valores dos fatores $f_{O}, f_{D}, f_{S}$ e cálculo do WCI para cada RL produzido no IPEN-CNEN/SP

TABELA 21 - Curvas de calibração obtidas para CONP ............................................... 110

TABELA 22 - Precisão e Exatidão intradia de CONP - $1^{\circ}$ dia de análise...........................112

TABELA 23 - Precisão e Exatidão intradia de CONP - $2^{\circ}$ dia de análise 
TABELA 24 - Precisão intermediária de CONP..................................................................112

TABELA 25 - \% de Recuperação - $1^{\circ}$ dia de análise ...................................................... 113

TABELA 26 - \% de Recuperação - 20 dia de análise .................................................... 113

TABELA 27 - \% de Recuperação - 30 dia de análise .................................................... 114

TABELA 28 - Curvas de calibração obtidas para Mibi.................................................... 115 


\section{LISTA DE FIGURAS}

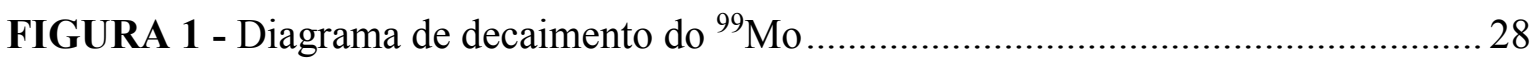

FIGURA 2 - Sistema típico de gerador de ${ }^{99} \mathrm{Mo} /{ }^{99} \mathrm{mTc}$................................................ 29

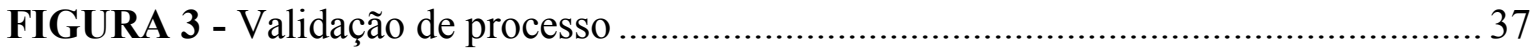

FIGURA 4 - Método de Amostragem por swab............................................................... 51

FIGURA 5 - Direções e movimentos recomendados na amostragem por swab ................ 52

FIGURA 6 - Esquema do método direto para determinação de COT ................................ 62

FIGURA 7 - Esquema da determinação de COT pelos métodos direto e indireto .............. 64

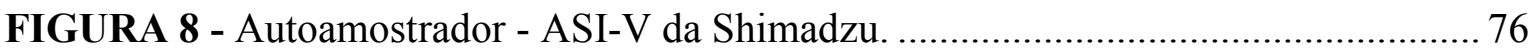

FIGURA 9 - Diagrama de fluxo do analisador de carbono ............................................. 77

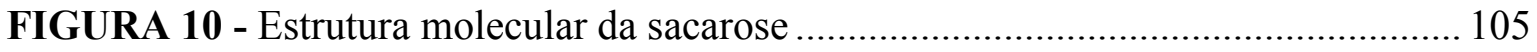

FIGURA 11 - Estrutura molecular da 1,4-benzoquinona................................................. 105

FIGURA 12 - Efeito da variação do volume de solução acidificante na análise de padrão de CONP $100 \mu \mathrm{gL}^{-1}$

FIGURA 13 - Efeito da variação do volume de oxidante na análise de padrão de CONP $100 \mu \mathrm{gL}^{-1}$ 108

FIGURA 14 - Efeito da variação do tempo de integração na análise de padrão de CONP $100 \mu \mathrm{gL}^{-1}$

FIGURA 15 - Efeito da variação do tempo de sparge na análise de padrão de CONP $100 \mu \mathrm{gL}^{-1}$

FIGURA 16 - Curvas de Calibração de CONP

FIGURA 17 - Curvas de Calibração obtidas para CONP/Mibi 


\section{LISTA DE SIGLAS E ABREVIATURAS}

\begin{tabular}{|c|c|}
\hline${ }^{99}$ Mo & Molibdênio 99 \\
\hline${ }^{99 m}$ Tc & Tecnécio 99 meta estável \\
\hline${ }^{99} \mathrm{TcO}_{4}^{-}$ & Pertecnetato \\
\hline$\left(\mathrm{NH}_{4}^{+}\right)\left(\mathrm{MoO}^{-}\right)$ & Molibdato de Amônio \\
\hline $\mathrm{Al}_{2} \mathrm{O}_{3}$ & Óxido de Alumínio \\
\hline ANVISA & Agência Nacional de Vigilância Sanitária \\
\hline AOAC & Association of Official Analytical Chemists \\
\hline $\mathbf{A P}$ & Água Purificada \\
\hline API & Água Para Injetável \\
\hline BPF & Boas Práticas de Fabricação \\
\hline $\mathbf{C a}$ & Área encontrada na amostra adicionada de padrão \\
\hline CAD & Charged Aerosol Detction \\
\hline CCDAE & Cromatografia em Camada Delgada de Alta Eficiência \\
\hline CG & Cromatografia Gasosa \\
\hline CI & Carbono Inorgânico \\
\hline CIP & Clean In Place \\
\hline
\end{tabular}

CLAE Cromatografia Líquida de Alta Eficiência

CLP Controlador Lógico Programável

CMD Concentração Média Determinada

Cna Área encontrada na amostra não adicionada de padrão

CNEN Comissão Nacional de Energia Nucclear

CO Carbono Orgânico 


\begin{tabular}{|c|c|}
\hline COAR & Carbono Orgânico Ácido Reagente \\
\hline COB & Carbono Orgânico Biológico \\
\hline COD & Carbono Orgânico Dissolvido \\
\hline CONP & Carbono Orgânico Não Purgável \\
\hline COP & Clean Out Place \\
\hline COPt & Carbono Orgânico Particulado \\
\hline COPu & Carbono Orgânico Purgável \\
\hline COT & Carbono Orgânico Total \\
\hline $\mathrm{COV}$ & Carbono Orgânico Volátil \\
\hline $\mathbf{C R}$ & Centro de Radiofarmácia \\
\hline CT & Carbono Total \\
\hline $\mathrm{CT}_{1}$ & Concentração Teórica \\
\hline DP & Desvio Padrão \\
\hline $\mathbf{D P}_{\mathbf{a}}$ & Desvio Padrão do coeficiente linear \\
\hline DPR & Desvio Padrão Relativo \\
\hline EEOP & Emissão de Elétrons Opticamente Simulada \\
\hline ELISA & Teste Imunoenzimático \\
\hline FA & Farmacopeia Americana \\
\hline FB & Farmacopeia Brasileira \\
\hline FDA & Food and Drug Administration \\
\hline FDG- ${ }^{18} \mathbf{F}$ & Fluordesoxiglicose- ${ }^{18} \mathrm{~F}$ \\
\hline FISPQ & Ficha de Informações de Segurança de Produtos Químicos \\
\hline $\mathrm{HCl}$ & Ácido Clorídrico \\
\hline $\mathrm{H}_{2} \mathrm{SO}_{3}$ & Ácido Sulfuroso \\
\hline
\end{tabular}




\begin{tabular}{|c|c|}
\hline $\mathrm{H}_{2} \mathrm{SO}_{4}$ & Ácido Sulfúrico \\
\hline $\mathrm{H}_{3} \mathrm{PO}_{4}$ & Ácido Fosfórico \\
\hline IC & Média de coeficiente angular \\
\hline ICH & International Conference on Harmonization \\
\hline INMETRO & Instituto Nacional de Metrologia, Qualidade e Tecnologia \\
\hline IPEN & Instituto de Pesquisas Energéticas e Nucleares \\
\hline ISO & International Organization for Standardization \\
\hline IUPAC & International Union of Pure and Applied Chemistry \\
\hline IVND & Infravermelho Não Dispersível \\
\hline $\mathbf{L}$ & Litros \\
\hline LD & Limite de Detecção \\
\hline LQ & Limite de Quantificação \\
\hline $\mathbf{m g ~ L ^ { - 1 }}$ & Miligrama por Litro \\
\hline $\min$ & Minutos \\
\hline $\mathbf{m L}$ & Mililitros \\
\hline MSDS & Material Safety Data Sheet \\
\hline $\mathrm{Na}^{+99 m} \mathrm{TcO}_{4}^{-}$ & Pertecnetato de sódio \\
\hline NDIR & Non-Dispersive InfraRed \\
\hline OMS & Organização Mundial da Saúde \\
\hline POP & Procedimento operacional padrão \\
\hline ppb & Partes por bilhão \\
\hline ppm & Partes por milhão \\
\hline PV & Protocolo de Validação \\
\hline PW & Potable Water \\
\hline
\end{tabular}


$\mathbf{R}_{\text {B }}$

$\mathbf{R}_{\mathbf{B Z}}$

RDC

RE

RL

RV

SS\%

$\mu g \mathbf{L}^{-1}$

UV

UV - VIS

WCI

WFI

WHO
Coeficiente de correlação

Soma residual dos quadrados mínimos de regressão linear

Concentração de 1,4-benzoquinona

Concentração de sacarose

Resolução da Diretoria Colegiada

Resolução Específica

Reagente Liofilizado

Relatório de Validação

Conformidade do Sistema

Microgramas por litro

Ultravioleta Visível

Espectroscopia por Ultravioleta Visível

Worst Case Index

Water for Injection

Word Health Organization 


\section{INTRODUÇÃO}

A indústria farmacêutica vem se aprimorando ao longo dos anos na busca pela qualidade dos seus produtos e enfrentando vários desafios na manutenção da segurança e no controle dos diversos processos envolvidos na fabricação de medicamentos, de forma a cumprir as exigências da legislação sanitária (ANDRADE, 2012).

A limpeza de equipamentos e instalações é um processo que tem assumido um papel de extrema importância na produção farmacêutica, tornando-se imprescindível a sua validação para garantir a qualidade dos produtos fabricados e o atendimento às normas e regulamentos dos órgãos sanitários de controle (ANDRADE, 2012).

Alguns métodos analíticos são utilizados na validação de limpeza, incluindo cromatografia líquida de alta eficiência (CLAE), condutividade, cromatografia iônica, pH, carbono orgânico total - COT (do inglês Total Organic Carbon - TOC), e até mesmo a análise visual. Cada técnica tem vantagens e desvantagens. Para matrizes solúveis em água, no entanto, quase qualquer composto residual pode ser detectado, se os seguintes testes analíticos não específicos (de triagem) são usados para a validação de limpeza: COT (para carbono /características orgânicas), o pH (para características ácido / base), e condutividade (para características iônicas) (PURCELL et al., 2004).

A combinação de métodos pode permitir identificar contaminantes provenientes de várias fontes, incluindo as águas de processos, ingredientes ativos, excipientes, e agentes de limpeza. Para utilizar estas técnicas, todo o resíduo detectado é assumido como sendo o composto pior caso, e, em seguida, é comparado com os critérios de aceitação estabelecidos. Se os resultados forem superiores aos critérios de aceitação, processos de limpeza adicionais são necessários.

Jenkins et al. (1996 apud PURCELL; STEVENS; WALLACE, 2004, p. 42) apoiou fortemente o uso da análise de COT em validação de limpeza, afirmando que "COT oferece capacidade de detecção extremamente baixa (ppm-partes por milhão e ppb-partes por bilhão), rápido tempo de análise da amostra, é de baixo custo em comparação com outros métodos, e pode detectar todos os resíduos à base de carbono" quando compararam COT, CLAE, cromatografia em camada delgada (CCD), ensaio imunoenzimático associado à espectrofotometria (UV), eletroforese, $\mathrm{pH}$, condutividade, e análise visual. 
Em outro estudo, Strege et al. (1996 apud PURCELL; STEVENS; WALLACE, 2004, p. 42) observou que a análise de COT também foi preferida para a análise de proteínas totais. Ele usou o COT em validação de limpeza de equipamentos em foram utilizadas drogas solúveis em água, excipientes e agentes de limpeza.

Alguns trabalhos vêm sendo desenvolvidos utilizando a determinação de COT para demonstrar a validação de limpeza em equipamentos utilizados em indústrias farmacêuticas. (CLEMENTINO, 2006; CLARK, 2000).

A análise de COT abrange a análise de uma variedade de substâncias orgânicas que contêm o átomo de carbono ligado covalentemente e em vários estados de oxidação. $\mathrm{O}$ carbono como um todo é expresso como carbono total $(\mathrm{CT})$ e o carbono inorgânico $(\mathrm{CI})$ corresponde à soma de carbonato, bicarbonato e $\mathrm{CO}_{2}$ dissolvido em água (CLESCERI et al,. 2005).

Os analisadores de COT são utilizados em uma ampla gama de indústrias farmacêuticas para avaliação do processo de controle da qualidade da água e pesquisa experimental. Eles são instrumentos essenciais no laboratório farmacêutico, das inspeções à qualidade da água utilizada na fabricação de fármacos até a avaliação da eficácia de limpeza (validação de limpeza), desempenhando importante e vital papel no processo de fabricação de medicamento e garantindo a conformidade com os regulamentos aplicáveis (SHIMADZU CORPORATION, 2010).

A mensuração do COT quer para os processos de validação de limpeza ou de monitoramento de água farmacêutica, pode ser realizada usando-se diferentes analisadores de carbono orgânico. O analisador identifica os níveis de carbono presentes na amostra por oxidação do carbono para dióxido de carbono presente, e consecutivamente detecta o dióxido de carbono produzido. Resultados para carbono orgânico total pode ser relatado tanto como COT ou CONP (carbono orgânico não purgável). O COT de uma amostra é constituído por carbono orgânico purgável (COP), carbono volátil, e CONP (carbono orgânico não purgável, de difícil de volatilização). De acordo com a USP, "a quantidade de COP em água farmacêutica é insignificante e pode ser descontado"; portanto, COT pode ser classificado como CONP e vice-versa (SHIMADZU CORPORATION, 1996).

Em uma radiofarmácia industrial, é necessária uma análise dos processos de produção a fim de verificar os equipamentos que necessitam de validação de limpeza e buscar referências na literatura para definir as técnicas analíticas mais adequadas. Deve-se considerar que, em função da radioatividade, muitos processos são dedicados e utilizam materiais descartáveis que são descartados ao final de uma produção. 
Além disso, apesar do aumento no uso de materiais plásticos descartáveis em áreas de produção e de laboratório, utensílios reutilizáveis de vidro ainda são largamente encontrados e equipamentos em aço inox são amplamente aceitos e usados em áreas limpas. Ressalta-se também a questão da sustentabilidade ambiental (necessidade de reciclagem e de problemas associados à destinação do material plástico), e o fato de que a maior parte dos procedimentos requer uso de vidro. Desta forma, instrumentos e equipamentos devem ser utilizados por razão científica ou econômica.

Para atender esta necessidade e também as normas e regulamentos dos órgãos sanitários de controle (ANVISA, U.S. Food and Drug Administration - FDA), os equipamentos devem ser limpos e os resíduos devem ser removidos, sendo imprescindível que haja a validação dos processos de limpeza. 


\section{OBJETIVO}

O objetivo deste estudo foi estabelecer o pior caso para realização da validação de limpeza dos equipamentos utilizados na produção de radiofármacos de reagentes liofilizados produzidos no Centro de Radiofarmácia - CR do IPEN-CNEN/SP , avaliar a utilização do teor de COT como indicador de limpeza dos equipamentos utilizados na fabricação desses radiofármacos, realizar a validação do método direto de determinação de COT e realizar testes de recuperação com o produto escolhido como pior caso. 


\section{REVISÃO DA LITERATURA}

\subsection{Radiofármacos}

Os radiofármacos são definidos como preparações farmacêuticas com finalidade diagnóstica ou terapêutica, que quando prontas para o uso, contêm um ou mais radionuclídeo (ANVISA, 2009b).

A Organização Mundial da Saúde (OMS) e a Agência Nacional de Vigilância Sanitária (ANVISA) classificam os radiofármacos em quatro categorias (ANVISA, 2009b; WHO, 2007):

a. Produtos radioativos prontos para uso;

b. Geradores de radionuclídeo;

c. Componentes não-radioativos (reagentes liofilizados - RL) para a preparação de compostos marcados com um componente radioativo (geralmente o eluato de um gerador de radionuclídeo);

d. Precursores utilizados para a marcação radioativa de outras substâncias antes da administração (ex. amostras provenientes dos pacientes, como células sanguíneas).

Quase sempre os radiofármacos são usados em quantidades traços e por isto geralmente possuem um mínimo efeito farmacológico. Estima-se que o uso destes produtos na Medicina Nuclear é quase que totalmente voltado para fins diagnósticos $(95 \%)$, sendo o restante utilizado para tratamento terapêutico (SAHA, 1998).

Os radiofármacos são constituídos por um componente radioativo (ou radionuclídeo) e um componente não radioativo (uma substância carreadora ou ligante). As características desses dois componentes e da interação entre eles determinam a função e utilidade dos radiofármacos. Esse ligante é escolhido com base na afinidade por determinado órgão ou participação na sua função fisiológica. Posteriormente, o ligante é marcado por um radionuclídeo adequado, de forma que as radiações emitidas a partir do radiofármaco, após sua administração, podem ser identificadas por um detector de radiação, permitindo assim a avaliação da estrutura ou função fisiológica do órgão (SAHA, 1998).

Em geral os radionuclídeos comumente usados na Medicina Nuclear são produzidos artificialmente em reatores, aceleradores lineares ou cíclicos (cíclotrons), ou indiretamente a partir de sistemas geradores (SAHA, 1998). 
Existem dois métodos principais pelos quais os radionuclídeos são produzidos em um reator: a fissão nuclear e a captura de nêutrons. Os nuclídeos produzidos por fissão possuem número atômico da faixa entre 28 a 65. Os radionuclídeos de fissão são normalmente isentos de carreador e, portanto, isótopos de alta atividade específica são obtidos a partir da físsão. Normalmente possuem excesso de nêutrons, decaindo principalmente pela emissão de partículas $\beta$-. Geralmente também possuem meia-vida física mais longa, e por isso podem ser utilizados em terapia. Na reação de captura de neutrons os núcleos alvo capturam um nêutron térmico e emitem raios $\gamma$ para produzir um isótopo do mesmo elemento. $\mathrm{O}$ radionuclídeo portanto não é livre de carregador, e sua atividade específica é relativamente baixa. Esses radionuclídeos possuem excesso de nêutrons, decaindo principalmente pela emissão de partículas $\beta^{-}$(SAHA, 1998).

A maioria dos radionuclídeos produzidos em aceleradores (cíclotrons) são pobres em nêutrons e, portanto, seu decaimento é por emissão de pósitrons ou captura de elétrons, característica que os tornam ideais para uso em diagnóstico "in vivo". Geralmente são livres de carreador e podem ser obtidos com altas atividades específicas (BOONE et. at, 2012).

Aceleradores de partículas são máquinas capazes de acelerar feixes de partículas carregadas, fazendo com que estes alcancem velocidades altíssimas, proporcionando energias capazes de produzirem matéria (pela da colisão destes feixes) em grande quantidade e com o feixe bem controlado. De acordo com sua forma, eles podem ser classificados em lineares ou circulares. Os aceleradores de partículas circulares (cíclotron, síncrotron) mantêm o feixe segundo uma trajetória curvilínea fazendo com que o feixe seja acelerado a cada volta (BATISTA; LUIZ; MONTEIRO, 2011).

Nos cíclotrons ocorre o bombardeamento de alvos estáveis com partículas carregadas positivamente, tais como: prótons $\left({ }_{1}^{1} \mathrm{H}\right)$, dêuterons $\left({ }_{1}^{2} \mathrm{H}\right) \mathrm{e}$ partículas alfa $\left({ }_{2}^{4} \mathrm{He}\right.$ ou $\left.\alpha\right)$ (SAHA, 1998). Os núcleos então ficam instáveis pelo excesso de prótons e desintegram-se por emissão de pósitrons $\left(\beta^{+}\right)$, como por exemplo, ${ }^{18} \mathrm{~F},{ }^{11} \mathrm{C},{ }^{13} \mathrm{~N}$ e ${ }^{15} \mathrm{O}$, ou captura eletrônica com emissão de radiação eletromagnética (raios $\gamma$ ), como ${ }^{67} \mathrm{Ga},{ }^{201} \mathrm{Tl},{ }^{123} \mathrm{I} \mathrm{e}{ }^{111} \mathrm{In}$ (BATISTA; LUIZ; MONTEIRO, 2011).

A produção de radionuclídeos a partir de geradores é mais vantajosa quando comparada a de reatores e cíclotrons, em geral o sistema é pequeno, de fácil transporte, pode ser utilizado por semanas até anos, permitindo seu uso em clínicas e hospitais (FERREIRA; MARQUES, 2012). Para separação do radionuclídeo “pai” do radionuclídeo “filho" podem ser utilizados vários métodos físico-químicos. $\mathrm{O}$ método mais utilizado e prático na rotina clínica 
é o sistema cromatográfico baseado em um material adsorvedor, inorgânico ou orgânico (OSSO; KNAPP, 2011; VALLABHAJOSULA, 2009).

Dentre os vários geradores de radionuclídeos utilizados em medicina nuclear, os geradores de ${ }^{90} \mathrm{Sr} /{ }^{90} \mathrm{Y},{ }^{68} \mathrm{Ge} /{ }^{68} \mathrm{Ga} \mathrm{e}{ }^{99} \mathrm{Mo} /{ }^{99 m} \mathrm{Tc}$ estão entre os mais utilizados. O gerador de ${ }^{99} \mathrm{Mo} /{ }^{99 \mathrm{~m}} \mathrm{Tc}$ é um sistema fechado, composto por uma coluna cromatográfica de óxido de alumínio $\left(\mathrm{Al}_{2} \mathrm{O}_{3}\right)$, na qual é depositada uma atividade conhecida de ${ }^{99} \mathrm{Mo}$ sob a forma de molibdato de amônio $\left(\mathrm{NH}_{4}^{+}\right)\left(\mathrm{MoO}_{4}^{-}\right)$, ficando este ligado à superfície das moléculas de alumina por um processo chamado adsorção. $\mathrm{O}{ }^{99} \mathrm{Mo}$ (pai) desintegra-se na coluna e origina o ${ }^{99 \mathrm{~m}} \mathrm{Tc}$ (filho). $\mathrm{O}{ }^{99 \mathrm{~m}} \mathrm{Tc}$ é eluído fazendo-se passar pela coluna uma solução salina estéril ( $\mathrm{NaCl}$ $0,9 \%$ ), onde ocorre uma troca dos íons cloreto com os íons ${ }^{99} \mathrm{TcO}_{4}^{-}$(mas não com $\left.{ }^{99} \mathrm{moO}_{4}^{-}\right)$, coletando-se no líquido eluente somente o ${ }^{99 \mathrm{~m}} \mathrm{Tc}$ na forma de pertecnetato de sódio $\left(\mathrm{Na}^{+99 \mathrm{~m}} \mathrm{TcO}_{4}^{-}\right)$, enquanto que o ${ }^{99} \mathrm{Mo}$ permanece adsorvido à coluna de alumina (SAHA, 1998; BOONE et al., 2012).

$\mathrm{O} \mathrm{Na}{ }^{99 m} \mathrm{TcO}_{4}$ é produzido como uma solução estéril, isenta de pirogênios, com atividade específica elevada e um $\mathrm{pH}$ de aproximadamente 5,5, ideal para preparações radiofarmacêuticas (BOONE et al., 2012).

Após um período de crescimento ideal de aproximadamente $24 \mathrm{~h}$, o gerador pode ser novamente eluído com rendimento teórico máximo de ${ }^{99 \mathrm{~m}} \mathrm{Tc}$. A vida útil de um gerador varia de 7 a 15 dias, dependendo da carga inicial de ${ }^{99}$ Mo. Em função do decaimento do elemento "pai", uma atividade menor de tecnécio-99m é eluída a cada dia (BOONE et al., 2012).

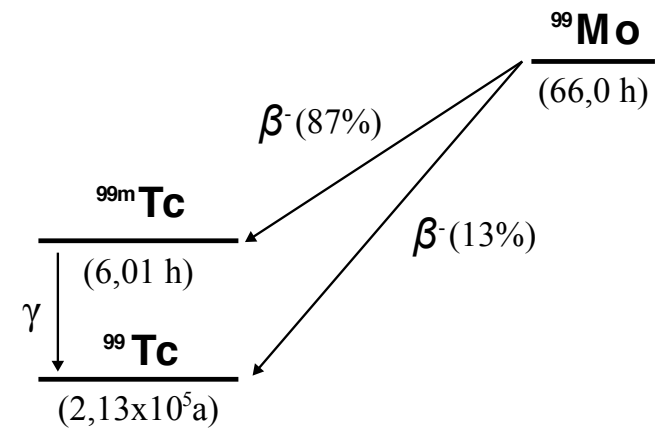

FIGURA 1 - Diagrama de decaimento do ${ }^{99} \mathrm{Mo}$ 


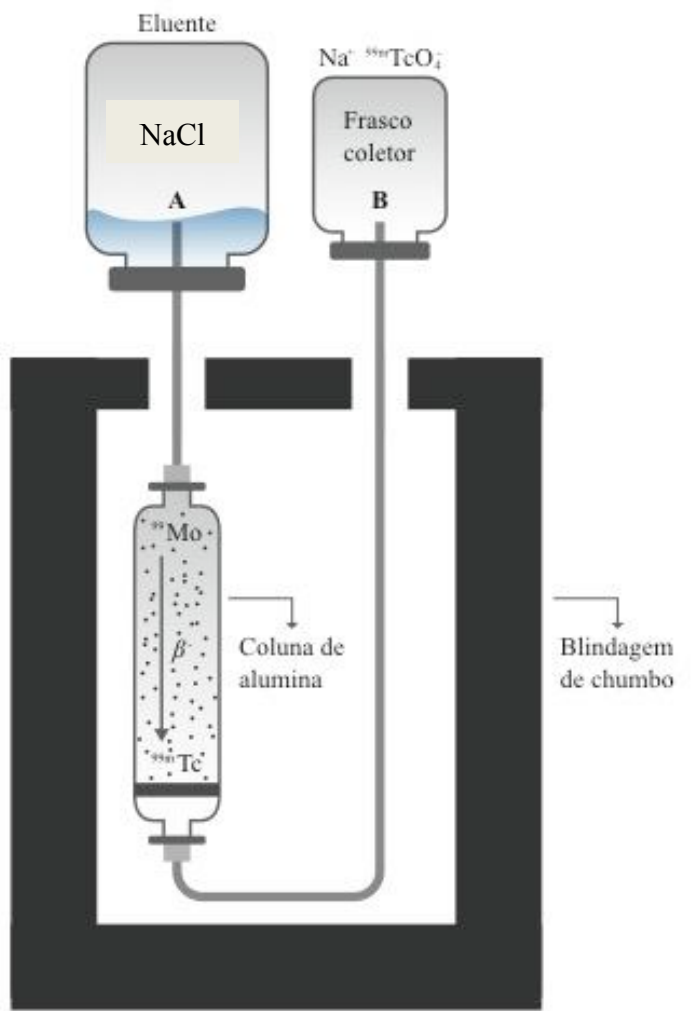

FIGURA 2 - Sistema típico de gerador de ${ }^{99} \mathrm{Mo} /{ }^{99} \mathrm{mTc}$

A atividade do filho cresce pelo decaimento do pai. O eluente no frasco A é puxado através da coluna e o nuclídeo filho é recolhido no tubo B sob vácuo (COELHO et al., 2006).

\subsubsection{Radiofármacos de tecnécio}

Os radiofármacos de tecnécio- $99 \mathrm{~m}\left({ }^{99 \mathrm{~m}} \mathrm{Tc}\right)$ vêm sendo utilizados na Medicina Nuclear como marcadores radioativos para diagnóstico de doenças e disfunções de órgãos e sistemas que compõe o corpo humano, correspondendo a mais de $80 \%$ dos exames da rotina da clínica médica. O elevado índice de utilização de tais compostos é resultado das propriedades físicas e químicas ideais do radioisótopo, tais como: meia-vida física de 6 horas; desintegração por emissão de radiação gama pura, com fótons de $140 \mathrm{keV}$ que permitem imagens com alta resolução espacial; praticidade na obtenção do radioisótopo a partir de um sistema gerador de ${ }^{99} \mathrm{Mo} /{ }^{99 \mathrm{~m}} \mathrm{Tc}$; possibilidade do metal atingir vários estados de oxidação, originando diferentes radiofármacos a partir da simples reconstituição de conjuntos de reativos liofilizados ("kits") (SAHA, 1998). O tecnécio pode existir em oito estados de oxidação, de $1^{+}$a $7^{+}$. A estabilidade destes estados de oxidação depende do tipo de ligante e do ambiente químico, mas os estados mais estáveis são o $7^{+}$e $4^{+}$(SAHA, 1998). 
O ${ }^{99 m}$ Tc é obtido do gerador de molibdênio sob a forma química de pertecnetato de sódio $\left(\mathrm{Na}^{+99 \mathrm{~m}} \mathrm{TcO}_{4}{ }^{-}\right)$. No íon pertecnetato $\left({ }^{99 \mathrm{~m}} \mathrm{TcO}_{4}{ }^{-}\right)$o ${ }^{99 \mathrm{~m}} \mathrm{Tc}$ apresenta um estado de oxidação $7^{+}$, que o torna uma espécie quimicamente não reativa que não complexa com qualquer composto por adição direta, sendo portanto necessária a redução prévia do ${ }^{99 \mathrm{~m}}$ Tc para um estado de oxidação menor. Vários são os agentes redutores utilizados, a saber, cloreto estanoso $\left(\mathrm{SnCl}_{2} \cdot 2 \mathrm{H}_{2} \mathrm{O}\right)$, citrato estanoso, ácido clorídrico concentrado $(\mathrm{HCl})$, boroidreto de sódio $\left(\mathrm{NaBH}_{4}\right)$, ditionito e sulfato ferroso. Dentre estes, o $\mathrm{SnCl}_{2} \cdot 2 \mathrm{H}_{2} \mathrm{O}$ é o mais comumente utilizado nos RL. As espécies de ${ }^{99 \mathrm{~m}} \mathrm{Tc}$ reduzidas são quimicamente reativas e combinam-se com uma ampla variedade de agentes ligantes formando complexos (SAHA, 1998).

\subsubsection{Reagentes liofilizados $-\mathbf{R L}$}

$\mathrm{O}^{99 \mathrm{~m}} \mathrm{Tc}$ possui uma eficiente capacidade para se complexar ou marcar uma série de produtos liofilizados, conhecidos como Reagentes Liofilizados (RL) ou simplesmente "kits frios". Os RL reagem com o ${ }^{99 \mathrm{~m}} \mathrm{Tc}$ proveniente do gerador de radionuclídeo dando origem a radiofármacos com propriedades específicas para o diagnóstico de patologias e disfunções de órgãos (ARAÚJO, 2008).

A primeira utilização do tecnécio como radiofármaco na clínica ocorreu na Universidade de Chigago, quando nos meados dos anos 60 Harper usou o ${ }^{99} \mathrm{mcO}_{4}^{-}$eluído de um gerador de ${ }^{99} \mathrm{Mo} /{ }^{99 \mathrm{~m}} \mathrm{Tc}$ para obtenção de imagens do fígado, cérebro e tireóide. $\mathrm{Na}$ sequência, no início dos anos 70, foi desenvolvido um kit instantâneo por Atkins, Eckelman e Richards, contendo num único frasco um agente redutor (cloreto estanoso) e um agente complexante ou ligante, produzindo um complexo de ${ }^{99 \mathrm{~m}} \mathrm{Tc}$ com alto rendimento radioquímico em solução aquosa estéril, dando início ao desenvolvimento de vários outros agentes de imagem com tecnécio como DTPA- $-{ }^{99 \mathrm{~m}} \mathrm{Tc}$ (imagem renal), pirofosfato- ${ }^{99 \mathrm{~m}} \mathrm{Tc}$ (imagem do esqueleto), entre outros (JONES; MAHMOOD, 2003).

Os RL são preparados a partir de solução mestra contendo os seguintes componentes:

- Agente ligante ou quelante: liga-se ao radionuclídeo e é responsável pela biodistribuição do radiofármaco no organismo, podendo ser representado por compostos orgânicos, inorgânicos e biomoléculas (peptídeos, anticorpos monoclonais e seus fragmentos e oligonucleotídeos);

- Agente redutor $\left(\mathrm{SnCl}_{2} \cdot 2 \mathrm{H}_{2} \mathrm{O}\right)$ : responsável pela redução do pertecnetato; 
- Aditivos e agentes conservantes (agentes antimicrobianos, antioxidantes, estabilizantes, entre outros).

Alíquotas dessa solução são dispensadas em frascos individuais e posteriormente o produto passa por um processo de liofilização, havendo a remoção da água por sublimação sob pressão reduzida, a baixas temperaturas em atmosfera de nitrogênio. A liofilização conserva as caracteírsticas e propriedades das substâncias de interesse, representada aqui pelo agente redutor, inibe a ação de microrganismos, confere maior estabilidade ao produto final prolongando o prazo de validade. Também torna o material seco no frasco mais solúvel em solução aquosa facilitando sua reconstituição e, assim, auxiliando na marcação por quelação (SAHA, 1998).

A radiofarmácia é cientificamente reconhecida como a subespecialidade essencial para a medicina nuclear. Sem os radiofármacos, procedimentos radiodiagnósticos ou radioterapêuticos não poderiam ser realizados (MATHER, 2001).

A radiofarmácia tem como campo de atuação a pesquisa e desenvolvimento, produção, controle de qualidade, garantia da qualidade e demais aspectos relacionados aos radiofármacos (CRF-SP, 2013).

O Instituto de Pesquisas Energéticas e Nucleares (IPEN), por meio do seu antigo Departamento de Processamento de Material Radioativo (TP), atual Centro de Radiofarmácia (CR), foi o pioneiro na produção de radioisótopos e radiofármacos no Brasil, tendo iniciado a produção experimental em 1959 com o radiofármaco ${ }^{131} \mathrm{I}$, usado para diagnóstico e terapia de doenças da tireoide. Posteriormente, desenvolveu o gerador de ${ }^{99} \mathrm{Mo} /{ }^{99 m} \mathrm{Tc}$ iniciando em 1981 o atendimento a hospitais e clínicas do país (ARAÚJO, 2008).

O IPEN tem desenvolvido e disponibilizado para a classe médica nuclear inúmeros RL para marcação com tecnécio-99, além de outros radiofármacos, tais como o cloreto de ${ }^{201} \mathrm{Tl}$ (para estudo da viabilidade cardíaca, o citrato de gálio-67 (para diagnóstico de tumores específicos e pesquisa de focos de inflamação e infecção), a Metaiodobenzilguanidina marcada com iodo-131 e iodo-123 (utilizada, respectivamente, na terapia e diagnóstico de feocromocitomas e neuroblastomas) e ${ }^{153} \mathrm{Sm}$ na forma de EDTMP $-{ }^{153} \mathrm{Sm}$ (utilizado como paliativo das dores provenientes de metástases ósseas de câncer de próstata e mama). Em 1999, o IPEN deu início a produção nacional do primeiro radioisótopo para uso em PET (Tomografia por Emissão de Pósitron), o ${ }^{18} \mathrm{~F}$. Desde então, o radiofármaco Fluordesoxiglicose- ${ }^{18} \mathrm{~F}$ (FDG${ }^{18} \mathrm{~F}$ ) vem ocupando um papel de destaque no estudo da viabilidade miocárdica e na localização 
de tumores, proporcionando diagnósticos mais precisos e precoces dos mais diversos tipos de cânceres (ARAÚJO, 2008).

\subsection{Garantia da Qualidade, Boas Práticas de Fabricação e Controle de Qualidade de Radiofármacos}

Garantia da qualidade é um conceito amplo que cobre todos os aspectos que influenciam individual ou coletivamente a qualidade de um produto, correspondendo à totalidade das providências tomadas com o objetivo de garantir que os produtos farmacêuticos tenham a qualidade requerida para o uso pretendido. A garantia da qualidade incorpora as Boas Práticas de Fabricação (BPF) e outros fatores, incluindo o design e desenvolvimento de produtos (ANVISA, 2010b; WHO, 2007).

A garantia da qualidade deve entre outras atribuições assegurar que o monitoramento ambiental, a qualificação de equipamentos e a validação dos processos sejam realizados apropriadamente de modo a permitir a avaliação da adequação das condições de fabricação (ANVISA, 2010b). Seu cumprimento está orientado primeiramente à diminuição dos riscos envolvidos nessa fabricação, os quais não podem ser detectados somente pela realização de ensaios nos produtos terminados. Os riscos são constituídos essencialmente por contaminação- cruzada, contaminação por partículas, troca ou mistura de produto (RAKIAS, ZOLLE, 1996; WHO, 2007).

\subsubsection{Boas Práticas de Fabricação (BPF)}

O cumprimento das BPF evita as contaminações, erros e confusões que possam tornar os fármacos inadequados à sua utilização (ANVISA, 2010b).

Os radiofármacos são preparados a partir de elementos radioativos que possuem tempo de meia-vida física específicos, variando de poucos minutos a alguns dias. Devido à meia-vida física curta, são liberados e administrados aos pacientes pouco tempo após sua produção, e, desta forma, os resultados de certos ensaios de controle de qualidade - ensaio microbiológico de esterilidade - é, portanto, retrospectivo. Neste sentido, a implantação e o cumprimento dos princípios de BPF é essencial e indispensável (WHO, 2007).

No Brasil, a Agência Nacional de Vigilância Sanitária (ANVISA) é o órgão normativo que regulamenta as BPF. Para os radiofármacos, os requisitos mínimos a serem observados em sua fabricação estão dispostos na Resolução da Diretoria Colegiada - RDC n ${ }^{\circ}$ 
17, de 16 de abril de 2010 (ANVISA, 2010b), a qual estabelece as BPF de Medicamentos e, suplementarmente, na RDC $n^{\circ}$ 63, de 18 de dezembro de 2009 (ANVISA, 2009a), a qual estabelece as BPF de Radiofármacos.

\subsubsection{Controle de qualidade}

O controle de qualidade envolve vários testes e medidas específicas que garantem a pureza, potência, a identidade do produto, segurança biológica, e eficácia dos radiofármacos (SAHA, 1998).

O controle de qualidade atua em conjunto com a garantia da qualidade em várias atividades; por exemplo, no monitoramento ambiental, para assegurar que seja apropriadamente realizado de modo a permitir a avaliação da adequação das condições de fabricação (ANVISA, 2009a; ANVISA, 2010b).

Para cada tipo de preparação radiofarmacêutica existe um conjunto de ensaios de controle de qualidade que devem ser realizados, e que asseguram a qualidade do produto final antes de sua administração. Podemos dividir estes testes em duas categorias: 1) Testes físicoquímicos, que indicam o nível de impurezas radionuclídicas e radioquímicas e determinam o $\mathrm{pH}$, a força iônica, a osmolalidade, e o estado físico da amostra; 2) Testes biológicos, que estabelecem a esterilidade, apirogenicidade, controle biológico e toxicidade do material (SAHA, 1998).

De acordo com a RDC 64/2009 (ANVISA, 2009b) as seguintes definições são estabelecidas:

- Pureza química: razão expressa em porcentagem da massa da molécula do composto de interesse em seu estado químico indicado, em relação à massa total da preparação. As impurezas químicas relevantes estão listadas com seus limites nas monografias individuais;

- Pureza radionuclídica: é a razão, expressa em porcentagem, da radioatividade do radionuclídeo em relação à radioatividade total do radiofármaco. As impurezas radionuclídicas relevantes estão listadas, com seus limites, nas monografias individuais;

- Pureza radioquímica: é a razão expressa em porcentagem de radioatividade do radionuclídeo de interesse no seu estado químico indicado, em relação à radioatividade total da preparação radiofarmacêutica. As impurezas radioquímicas relevantes estão listadas, com seus limites, nas monografias individuais. 


\subsection{Limpeza na Indústria Farmacêutica}

Pode-se definir limpeza como a remoção de resíduos e contaminantes, e estes podem ser o próprio produto fabricado em um determinado equipamento, resíduos que se originam do procedimento de limpeza (detergentes/saneantes) ou produtos da degradação resultantes do próprio processo de limpeza (FDA, 1993).

A fabricação de medicamentos exige um alto nível de sanitização e higiene que devem ser observadas em todas as etapas desse processo. As atividades desenvolvidas devem abranger pessoal, instalações, equipamentos e utensílios, materiais de produção e recipientes, produtos para limpeza e desinfecção e qualquer outro aspecto que possa constituir fonte de contaminação para o produto, devendo ser eliminadas as possíveis fontes. A ocorrência de contaminação cruzada deve ser evitada por meio de técnicas apropriadas ou de medidas organizacionais, a saber: utilização de procedimentos validados de limpeza e de descontaminação, bem como ensaios de resíduos (ANVISA, 2010b).

É responsabilidade do fabricante de produtos farmacêuticos reproduzir de forma consistente a qualidade pretendida dos produtos, tendo papel primordial na manutenção dessa qualidade a limpeza de todos os equipamentos/utensílios que entram em contato direto com os produtos no processo de fabricação, de forma a impedir a contaminação cruzada e a adulteração de medicamentos com outros ingredientes ativos, como compostos não-intencionais ou

contaminantes microbiológicos. É essencial que se tenha procedimentos escritos de limpeza para todos os equipamentos ou conjunto de equipamentos utilizados no processo produtivo (ANVISA, 2010b).

Especial consideração deve ser dada à limpeza, esterilização e funcionamento dos equipamentos liofilizadores utilizados na preparação de reagentes liofilizados (ANVISA, 2009a).

\subsubsection{Tipos de contaminação (LAKSHMANA; SURIYAPRAKASH, 2010)}

1. Contaminação cruzada com ingredientes ativos

A contaminação de um lote de um produto com níveis significativos de ingredientes ativos residuais de um lote anterior não pode ser tolerada, visto que, além de sujeitar os consumidores ou pacientes a contaminantes não intencionais, podem também ocorrer potenciais interações sinérgicas clinicamente significativas entre produtos químicos farmacologicamente ativos. 
2. Contaminação com materiais ou compostos não-intencionais

Embora grande parte dos ingredientes inertes utilizados em medicamentos sejam geralmente reconhecidos como seguros para consumo humano, o processo produtivo farmacêutico inclui várias etapas, e, a manutenção e limpeza dos equipamentos pode se constituir numa potencial fonte de contaminação através de artigos como lubrificantes, agentes de limpeza química (solventes e detergentes) e peças de ferramentas de limpeza (filamentos de escovas/pincéis, fibras de panos de limpeza).

\section{Contaminação Microbiológica}

Outro tipo de contaminação pode advir das condições de manutenção, limpeza e armazenamento dos equipamentos, as quais podem fornecer ambiente bastante propício ao crescimento microbiano quando não são adequadamente controladas.

\subsubsection{Tipos de limpeza}

Para o estabelecimento de um programa de Validação de Limpeza, a caracterização dos tipos de limpeza utilizados é fator imprescindível, visto que fatores importantes podem ser revelados quanto ao controle e reprodutibilidade do processo, qual a melhor forma de desafiálo, a forma adequada de coletar as amostras, bem como a melhor forma de monitorar a eficácia durante a rotina de limpeza (MINGORANCE, 2005a).

\subsubsection{Limpeza manual}

A limpeza manual é definida como aquela que é feita diretamente no equipamento por um operador treinado, com ferramentas manuais e agentes de limpeza. Existem parâmetros considerados críticos nesse tipo de limpeza, e que devem ser controlados e monitorados, tais como a quantidade de agentes de limpeza, o volume de água de enxágue, a temperatura de lavagem e das soluções de enxágue, o tempo gasto para se lavar e a quantidade de ciclos de limpeza, além da concentração de detergente utilizada. Procedimentos operacionais padrão (POPs) escritos contendo especificações para desmontagem do equipamento e os passos a serem seguidos durante todo processo de limpeza são essenciais para garantir sua reprodutibilidade. O controle da limpeza manual é feito, principalmente, pelo treinamento dos operadores, procedimentos de limpeza bem definidos, exame visual do equipamento após e antes do próximo uso, bem como programas bem definidos de controle de mudanças. A garantia 
da reprodutibilidade se baseia no cumprimento estrito dos procedimentos escritos (PDA, 2012; PERES, 2001).

\subsubsection{Limpeza semiautomática}

A limpeza semiautomática, ao contrário da limpeza manual, utiliza vários níveis de controle automático. Pode consistir na simples remoção de juntas e acessórios para limpeza manual antes da limpeza automatizada CIP de um tanque ( Automated Clean in Place-CIP), ou desmontagem de uma bomba antes da limpeza em um sistema automatizado COP ( Automated Clean out Place-COP-system). No outro extremo, pode haver a utilização de spray de alta pressão para limpeza de superfícies, ou uso de válvulas que alimentam spray balls dentro de um vaso no equipamento. Esse tipo de limpeza requer o uso de equipamentos mais sofisticados para auxiliar os operadores na execução dos procedimentos de limpeza (MINGORANCE, 2005a; PDA, 2012).

\subsubsection{Limpeza automática}

Trata-se de um tipo de limpeza que utiliza a automação do processo, com programação de um ou vários ciclos de limpeza, sem necessidade da presença contínua dos operadores. Os resultados da limpeza automática são reprodutíveis, desde que o sistema seja devidamente projetado, instalado e validado (MINGORANCE, 2005a; PDA, 2012).

São considerados parâmetros críticos de limpeza para a limpeza automática: volume dos agentes de limpeza, o volume da água de rinsagem, as taxas de fluxo e temperatura das soluções de limpeza e rinsagem, duração dos ciclos de limpeza e rinsagem, a pressão da solução, faixas de operação e concentração de detergente (MINGORANCE, 2005a; PDA, 2012).

Em um sistema de limpeza automática, a limpeza pode ser controlada através de um computador ou controlador lógico programável (CLP). Dada à complexidade dos mais recentes CLP e interfaces de computador, treinamento e validação são imprescindíveis, uma vez que impactam diretamente na capacidade do sistema para fornecer uma limpeza consistente, assegurando-se assim o cumprimento dos parâmetros críticos dos ciclos de limpeza (MINGORANCE, 2005a; PDA, 2012). 


\subsection{Validação}

A validação pode ser descrita como o ato documentado que atesta que um procedimento, processo, equipamento, material, atividade ou sistema, realmente conduz aos resultados esperados de forma consistente. Os estudos de validação são uma parte essencial das BPF e devem ser conduzidos de acordo com protocolos pré-definidos e aprovados (ANVISA, 2010b).

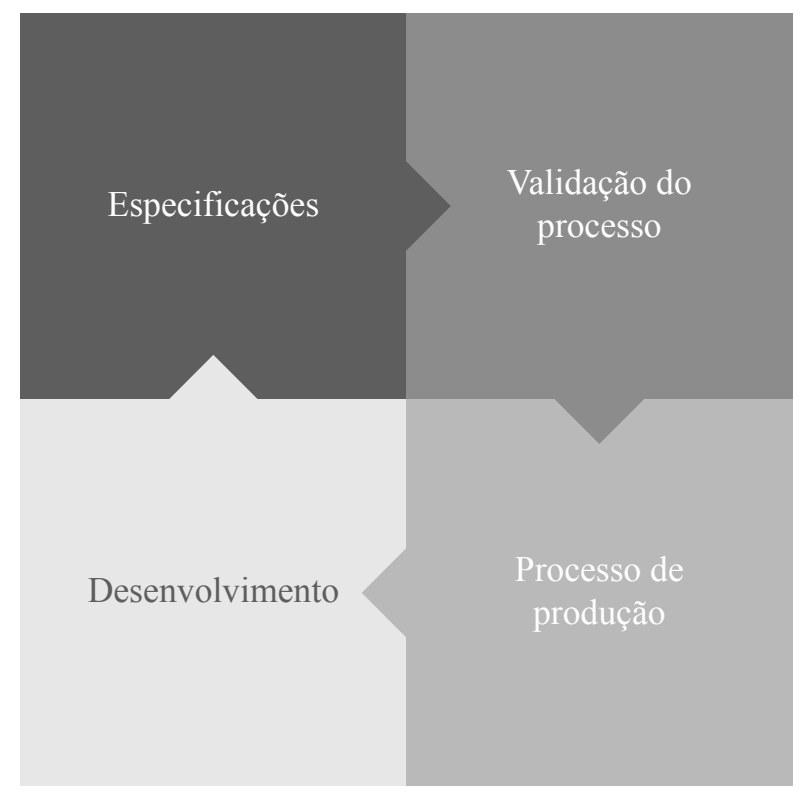

FIGURA 3 - Validação de processo

(Fonte: Adaptado de SANTOS, 2010)

A validação pauta-se em dois documentos essenciais: O Protocolo de Validação (PV), que é o documento que descreve as atividades a serem realizadas na validação de um projeto específico, incluindo o cronograma, responsabilidades e os critérios de aceitação para a aprovação de um processo produtivo, procedimento de limpeza, método analítico, sistema computadorizado ou parte destes para uso na rotina; e o Relatório de Validação (RV), que corresponde ao documento no qual os registros, resultados e avaliação de um programa de validação são consolidados e sumarizados. Pode também conter propostas de melhorias. A ANVISA determina que a validação não deve ser considerada um exercício único, e que após a aprovação do relatório de validação, deve haver um programa contínuo de monitoramento, o qual deve ser embasado em uma revisão periódica (ANVISA, 2010b).

Numa indústria farmacêutica, os estudos de Validação podem abranger diversas áreas, tais como a Validação dos processos produtivos, Validação do Tempo de Estocagem, que determina o tempo máximo em que o produto pode aguardar até que seja iniciada outra etapa 
do seu processo, Validação do estado de qualificação dos equipamentos e Validação dos Processos de Limpeza dos equipamentos (BAGO, 2010).

\subsection{Validação de Limpeza}

A validação da limpeza consiste na evidência documentada que demonstra que os procedimentos de limpeza removem os resíduos a níveis pré-determinados de aceitação. Devese levar em consideração fatores como o tamanho do lote, dosagem, dados toxicológicos, solubilidade e área de contato do equipamento com o produto. A validação de limpeza deve demonstrar não apenas que o procedimento é capaz de remover de forma consistente os resíduos do produto fabricado anteriormente abaixo de níveis aceitáveis, mas também que o próprio procedimento de limpeza não contribui para níveis inaceitáveis de materiais residuais no equipamento, fazendo com que o próximo produto a ser fabricado não contenha substância do produto anterior, ou ainda, que não haja contaminação cruzada (ANVISA, 2010b; KUMAR; SANJEEV; SHARMA, 2012; PERES, 2001).

O objetivo da validação de limpeza é verificar a eficácia do procedimento de limpeza para a remoção dos resíduos do produto, produtos de degradação, conservantes, excipientes e / ou agentes de limpeza, bem como o controle de possíveis contaminantes microbianos. Além disso, existe a necessidade de assegurar que não há risco associado com a contaminação cruzada dos ingredientes ativos (CHINCHOLE; POUL; WAGHMARE, 2013).

Um relatório final sobre o sistema de validação de limpeza irá atestar que os estudos e dados comprovam que o processo está sob controle e limpa como o esperado. Este relatório também detalhará quando e por que a revalidação precisa acontecer (CHINCHOLE; POUL; WAGHMARE, 2013).

Validar todos os processos de limpeza dentro de uma planta farmacêutica que produz vários produtos seria um processo demorado, de custo elevado, cujos resultados seriam obtidos a longo prazo, o que certamente inviabilizaria a conclusão eficiente e desejável. Estimase que, numa planta onde são fabricados n produtos, o número de possibilidades para se validar a limpeza de equipamentos seja da ordem de $\mathbf{n ! ~ / ~ ( n - 2 ) ! , ~ o n d e ~} \mathbf{n}$ ! é o fatorial do número $n$ dado por n.(n-1).(n-2).3.2.1. Assim, uma unidade que fabrica 5 produtos, o número de possibilidades para se validar a limpeza de todos os processos seria de 120 situações (ALENCAR et al., 2006).

A validação deve considerar situações críticas ou piores casos entre os produtos ou processos representativos para um grupo similar. 
De acordo com o ICH Q7A, se vários ingredientes farmacêuticos ativos ou intermediários são produzidos em um mesmo equipamento e este equipamento é limpo pelo mesmo procedimento, pode-se selecionar apenas um destes ativos para validação de limpeza. Esta seleção, denominada de seleção de "pior caso" (Worst Case), deve ser baseada na solubilidade e dificuldade de limpeza, e o cálculo dos limites máximos de resíduos com base na potência, toxicidade e estabilidade (FDA, 2001). O mesmo critério é apontado pela World Health Organization (WHO), ou seja, não há necessidade de validações individuais para procedimentos de limpeza e processos similares, considerando-se aceitável o estudo de validação do pior caso, devendo o representante escolhido ser o que apresente maior dificuldade de limpeza (WHO, 2007).

Diante disso, o cálculo do índice Worst Case Index (WCI), que considera simultaneamente informações de toxicidade, solubilidade, dificuldade de limpeza, além da taxa de ocupação de cada produto em cada unidade, pode ser uma boa estratégia para validação de limpeza (ALENCAR; CLEMENTINO; NETO, 2006).

\subsubsection{Elementos da validação de limpeza (APIC, 1999)}

Um estudo de Validação de Limpeza dentro de uma indústria farmacêutica deve contar com os seguintes elementos:

- Estabelecimento de critérios de aceitação;

- Procedimento de Limpeza: Identificação do equipamento; Caracterização dos produtos (previamente: atividade / toxicidade, solubilidade, e subsequente: dosagem, tamanho do lote); Determinação e caracterização dos agentes de limpeza;

- Métodos analíticos e sua validação;

- Processo de amostragem e sua validação;

- Protocolo de Validação;

- Relatório de Validação.

\subsubsection{Estabelecimento de critérios de aceitação}

O estabelecimento dos limites de limpeza e critérios de aceitação apropriados são elementos essenciais para que se tenha um programa de validação de limpeza confiável e bem sucedido (APIC, 1999; CHINCHOLE; POUL; WAGHMARE, 2013). 
Esses limites são um valor numérico real e são uma das exigências dos critérios de aceitação de um protocolo de validação de limpeza (Mingorance, 2005b).

O guia para determinação de limites de resíduos do FDA estabelece que os limites devem ser lógicos, práticos, viáveis e verificáveis (FDA, 1993).

Os limites devem lógicos no sentido de terem como base a compreensão do processo (CHINCHOLE; POUL; WAGHMARE, 2013). Devem ser práticos no sentido de serem apropriados para a limpeza a ser validada, bem como devem ser verificáveis por adequados meios de detecção e alcançáveis pela metodologia analítica disponível para o produto específico. É imprescindível que estes limites sejam cientificamente justificáveis (MINGORANCE, 2005b).

A ANVISA estabelece no Guia de Validação de Limpeza para Farmoquímicas não ser adequado a adoção do limite de detecção do método analítico como critério de aceitação, dado que as técnicas analíticas instrumentais se sujeitam aos constantes avanços tecnológicos (ANVISA, 2013).

Diversas metodologias têm sido propostas para estabelecimento dos limites de aceitação. Dentre os vários critérios adotados por indústrias farmacêuticas, a ANVISA (2013) e o FDA (Food Drug Administration) dos Estados Unidos da América referenciam aqueles estabelecidos no trabalho realizado por Fourman e Mullen e adotados pela empresa Eli Lilly, que estabelece os seguintes critérios (ALENCAR et al., 2004; FOURMAN; MULLEN, 1993; LEBLANC, 1998):

- O equipamento deve estar visualmente limpo. Nenhuma quantidade de resíduo deve ser visível no equipamento após os procedimentos de limpeza terem sido efetuados;

- Não mais do que $10 \mathrm{ppm}$ de qualquer produto pode aparecer no produto a ser fabricado subsequentemente;

- Não mais que $0,1 \%$ (1/1000 ou a milésima parte) da dose mínima diária de qualquer produto/contaminante pode aparecer na dose diária máxima do produto a ser fabricado subsequentemente. Para injetáveis utiliza-se um fator de segurança igual a 0,0001, ou seja, o limite aceitável é de apenas $0,01 \%$ (1/10000 ou a décima milésima parte) da dose diária mínima do contaminante na dose diária máxima do produto subsequente. Para produtos tópicos, utilizase um fator de segurança igual 0,01 , ou seja, o limite aceitável é de 1\% (1/100 ou a centésima parte) da dose diária mínima do contaminante na dose diária máxima do produto subsequente. 


\subsection{Determinação química}

Diversas metodologias têm sido propostas para estabelecimento dos limites de aceitação, sendo usual e preferível a utilização de dados toxicológicos ou terapêuticos, quando estes estão disponíveis.

$\mathrm{Na}$ indisponibilidade de tais dados, pode-se fazer uso dos níveis de produtos permitidos nos produtos produzidos posteriormente (ANVISA, 2013):

- Limites baseados em dados toxicológicos: Uma quantidade diária aceitável é calculada com fatores de segurança apropriados que são convertidos na quantidade máxima permitida para o insumo farmacêutico ativo;

- Limites baseados na dose farmacológica (dose diária terapêutica): Neste caso devem-se reduzir os níveis de resíduos do produto, em cada peça do equipamento, de forma que não haja mais do que $1 / 1000$ da dose terapêutica no próximo produto a ser produzido no equipamento. O protocolo de validação deve incluir os cálculos que envolvem este tipo de método como critério de aceitação;

- Limites gerais de níveis de produto que podem aparecer no produto seguinte (limites de 10 ppm até $0,1 \%$, tendo como base o Guia Q3 do ICH, que indica ser possível a presença de valores de até $0,1 \%$ de impureza individuais desconhecidas ou $0,5 \%$ de impurezas totais desconhecidas no produto).

\subsection{Determinação física}

A inspeção visual é um importante parâmetro a ser utilizado na validação de limpeza e tal quesito deve estar presente como critério de aceitação no protocolo de validação. A verificação visual do equipamento durante o processo de limpeza deve ser habitual, de forma a verificar a ausência de resíduos visíveis. Durante a validação, atenção especial deve ser dada às áreas mais difíceis de serem limpas e verificadas, tais como haste de agitação e válvulas. $\mathrm{O}$ padrão de visualmente limpo pode ser utilizado tanto para fins de validação como para monitorização (AMOL; GULSHAN; PANKAJ, 2013; ANVISA, 2013).

O Guide to Inspections Validation of Cleaning Processes (Guia de Inspeções para Processos de Validação de Limpeza) da FDA limita o uso do critério "visualmente limpo" apenas aos processos de limpeza entre lotes do mesmo produto (FDA, 1993).

Em virtude disso, as indústrias pouco têm investido na exploração do critério da inspeção visual como meio único na determinação da limpeza de equipamentos nas instalações 
farmacêuticas. Tal critério foi inicialmente proposto por Mendenhall e Leblanc (FLETCHER, 2013).

O limite (linha divisória) entre visualmente limpo e visualmente sujo pode ser considerado como sendo em torno de $4 \mu \mathrm{g} / \mathrm{cm}^{2}$ (FOURMAN; MULLEN, 1993).

De acordo com Leblanc (1998), nos casos em que se calcula o limite de aceitação por área de superfície $\left(\mathrm{L}_{2}\right)$ e obtêm-se um valor significantemente maior do que $4 \mu \mathrm{g} / \mathrm{cm}^{2}$ para uma dada superfície crítica claramente visível, o padrão visualmente limpo pode ser estabelecido como único critério de aceitação. Já para os casos de medicamentos potentes, para os quais $\mathrm{L}_{2}$ seria tipicamente bem abaixo de $1 \mu \mathrm{g} / \mathrm{cm}^{2}$, o padrão visualmente limpo não teria nenhum significado em relação à adequação da limpeza, uma vez que uma superfície visualmente suja indicaria uma falha de limpeza, porém uma superfície visualmente limpa não indicaria claramente se o resíduo estaria em um nível aceitável. Para casos críticos, pode-se determinar o limite em que um resíduo específico não é visível através da aplicação de diferentes níveis do resíduo (por exemplo, 0,5, 1,0, 2,0, 4,0, e $8,0 \mu \mathrm{g} / \mathrm{cm}^{2}$ ) em coupons de aço inoxidável, sob determinados parâmetros de visualização (ângulo de visão, intensidade da luz, distância), e submeter à avaliação de observadores treinados, estabelecendo-se o nível de aceitação de limpeza visual para o resíduo específico como o maior nível de resíduos no qual todos os observadores considerarem que os coupons estejam visualmente limpos (LEBLANC, 1998).

Um importante parâmetro que também deve ser considerado para a determinação do limite de resíduo visível (visible residue limit-VRL) é a subjetividade do observador.

Além dos parâmetros citados anteriormente e que afetam o VRL, Fletcher (2013) apontou para novos dados que indicam haver grande variação do VRL em diferentes tipos de superfície (diferentes matérias de construção, diferentes rugosidades) e entre diferentes compostos, devendo tais limitações ser reconhecidas e o risco avaliado caso a caso.

\subsection{Determinação microbiológica (AMOL; GULSHAN; PANKAJ, 2013; ANVISA, 2013; FDA, 1993)}

Aspectos microbiológicos de limpeza dos equipamentos envolvidos na produção farmacêutica devem ser levados em conta, quer seja para procedimentos manuais, COP ou CIP, com foco principal na prevenção ao invés da remoção posterior da contaminação (FDA, 1993). 
Devem ser realizados estudos adequados (com swabs e/ou rinsagem) em locais onde possa haver contaminação microbiana de lotes subsequentemente produzidos e que possam representar risco à qualidade do produto, de forma a obter-se evidências de que a limpeza e armazenagem de materiais rotineiros não propicie a proliferação microbiana (AMOL; GULSHAN; PANKAJ, 2013; ANVISA, 2013).

Dessa forma, é importante que os equipamentos sejam devidamente secos antes de serem armazenados, evitando-se sob nenhuma circunstância a permanência de água estagnada no equipamento após as operações de limpeza. Importante que se estabeleça previamente ao início da limpeza os prazos para o armazenamento de equipamentos sujos, bem como os prazos e as condições para o armazenamento de equipamentos limpos (AMOL; GULSHAN; PANKAJ; 2013; ANVISA, 2013).

O controle da biocarga através da adequada limpeza e armazenagem de equipamento é importante para assegurar que os procedimentos de esterilização ou de sanitização subsequentes alcancem a necessária garantia de esterilidade. Isto também é particularmente importante do ponto de vista do controle de pirogênio no processamento estéril uma vez que o processamento em processos de esterilização do equipamento pode não ser adequado para alcançar a inativação significativa ou remoção de pirogênios (AMOL; GULSHAN; PANKAJ, 2013; ANVISA, 2013).

\subsection{Fórmulas para cálculo dos critérios de aceitação}

\section{- Critério 1 - Dose Terapêutica Diária do Produto Contaminante no Produto}

\section{Subsequente}

Passo 1 - Cálculo do Limite no Produto Subsequente $\left(\mathrm{L}_{1}\right)$

$$
\mathrm{L}_{1}=\frac{1}{\mathrm{~F}} \times \frac{\mathrm{Z}}{\mathrm{W}}
$$

Onde:

$\mathbf{L}_{1}$ - Limite no produto subsequente em $\mathrm{mg} / \mathrm{g}$;

F - Fator de segurança (100 para produtos de uso tópico, 1000 para produtos de uso oral e 10000 para injetáveis); 
$\mathbf{Z}$ - Dose mínima diária do produto a ser limpo (contaminante) em $\mu \mathrm{g}$;

W - Dose máxima diária do produto subsequente (mesma unidade de Z).

Passo 2 - Cálculo do Limite Por Área de Superfície $\left(\mathrm{L}_{2},\right)$

Uma vez determinado o limite no produto subsequente, determina-se então o limite de resíduo em termos de nível de contaminação do ingrediente ativo por unidade de superfície do equipamento $\left(\mathrm{L}_{2}\right.$, em $\left.\mu \mathrm{g} / \mathrm{cm}^{2}\right)$, o qual depende do limite no produto subsequente (estabelecido como o menor entre $\mathrm{L}_{1}$ e $10 \mathrm{ppm}$ ), do tamanho do lote do produto subsequente $(\mathrm{em} \mathrm{Kg})$ e da área de superfície do equipamento compartilhada $\left(\mathrm{em}^{2} \mathrm{~cm}^{2}\right.$. Dessa forma, este cálculo é matematicamente estabelecido como:

$$
\mathrm{L}_{2}=\frac{\mathrm{L}_{1} \times \mathrm{TLPP}}{\mathrm{ASE}} \times 1000
$$

Onde:

L2 - Limite por área de superfície compartilhada $\left(\mathrm{em} \mu \mathrm{g} / \mathrm{cm}^{2}\right)$;

$\mathbf{L}_{1}$ - Limite no produto subsequente calculado pela equação 1;

TLPP - Tamanho mínimo do lote do próximo produto fabricado (em $\mathrm{Kg}$ );

ASE - Área de superfície do equipamento $\left(\mathrm{em} \mathrm{cm}^{2}\right)$;

1000 - Fator de conversão para contabilizar ppm (o limite do lote subsequente) e converter kg em g (para TLLP).

Ao determinar a área de superfície, deve-se considerar todas as superfícies de contato compartilhadas do produto, incluindo as tubulações, mangueira, defletores, etc, ou seja, toda a área dos equipamentos de toda a rota produtiva que entra em contato com o produto.

Passo 3 - Cálculo do Limite na Amostra Analisada - $\mathrm{L}_{3}$

Outro limite importante e fundamental para a análise de cada ponto de amostragem é o limite de aceitação do resíduo contaminante na amostra analisada $\left(\mathrm{L}_{3}\right.$, em microgramas por 
grama, microgramas por $\mathrm{mL}$, ou partes por milhão), onde se mede o agente ativo na solução através da amostragem por swab e dessorção deste em um solvente adequado, ou se mede o agente ativo na água de enxágue através da amostragem por rinsagem. Para tanto é necessário conhecer o limite de resíduo por área de superfície $\left(\mathrm{L}_{2}\right)$, a área de superfície em $\mathrm{cm}^{2}$, e a quantidade de solvente utilizado na amostragem (em gramas ou mL).

$$
\mathrm{L}_{3}=\mathrm{L}_{2} \times \frac{\mathrm{A}}{\mathrm{VA}}
$$

Onde:

L3 - Limite de aceitação do contaminante na amostra analisada;

$\mathbf{L}_{2}$ - Limite por área de superfície compartilhada calculado pela equação 2;

A - Área em $\mathrm{cm}^{2}$ (Toda área compartilhada para o caso do uso de água de rinsagem, ou a área amostrada para o uso de swab);

VA - Volume de solvente utilizado para fazer a amostragem por rinsagem (água de rinsagem) ou o volume utilizado na recuperação para o caso da amostragem por swab, expressos em ml.

\section{- Critério 2 - 10 ppm no Produto Subsequente}

Passo 1 - Cálculo do Limite 10 ppm - L10ppm

$$
\text { Limite }_{10 p p m}=10 \times \text { TLPP }
$$

Onde:

10 - Representa o limite de aceitação 10 ppm $(\mu \mathrm{g} / \mathrm{mL}$ ou $\mu \mathrm{g} / \mathrm{g})$;

TLPP - Tamanho mínimo do lote do próximo produto fabricado (em $\mathrm{Kg}$ ).

Passo 2 - Cálculo do Limite Por Área de Superfície $\left(\mathrm{L}_{2} *\right)$ 


$$
\mathrm{L}_{2 *}=\frac{\mathrm{L}_{10 \mathrm{ppm}}}{\mathrm{ASE}} \times 1000
$$

Onde:

L2* - Limite por área de superfície compartilhada $\left(\mathrm{em} \mu \mathrm{g} / \mathrm{cm}^{2}\right)$;

L10ppm - Limite 10 ppmcalculado pela equação 4;

ASE - Área de superfície do equipamento;

1000 - Fator de conversão para contabilizar ppm e converter kg em g (para TLLP).

Passo 3 - Cálculo do Limite na Amostra Analisada - L 3 *

$$
\mathrm{L}_{3 *}=\mathrm{L}_{2 *} \times \frac{\mathrm{A}}{\mathrm{VA}}
$$

Onde:

$\mathbf{L}_{3}$ - Limite de aceitação do contaminante na amostra analisada;

$\mathbf{L}_{2}$ * Limite por área de superfície compartilhada;

A - Área em $\mathrm{cm}^{2}$ (Toda área compartilhada para o caso do uso de água de rinsagem, ou a área amostrada para o uso de $s w a b)$;

VA - Volume de solvente utilizado para fazer a amostragem por rinsagem (água de rinsagem) ou o volume utilizado na recuperação para o caso da amostragem por $s w a b$, expressos em ml.

- Fator de Recuperação (ANVISA, 2013; LEBLANC, 1998; WHO, 2006)

O limite $\mathrm{L}_{3}$ é o limite de aceitação na amostra analisada. Ele deve ser ajustado por um fator de recuperação do $s w a b$, que pode ser feito de duas maneiras. Um método consiste em incluir o fator de recuperação do $s w a b$ no cálculo analítico real dividindo o resultado analítico pelo fator de recuperação. 
Por exemplo, se o fator de recuperação do $s w a b$ é $0,80(80 \%)$ e o procedimento analítico der um valor de $1,3 \mathrm{ppm}$, então o limite deve ser ajustado dividindo-se o resultado analítico pelo fator de recuperação para chegar em uma determinação de $1,3 \mathrm{ppm} \div 0.80=1,6$ ppm.

Outra alternativa é incluir o fator de recuperação na Equação 3. Neste caso, o fator de recuperação de 0,80 deve ser incluído no numerador. Embora os números utilizados serão diferentes, comparando o efeito líquido do resultado analítico ao limite será logicamente o mesmo.

Deve ser feita uma padronização de como isso será feito, a fim de evitar situações nas quais o fator de recuperação é usado tanto nos cálculos do limite $\mathrm{L}_{3}$ quanto na determinação do resultado analítico do solvente da amostra dessorvida. No cálculo final do fator de recuperação, sugere-se levar em consideração o menor resultado de recuperação encontrado e não a média dessas recuperações. Resultados com alta discrepância, para os fatores de recuperação, devem ser investigados com o objetivo de eliminar a causa da dispersão.

De acordo com a OMS uma recuperação maior que $80 \%$ é considerada boa, entre $50 \%$ e $80 \%$ razoável e menor que 50\% questionável. Já para ANVISA são desejáveis fatores de recuperação acima de 75,0\% (OMS, 2006; ANVISA, 2006).

\section{- Critério de Aceitação Baseado em Dados Toxicológicos (ANVISA, 2013)}

Quando não se conhece a dose terapêutica (por exemplo, para intermediários e detergentes), o critério de aceitação pode ser estabelecido com base em dados toxicológicos, utilizando-se o nível de efeito adverso não observado - NOEL (No Obervable Effect Level) para cálculo da quantidade aceitável de contaminante a ser transferida para o próximo produto MACO (Maximum Allowable Carryover).

Passo 1 - Cálculo do NOEL

Primeiramente calcula-se o nível de efeito adverso não observado - NOEL (No Obervable Effect Level) de acordo com a Eq. 7, para depois utilizar o resultado para se estabelecer o MACO. 


$$
\mathrm{NOEL}=\frac{\mathrm{LD}_{50} \times 70}{2000}
$$

Passo 2 - Cálculo do MACO

Com o resultado obtido anteriormente, calcula-se então o MACO de acordo com a Eq. 8:

$$
\text { MACO }=\frac{\text { NOEL } \times T M L}{F S \times D T D}
$$

Onde:

NOEL - Nível de efeito adverso não observado;

$\mathbf{L D}_{50}$ - Dose letal em $\mathrm{g} / \mathrm{Kg}$;

$70 \mathrm{Kg}$ - Peso médio de um adulto;

2000 - Constante empírica, equivalente a $2000 \mathrm{mg} / \mathrm{kg}$ de peso corpóreo, recomendada pela Organização Mundial da Saúde - OMS;

DTD - Maior valor de dose terapêutica diária para o produto que sofre a contaminação;

TML - Tamanho mínimo de lote do produto que sofre a contaminação;

FS - Fator de segurança.

O valor do fator de segurança (FS) varia dependendo da rota de administração utilizada para o NOEL, conforme TAB. 1 (ANVISA, 2013).

TABELA 1 - Fator de Segurança segundo rota de administração

\begin{tabular}{cc}
\hline Rota de administração & FS \\
\hline Tópica & $10-100$ \\
Produtos orais & $100-1000$ \\
Parenterais & $1000-10000$ \\
\hline
\end{tabular}

Fonte: ANVISA, 2013. 
3.5.1.2 Procedimento de limpeza (BANERJEE et al., 2011; KUMAR; SANJEEV; SHARMA, 2012; PERES, 2001)

Os procedimentos de limpeza devem ser suficientemente detalhados para permitir que os operadores limpem cada tipo de equipamento de uma forma reprodutível e eficaz, eliminando a possibilidade de qualquer inconsistência durante o processo de limpeza, incluindo:

1. Instruções para remoção ou obliteração da identificação do lote anterior; caracterização dos produtos (previamente: atividade / toxicidade, solubilidade, e subsequente: dosagem, tamanho do lote);

2. Atribuição de responsabilidade para a limpeza de equipamentos;

3. Parâmetros do equipamento a serem avaliados:

- Identificação do equipamento a ser limpo;

- Áreas de difícil limpeza;

- Propriedade dos Materiais;

- Facilidade de desmontagem. Se for caso disso, as instruções de montagem e desmontagem de cada artigo de equipamentos para garantir a limpeza adequada;

- Equipamento fixo ou não.

4. Resíduos a serem limpos:

- Limites de limpeza;

- Solubilidade dos resíduos;

- Duração de campanhas.

5. Parâmetros do agente de limpeza a serem avaliados:

- Preferencialmente materiais que são normalmente utilizados no processo;

- Detergentes disponíveis (minimizar o uso de detergentes a menos que seja absolutamente necessário). Além disso, uma descrição completa dos métodos e materiais, incluindo diluição de agentes de limpeza usados para limpar equipamentos;

- Solubilidade;

- Considerações ambientais;

- Considerações de saúde e segurança.

6. Técnicas de limpeza a serem avaliadas:

- Limpeza manual;

- CIP (Clean-in place);

- $\operatorname{COP}($ Clean-out-of-place); 
- Semi- automática;

- Automática;

- Considerações de tempo, incluindo horários de limpeza, incluindo, se for caso disso, os horários de higienização. Deve-se ainda estabelecer o tempo máximo que pode decorrer entre a conclusão do tratamento e limpeza do equipamento, quando for o caso (FDA, 2001);

- Número de ciclos de limpeza.

Os procedimentos de limpeza devem ser rigorosamente seguidos e desenvolvidos para todos os equipamentos/utensílios que entram em contato direto com os produtos no processo de fabrico, e também para as peças que não entram em contato direto com o produto, mas que podem comprometer a limpeza das peças consideradas críticas (GOMES, 2012).

Um procedimento de limpeza, uma vez validado, assegura a produção de lotes uniformes de acordo com as especificações requeridas, além de aperfeiçoar os conhecimentos dos processos produtivos, assegurando que estes se encontram sob controle, diminuindo assim o risco de desvio de qualidade e o risco de não conformidades relativas aos requisitos estabelecidos (GOMES, 2012).

\subsubsection{Amostragem}

Existem dois métodos de amostragem aceitáveis que são geralmente empregados: amostragem direta da superfície mediante esfregaço (swab) e/ou amostragem indireta (utilização de soluções de rinsagem). É desejável que se possa combinar os dois métodos, especialmente nas circunstâncias onde o acesso às peças dos equipamentos possa diminuir a amostragem direta da superfície (ANVISA, 2013; APIC, 1999; HEALTH PRODUCTS AND FOOD BRANCH INSPECTORATE, 2000).

\subsection{Amostragem por swab}

Uma vez que a amostragem com $s w a b$ não cobre toda a superfície do equipamento, é importante que, no mínimo, os locais de esfregaço representem os locais de pior caso do equipamento e que o resultado seja extrapolado para a área total da superfície do equipamento (ANVISA, 2013; APIC, 1999 ).

A escolha do tipo de material de amostragem deve ser criteriosa e levar em conta o possível impacto e interferência nos resultados dos ensaios, bem como na capacidade de 
recuperação das amostras com a devida precisão. A avaliação do material é de suma importância, de forma que haja compatibilidade do $s w a b$ com os ativos/resíduos para que não ocorra qualquer degradação do composto. O solvente a ser utilizado na extração deve proporcionar uma boa solubilidade do composto e também não deve causar sua degradação. Diante disso, o programa de validação deve assegurar que a forma de amostragem e o solvente utilizado sejam satisfatórios e possam ser facilmente utilizáveis (AMOL; GULSHAN; PANKAJ, 2013; ANVISA, 2013; HEALTH PRODUCTS AND FOOD BRANCH INSPECTORATE, 2000)

Estudos de recuperação (\%) do $s w a b$ devem ser realizados de forma a determinar a eficiência e do esfregaço, ou seja, a capacidade do swab de remover quantitativamente o contaminante da superfície amostrada. $\mathrm{O}$ estudo deve mimetizar exatamente o procedimento utilizado na prática: mesmo swab, o mesmo tipo de material constituinte do equipamento e definição da área (ANVISA, 2013; APIC, 1999; CHINCHOLE; POUL; WAGHMARE, 2013).

A amostragem por swab apresenta a vantagem de possibilitar que áreas razoavelmente acessíveis e de mais difícil limpeza possam ser avaliadas, proporcionando o estabelecimento de um nível de contaminantes ou resíduos por determinada área de superfície. Além disso, os resíduos secos ou insolúveis podem ser recolhidos pela remoção física (AMOL; GULSHAN; PANKAJ, 2013; ANVISA, 2013; HEALTH PRODUCTS AND FOOD BRANCH INSPECTORATE, 2000).

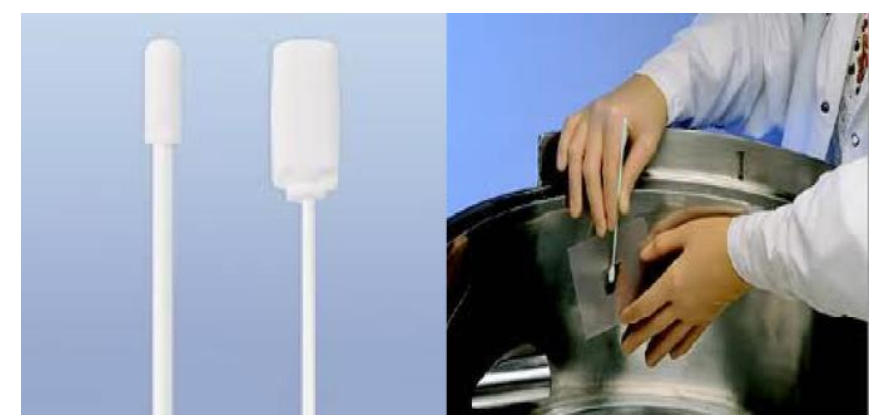

FIGURA 4 - Método de Amostragem por swab

(Fonte: CHINCHOLE; POUL; WAGHMARE, 2013)

Após limpeza e secagem do equipamento, realiza-se o esfregaço com $s w a b$ umedecido em solvente uma pequena área previamente calculada do equipamento e, posteriormente, o swab é inserido em um frasco apropriado contendo um volume conhecido do solvente, devidamente selecionado para a extração do resíduo, e no qual este é solúvel. Em seguida procede-se a análise da amostra através de métodos analíticos com adequada 
sensibilidade, e a quantidade de resíduo encontrada é extrapolada para todo o equipamento. Tal cálculo permite a determinação do pior caso do potencial resíduo no produto subsequente. Geralmente utiliza-se swabs especiais, tais como: Whatman [R], Texwipe [R], ou Coventry [R] (ANVISA, 2013; CHINCHOLE, POUL, WAGHMARE, 2013).

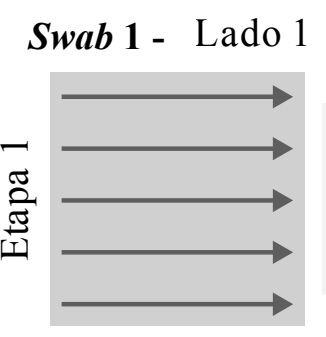

Swab 2 - Lado 1

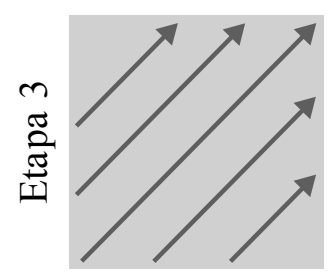

Virar o Swab,

Swab em

direção

perpendicular

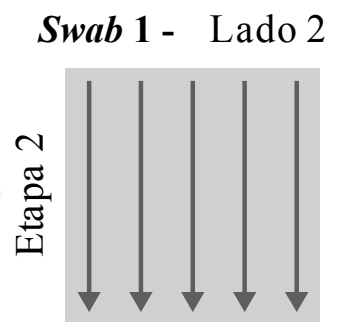

Swab 2 - Lado 2

Virar o Swab, Swab em direção perpendicular

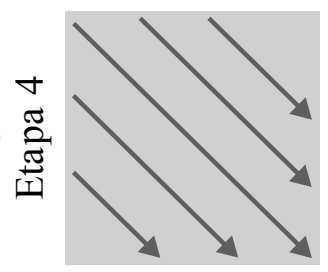

FIGURA 5 - Direções e movimentos recomendados na amostragem por swab (Fonte: CHINCHOLE; POUL; WAGHMARE, 2013)

\subsection{Amostragem por Rinsagem}

A rinsagem é um método de amostragem que se mostra mais simples do que a amostragem por $s w a b$, e embora não seja direto, propicia a cobertura total da superfície do equipamento, inclusive das partes que não são acessíveis ao $s w a b$ ou que não podem ser desmontadas rotineiramente, tais como vedações, frestas e tubulações (ANVISA, 2013; APIC, 1999; CHINCHOLE; POUL; WAGHMARE, 2013; HEALTH PRODUCTS AND FOOD BRANCH INSPECTORATE, 2000). É importante atentar para o fato de que o resíduo ou contaminante pode ser insolúvel ou estar fisicamente ocluído no equipamento (HEALTH PRODUCTS AND FOOD BRANCH INSPECTORATE, 2000).

O método baseia-se na determinação analítica adequada de uma amostra do solvente (geralmente água) utilizado no último ciclo de lavagem devidamente estabelecido no procedimento de limpeza. Assim, o volume de solvente utilizado no último enxágue deve ser conhecido de forma a permitir a determinação quantitativa da contaminação (ANVISA, 2013; CHINCHOLE; POUL; WAGHMARE, 2013). Diante disso, é importante que a coleta das amostras considere a localização, o tempo e volume. 
A rinsagem ocorre após a limpeza do equipamento ter sido finalizada. Deve ser assegurado que o solvente escolhido permita a apropriada recuperação dos resíduos a serem quantificados, realizando-se testes de recuperação (ANVISA, 2013; APIC, 1999; CHINCHOLE; POUL; WAGHMARE, 2013).

\subsubsection{Métodos analíticos utilizados em validação de limpeza}

Um aspecto importante na validação de limpeza é a escolha dos métodos analíticos, que devem levar em consideração não apenas as substâncias ativas, mas também a possível interferência dos excipientes, agentes de limpeza, temperatura e outras condições utilizadas durante o processo de limpeza (CLEMENTINO, 2006). Um dos desafios na execução da validação de limpeza é o desenvolvimento de métodos analíticos sensíveis, pois a incapacidade de um método em detectar alguns resíduos pode significar que o método não é suficientemente sensível parao resíduo em questão, ou o procedimento de amostragem não é suficiente (ARAYNE et al., 2008).

O método de análise a ser utilizado na validação de limpeza deve ser capaz de quantificar uma determinada substância abaixo do limite de aceitação. Uma questão crítica da validação de limpeza é a definição do limite de aceitação. Para tanto, têm-se métodos específicos e não específicos e muito destes são complementares entre si (CLEMENTINO, 2006).

Um método específico é aquele capaz de detectar um composto original na presença de potenciais contaminantes. São exemplos de métodos específicos a CLAE, cromatografia iônica, espectrofotometria, eletroforese capilar e outros métodos cromatográficos. Os métodos não específicos são aqueles que detectam compostos que produzem uma determinada resposta. Dentre eles, podemos citar o carbono orgânico total (COT), o pH e a condutividade. COT é ideal para a detecção de todos os compostos que contêm carbono, incluindo espécies ativas, excipientes, e agentes de limpeza (CLEMENTINO, 2006; SHIMADZU CORPORATION, 2010).

A desvantagem dos métodos específicos, particularmente da CLAE é que um novo procedimento deve ser desenvolvido para cada substância ativa que é fabricada. Esse processo de desenvolvimento do método pode requerer muito tempo e além disso, as análises por CLAE devem ser realizadas num período de tempo relativamente curto após a amostragem para evitar qualquer deterioração química da substância ativa. Finalmente, a sensibilidade dos métodos de CLAE pode ser limitada pela presença de produtos de degradação (CLEMENTINO, 2006). 
A análise de COT podeser adaptada a qualquercomposto de fármacoou o agentede limpeza que contém carbono. O método é sensível na faixa de $\mu \mathrm{g} \mathrm{mL}^{-1}$ (ppb) e consome menos tempo do que CLAE ou UV/Vis. O método para COT está estabelecido para a análise da água para injecção (API) e purificada(AP), e modificações simples deste método podem permitir que seja utilizado na validação de limpeza (SHIMADZU CORPORATION, 2010).

A TAB. 2 mostra uma série de técnicas analíticas utilizadas em testes com amostras para validação de limpeza, e a TAB. 3 mostra os tipos de analitos e a respectiva metodologia analítica utilizada para cada um.

TABELA 2 - Técnicas analíticas usadas na Validação de Limpeza

\begin{tabular}{|c|c|}
\hline Métodos analíticos tradicionais & Métodos analíticos modernos \\
\hline \multirow{9}{*}{$\begin{array}{l}\text { 1. Gravimetria } \\
\text { 2. } \mathrm{pH} \\
\text { 3. Colorimetria } \\
\text { 4. Espectroscopia - UV }\end{array}$} & $\begin{array}{l}\text { 1. Técnicas Cromatográficas: CCDAE, } \\
\text { CLAE, CG }\end{array}$ \\
\hline & 2. Carbono orgânico total - COT \\
\hline & 3. Espectroscopia de absorção atômica \\
\hline & 4. Charged aerosol detection(CAD) \\
\hline & 5. Teste Imunoenzimático: ELISA \\
\hline & 6. Eletroforese capilar \\
\hline & $\begin{array}{l}\text { 7. Emissão de elétrons opticamente } \\
\text { simulada (EEOS) }\end{array}$ \\
\hline & 8. Espectrofotômetro de massa portátil \\
\hline & 9. Bioluminescência \\
\hline
\end{tabular}

Fonte: AMOL; GULSHAN; PANKAJ, 2013.

TABELA 3 - Métodos comumente utilizados para diferentes analitos

\begin{tabular}{ll}
\hline \multicolumn{1}{c}{ Analito } & \multicolumn{1}{c}{ Método analítico } \\
\hline \multirow{2}{*}{ Proteínas } & Teste Imunoenzimático (ELISA), \\
& CLAE, COT \\
Compostos orgânicos & COT, CLAE, UV-VIS, TDS
\end{tabular}


TABELA 3 - Métodos comumente utilizados para diferentes analitos

\begin{tabular}{ll}
\hline \multicolumn{1}{c}{ Analito } & \multicolumn{1}{c}{ Método analítico } \\
\hline Compostos inorgânicos & Condutividade, pH, TDS \\
Sistemas biológicos & Análises de células \\
\hline
\end{tabular}

Fonte: AMOL; GULSHAN; PANKAJ, 2013.

A TAB. 4 compara a capacidade de detecção de algumas técnicas analíticas para substâncias de interesse na validação de limpeza.

TABELA 4 - Comparação da capacidade de detecção das técnicas analíticas

\begin{tabular}{c|ccc}
\hline \multirow{2}{*}{ Método Analítico } & \multicolumn{3}{|c}{ Capacidade de detecção } \\
& Fármacos residuais & Excipientes & Agentes de Limpeza \\
\hline COT & Sim & Sim & Sim \\
CLAE & Sim & Sim & Não \\
CCD & Sim & Sim & Não \\
Espectrofotometria & Sim/Não* & Sim/Não* & Não \\
Condutividade & Não & Não & Sim \\
\hline * Dependente do analito em estudo & & \\
CLAE: Cromatografia líquida de alta eficiência \\
CCD: Cromatografia em camada delgada
\end{tabular}

A metodologia analítica utilizada no processo de Validação de Limpeza deve ser validada e documentada a fim de que os resultados possam ser confiáveis. Para tanto, os seguintes critérios básicos devem ser seguidos (ANVISA, 2013):

- A capacidade de detectar a substância (s) alvo em níveis compatíveis com os critérios de aceitação;

- A capacidade para detectar a substância alvo (s) na presença de outros materiais que podem também estar presentes na amostra (seletividade);

- O método analítico deve incluir cálculos para converter a quantidade de resíduo detectada na amostra para $100 \%$, se os dados de recuperação gerados indicarem uma recuperação fora de um intervalo permitido; 
- Deve-se considerar a estabilidade das amostras caso o intervalo de tempo entre a amostragem e a execução da sua análise afete a integridade da amostra.

\subsubsection{Protocolo e relatório de validação (ANVISA, 2013; APIC, 1999; CHINCHOLE; POUL; WAGHMARE, 2013)}

O protocolo deve ser preparado previamente ao início do estudo e deve incluir ou referenciar a documentação requerida para fornecer as seguintes informações:

- Objetivo do estudo: indicar o procedimento de limpeza a ser validado (produto a ser removido e o equipamento relacionado). Se o propósito do estudo for demonstrar a aceitabilidade para um procedimento de limpeza de um grupo de produtos, o racional deve estar detalhado. Os procedimentos de limpeza devem estar identificados (agentes de limpeza, parâmetros do equipamento, número de ciclos de limpeza etc.);

- Escopo do estudo: A empresa deve avaliar o processo e determinar quais resíduos devem ser testados e quais não devem baseada num racional científico;

- Identificação dos parâmetros do processo a serem verificados: Especialmente em processos automatizados ou semiautomatizados;

- Procedimentos de amostragem e inspeção. Os tipos de métodos de amostragem, onde as amostras serão retiradas e as quantidades devem ser detalhadas;

- Responsabilidades durante o estudo;

- Métodos utilizados (devem ser referenciados);

- Critérios de aceitação;

- Controle de mudanças;

- Aprovação do protocolo antes do estudo ser iniciado.

O relatório de validação é o documento no qual os registros, resultados e avaliação de um programa de validação são consolidados e sumarizados e deve incluir: referências dos procedimentos utilizados, resultados dos testes físicos e químicos ou referências associadas, conclusões a respeito da aceitabilidade dos resultados, recomendações baseadas nos resultados ou informações relevantes obtidas durante o estudo, aprovação das conclusões e revisão dos desvios do protocolo. Pode também conter propostas de melhorias (ANVISA, 2013; BAGO, 2010). 
Na TAB. 5 estão descritas as várias etapas necessárias ao processo de validação de limpeza, divididas em fases.

TABELA 5 - Fases do Processo de Validação de Limpeza

\begin{tabular}{|c|c|c|c|}
\hline \multirow[b]{2}{*}{ Fase 1} & $\begin{array}{l}\text { Determinar o } \\
\text { procedimento de limpeza } \\
\text { mais apropriado ao } \\
\text { equipamento }\end{array}$ & $\begin{array}{l}\text { Desenvolver e validar o } \\
\text { método de amostragem e } \\
\text { selecionar os métodos } \\
\text { analíticos utilizados na } \\
\text { determinação dos } \\
\text { resíduos }\end{array}$ & $\begin{array}{l}\text { Avaliar as superfícies do } \\
\text { equipamento e } \\
\text { determinar: }\end{array}$ \\
\hline & $\begin{array}{l}\text { 2. O método de limpeza } \\
\text { será determinado pelo } \\
\text { processo, equipamento, } \\
\text { agentes de limpeza e as } \\
\text { técnicas de limpeza } \\
\text { disponíveis. } \\
\text { 3. Todos os aspectos do } \\
\text { procedimento de limpeza } \\
\text { devem ser claramente } \\
\text { definidos em } \\
\text { procedimentos } \\
\text { operacionais (POPs), se } \\
\text { são manuais, CIP (clean } \\
\text { in place) ou COP (clean } \\
\text { out place). }\end{array}$ & $\begin{array}{l}\text { 1. Swab } \\
\text { 2. Rinsagem } \\
\text { Determinar a } \\
\text { porcentagem de } \\
\text { recuperação, bem como } \\
\text { os parâmetros de } \\
\text { metodologia analítica } \\
\text { (especificidade, } \\
\text { linearidade, intervalo, } \\
\text { precisão, limite de } \\
\text { detecção, limite de } \\
\text { quantificação e exatidão } \\
\text { do método) }\end{array}$ & $\begin{array}{l}\text { - Pontos mais difíceis de } \\
\text { limpar, considerados } \\
\text { como "pior caso" } \\
\text { (amostragem com swab) } \\
\text { - Volume e tipo de } \\
\text { solvente a ser empregado } \\
\text { (amostragem por } \\
\text { rinsagem); } \\
\text { - Superfície dos } \\
\text { Equipamentos } \\
\text { (necessário para o cálculo } \\
\text { do limite de resíduo em } \\
\text { lotes subsequentes }\end{array}$ \\
\hline Fase 2 & $\begin{array}{l}\text { Desenvolver o protocolo d } \\
\text { a ser limpo }\end{array}$ & alidação de limpeza pa & oroduto e o equipamento \\
\hline
\end{tabular}


TABELA 5 - Fases do Processo de Validação de Limpeza

\begin{tabular}{l|l}
\hline Que deve abranger, por exemplo: \\
1. Introdução; \\
3. Escopo; \\
4. Procedimento de limpeza; \\
5. Procedimentos de amostragem; \\
6. Procedimento analíticos; \\
7. Os limites de aceitação / limpeza; \\
8. Critérios de aceitação para a validação; \\
9. Teste de recuperação; \\
Observação: Para produção em campanha, definir o tamanho da campanha \\
(tempo, número de lotes, etc.).
\end{tabular}

Fonte: APIC, 1999.

\subsection{Carbono Orgânico Total (COT, ou do inglês, TOC)}

\subsubsection{Tipos de carbono}

O carbono (C) é um elemento químico de grande importância para os seres vivos, visto que participa da composição química e todos os componentes orgânicos e de uma grande parcela dos inorgânicos também. Tal elemento está localizado na família 4A da tabela periódica, apresenta o número atômico $(\mathrm{Z}) 6$ e massa atômica (A) 12. Existem três formas básicas de carbono que podem estar presentes na natureza: C elementar (incluindo carvão, fuligem e grafite); Carbono inorgânico (CI), sob forma de carbonatos; e Carbono orgânico 
(CO), resultante da decomposição de plantas e animais ou de contaminantes provenientes das atividades humanas, definido como todo átomo de carbono ligado covalentemente a uma determinada molécula (SCHUMACHER, 2002).

Os métodos e os instrumentos utilizados para mensurar o carbono orgânico total (COT) analisam frações de carbono total (CT) e mensuram o COT por duas ou mais determinações. Estas frações de carbono total são definidas como: carbono inorgânico (IC) - o carbonato, bicarbonato, e $\mathrm{CO}_{2}$ dissolvido; carbono orgânico total (COT) - todos os átomos de carbono covalentemente ligados a moléculas orgânicas. A classificação das frações de CO está relacionada na TAB. 6 (BISUTTI; HILKE; RAESSLER, 2004).

TABELA 6 - Classificação do Carbono Orgânico conforme características físico-químicas

\begin{tabular}{|c|c|c|}
\hline Classificação & Símbolo & Descrição \\
\hline Total & $\mathrm{COT}$ & $\begin{array}{l}\text { Toda forma de carbono de fonte orgânica ligado } \\
\text { covalentemente } \\
\mathrm{COT}=\mathrm{COD}+\mathrm{COPu}\end{array}$ \\
\hline Dissolvido & $\mathrm{COD}$ & $\begin{array}{l}\text { Toda espécie de carbono solúvel, não filtrável por } \\
\text { membrana de } 0,45 \mu \mathrm{m}\end{array}$ \\
\hline Particulado & $\mathrm{COPt}$ & $\begin{array}{l}\text { Possui partículas suspensas retidas por membranas de } \\
\text { ordem de } 0,2-10 \mu \mathrm{m}\end{array}$ \\
\hline Volátil & $\mathrm{COV}$ & $\begin{array}{l}\text { Compostos de baixo peso molecular e pontos de fusão } \\
\text { abaixo de } 100^{\circ} \mathrm{C}\end{array}$ \\
\hline Purgável & $\mathrm{COPu}$ & Matéria orgânica decomposta por pulverização \\
\hline Não Purgável & CONP & Matéria orgânica não decomposta por pulverização \\
\hline Ácido-reagente & COAR & Matéria orgânica decomposta por tratamento com ácido \\
\hline Biológico & $\mathrm{COB}$ & Composto de origem biológica \\
\hline
\end{tabular}
Fonte: BENEDETTI, 2012.

\subsubsection{Métodos analíticos para determinação de carbono orgânico total (COT)}

Em água potável, o carbono inorgânico se apresenta nas formas do dióxido de carbono, ácido carbônico e suas formas dissociadas, podendo ainda estar presentes formas minerais particuladas como a calcita. A matéria orgânica presente na água origina em grande 
parte o carbono orgânico, podendo este também resultar da reação com produtos desinfetantes (ALENCAR; CLEMENTINO; NETO, 2008).

As análises de COT são amplamente utilizadas na indústria farmacêutica, quer seja no controle da água farmacêutica utilizada nos processos de limpeza e na preparação de medicamentos, bem como na validação de limpeza. Com a edição da Farmacopeia Americana - USP XXIII estabeleceu-se o monitoramento dos níveis de carbono orgânico total (COT) para água com fins farmacêuticos, seja ela água purificada - AP (PW, do inglês, potable water) ou água para injetável - API (WFI, do inglês, water for injection), ficando o parâmetro inicialmente limitado em $500 \mu \mathrm{g} \mathrm{L}^{-1}$ (ppb) para AP. Através da determinação de COT podem ser mensurados os compostos ativos, excipientes, agentes de limpeza, e produtos orgânicos do sistema de água no interior da amostra, o que torna tal metodologia analítica uma importante ferramenta para o fornecimento de resultados que evidenciem a presença de vários produtos químicos em estudo dentro da amostra, em poucos minutos (ALENCAR; CLEMENTINO; NETO, 2008; SHIMADZU CORPORATION, 2010).

Para a realização das análises de COT, as indústrias utilizam um analisador de carbono, o qual é capaz de identificar o teor de carbono presente nas amostras mediante oxidação do carbono para a forma simples de dióxido de carbono $\left(\mathrm{CO}_{2}\right)$, detectando e quantificando consequentemente o gás resultante dessa conversão. Os resultados obtidos para COT podem ser expressos como COT ou CONP (carbono orgânico não-purgável). Em uma amostra, o COT é constituído pelo carbono orgânico purgável (COPu), carbono volátil (COV), e CONP (SHIMADZU CORPORATION, 2010).

Vários métodos de oxidação e de detecção em conjunto uns com os outros podem ser utilizados para a análise de carbono, e tal combinação depende da preferência do utilizador, dos níveis de detecção exigidos, da oxidação e método de detecção, da matriz da amostra, bem como das características e/ou tipo de amostra (sólido ou líquido) (SHIMADZU CORPORATION, 2010). A determinação do COT pode ser feita de forma direta ou indireta. A idéia é converter todas as diferentes formas de carbono em $\mathrm{CO}_{2}$, o qual é facilmente mensurável. Tanto no método direto quanto no indireto a remoção do carbono inorgânico é uma etapa prévia (ALENCAR; CLEMENTINO; NETO, 2008; BISUTTI; HILKE; RAESSLER, 2004).

\subsubsection{Método Direto para Determinação de COT}

No método direto, o CO presente na amostra é medido de duas maneiras. Primeiramente remove-se o CI através de tratamento ácido ou por calcinação, para 
posteriormente medir o $\mathrm{CO}$. Na calcinação, o $\mathrm{CO}$ é queimado, enquanto que no tratamento ácido o CI é removido. O tratamento com ácido tem como objetivo a eliminação do CI, assumindo-se que todo o CI está presente na forma de carbonatos e que estes reagem facilmente com ácido produzindo $\mathrm{CO}_{2}$.

Os ácidos normalmente utilizados são o $\mathrm{HCl}, \mathrm{H}_{3} \mathrm{PO}_{4}, \mathrm{H}_{2} \mathrm{SO}_{3}$ ou $\mathrm{H}_{2} \mathrm{SO}_{4}$ descritos na TAB. 7 (BISUTTI; HILKE; RAESSLER, 2004).

$\mathrm{O} \mathrm{CO}_{2}$ produzido é arrastado com um gás inerte sendo posteriormente quantificado após captação por detectores específicos. Compostos orgânicos voláteis podem ser arrastados (purgados) nessa corrente de arraste, e, nas águas para consumo humano, normalmente, esses compostos são desprezíveis. Nesse caso, a fração não purgável de carbono orgânico (CONP) é equivalente ao COT, isto é, se CONP for representado pela equação CONP $=\mathrm{COT}-\mathrm{COP}$, e se COP for desprezível, resulta em CONP = COT (Eq. 9), onde COP é a fração purgada junto com o gás de arraste (ALENCAR; CLEMENTINO; NETO, 2008; SHIMADZU CORPORATION, 2010).

$$
\begin{gathered}
\text { CONP }=\text { COT }- \text { COP } \\
\text { CONP }=\text { COT }
\end{gathered}
$$

TABELA 7 - Critério para escolha e aplicação dos ácidos utilizados na determinação de COT

\begin{tabular}{cl}
\hline Ácido & \multicolumn{1}{c}{ Especificações } \\
\hline $\mathrm{HCl}$ & $\begin{array}{l}\text { Reagente com } \mathrm{CO}_{3}{ }^{-2} \text { principalmente em amostras sólidas. Pode induzir à } \\
\text { reação de } \mathrm{CO} \text { quando aquecida. }\end{array}$ \\
\hline & Ácido não oxidante. Amplamente aplicado em análises de combustão a altas \\
$\mathrm{H}_{3} \mathrm{PO}_{4}$ & $\begin{array}{l}\text { temperaturas em amostras de água. Deve-se aplicar um método de remoção de } \\
\text { gás clorídrico }\left(\mathrm{Cl}_{2}\right) \text { para evitar interferência ou ineficácia da reação. }\end{array}$ \\
\hline $\mathrm{H}_{2} \mathrm{SO}_{3}$ & $\begin{array}{l}\text { Geralmente utilizado em tratamentos de solo. Promove perda menor que } 2 \% \\
\text { de CO, mas pode constituir uma fonte de contaminação de CO. }\end{array}$ \\
\hline Outros & Com os ácidos $\mathrm{H}_{2} \mathrm{SO}_{4}, \mathrm{HNO}_{3}$ e $\mathrm{HClO}_{4}$, a perda de CO é maior que $80 \%$. O \\
ácidos & $\mathrm{HClO}_{4}$ sob aquecimento pode se converter em espécies de percloratos tóxicos. \\
\hline
\end{tabular}


Uma vez realizada a acidificação e remoção do CI, o COT não volatilizado ou purgado remanescente na amostra é submetido a um método de oxidação. A oxidação do COT pode ser pode ser térmica ou química ou ainda por raios ultravioletas. No método químico de oxidação faz-se o uso de diferentes soluções oxidantes, bem como diferentes tempos de digestão e de temperaturas para oxidação do CO (ALENCAR; CLEMENTINO; NETO, 2008; BISUTTI; HILKE; RAESSLER, 2004).

A FIG. 6 apresenta o esquema do método direto de determinação do COT.

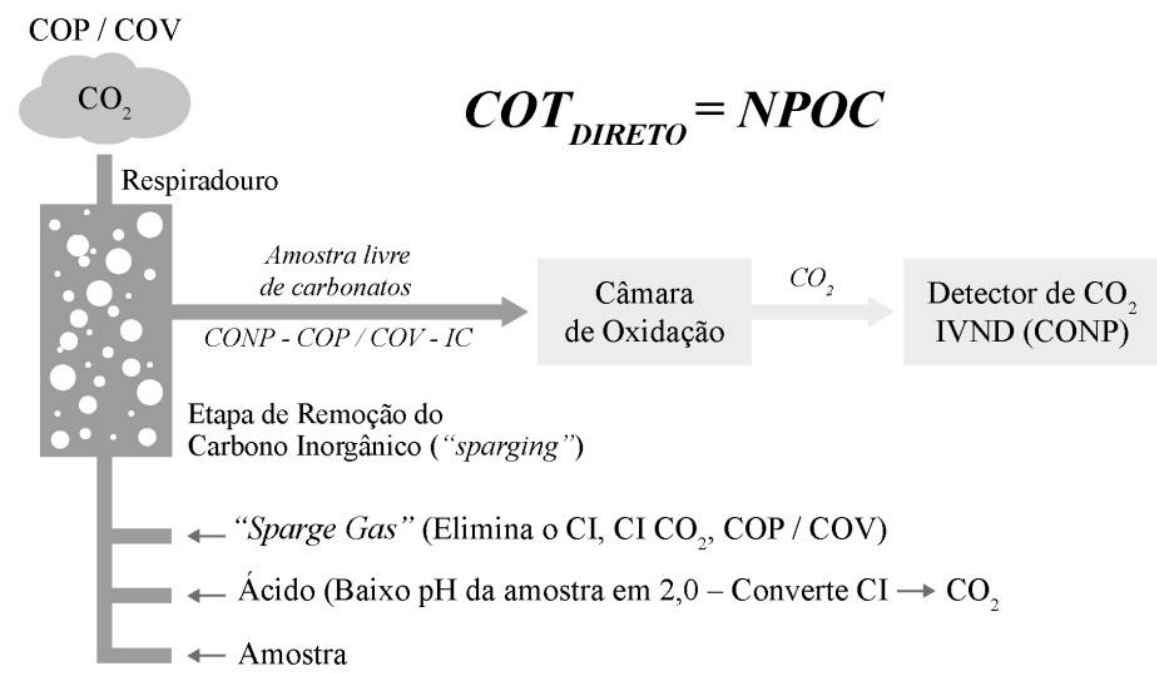

FIGURA 6 - Esquema do método direto para determinação de COT

(Fonte: Adaptado de TELEDYNE ANALYTICAL INSTRUMENTS, s.d.)

Na oxidação por UV, a amostra líquida passa sobre a luz UV, sendo o oxidante continuamente gerado. A oxidação por UV é ideal para análise de COT de água purificada e água para injetáveis, mas normalmente não é suficientemente forte as matrizes contendo carbono encontradas na maioria das validações da limpeza.

$\mathrm{O}$ persulfato $\left(\mathrm{K}_{2} \mathrm{~S}_{2} \mathrm{O}_{8}\right)$ é geralmente utilizado para a determinação de COT em amostras de água e pode ser ativado quer por calor ou por raios UV. O persulfato aumenta substancialmente a eficiência de oxidação. A combinação da técnica de oxidação UV associada com persulfato é poderosa o suficiente para quase todas as necessidades da validação de limpeza e ainda apresenta um bom desempenho para águas com baixos teores de COT (BISUTTI; HILKE; RAESSLER, 2004).

A chave para alcançar resultados precisos com baixo nível de COT é maximizar a resposta de carbono da amostra, minimizando a resposta fundo de carbono. Dada a sua resposta superior para amostra-ruído, a maioria dos laboratórios utiliza equipamentos que realizam a 
oxidação com persulfato associada à oxidação térmica e luz UV, pois esta tecnologia alcança uma precisão mais elevada e limites de detecção mais baixos, bem como consegue uma boa exatidãoem toda a faixa de análise, além de requerer muito menos esforço e manutenção do que a técnica de combustão. A comparação e limitações das técnicas utilizadas na determinação do COT são apresentadas na TAB. 8 (BISUTTI; HILKE; RAESSLER, 2004; SHIMADZU CORPORATION, 2010).

TABELA 8 - Técnicas utilizadas na determinação de COT

\begin{tabular}{|c|c|c|}
\hline Método & $\begin{array}{l}\text { Técnica / } \\
\text { Reagente }\end{array}$ & Limitações \\
\hline \multirow[t]{2}{*}{ Oxidação Química } & Cromato & $\begin{array}{l}\text { Reage apenas com formas mais facilmente } \\
\text { oxidáveis de } \mathrm{CO} \text {, podendo sofrer interferências } \\
\text { por } \mathrm{Cl}^{-}, \mathrm{Fe}^{+2} \text { e } \mathrm{MnO}_{2} \text {. }\end{array}$ \\
\hline & Persulfato & $\begin{array}{l}\text { Necessidade da ativação por luz UV e/ou } \\
\text { aquecimento. Pode sofrer interferências de } \mathrm{Cl}^{-} \text {. }\end{array}$ \\
\hline $\begin{array}{c}\text { Oxidação } \\
\text { Fotocatalítica }\end{array}$ & Luz UV & $\begin{array}{l}\text { Matérias articuladas e soluções coloidais não são } \\
\text { completamente oxidadas. }\end{array}$ \\
\hline & Seca & Requer temperaturas muito altas $\left(1000-1100^{\circ} \mathrm{C}\right)$. \\
\hline Combustão & Úmida & Requer meio ácido para ativar a reação. \\
\hline
\end{tabular}

Fonte: Adaptado de BENEDETTI, 2012.

$\mathrm{O} \mathrm{CO}_{2}$ produzido nesta oxidação é então novamente arrastado por um gás inerte até um detector específico onde é efetuada a leitura para posteriormente, através de uma curva de calibração, serem obtidos os resultados dos níveis COT.

\subsubsection{Método Indireto para Determinação de COT}

A determinação indireta é a mais comumente utilizada nas amostras líquidas, sendo o COT obtido pela subtração do carbono inorgânico (CI) do conteúdo total de carbono (CT) presente na amostra, determinados de forma isolada e independente através da equação matemática simples descrita na Eq. 10. 
Uma alíquota da amostra é acidificada resultando na liberação de $\mathrm{CO}_{2}$, com a consequente quantificação do CI, a exemplo do método anterior. Numa segunda alíquota, o CT é obtido pela oxidação com persulfato associada à oxidação por calor e luz UV, resultando em $\mathrm{CO}_{2}$ (BISUTTI; HILKE; RAESSLER, 2004; CLARK, 2000; FURLONG; PURCELL; WALLACE, 1996).

Na FIG. 7 o método direto e o indireto para determinação de COT estão esquematizados para melhor elucidação do processo.

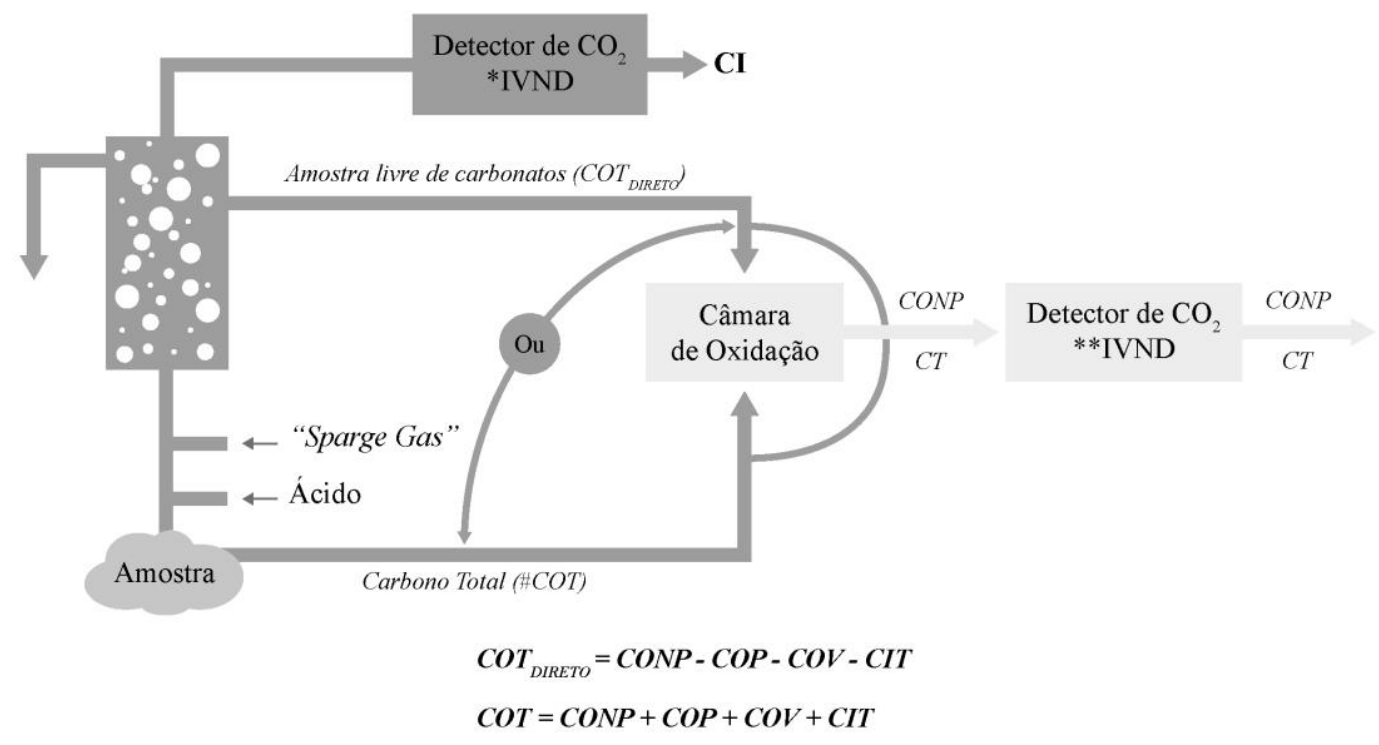

FIGURA 7 - Esquema da determinação de COT pelos métodos direto e indireto (Fonte: Adaptado de TELEDYNE ANALYTICAL INSTRUMENTS, s.d.)

A metodologia escolhida para mensuração de COT deve demonstrar ser apropriada para a finalidade a qual se destina, cumprindo portanto os requisitos de confiabilidade dos resultados (Jenkins et al.,1996 apud PURCELL; STEVENS; WALLACE, 2004, p. 42).

A forma de detecção do $\mathrm{CO}_{2}$ produzido nas etapas de oxidação pode diferir de equipamento para equipamento, sendo tão importante quanto a seleção do método de oxidação. As duas tecnologias básicas e mais utilizadas são a condutividade e a espectroscopia com infravermelho não dispersível (IVND ou NDIR, do inglês Non-Dispersive InfraRed).

A espectroscopia com infravermelho não dispersível é um método mais prático e livre da interferência de outros compostos da solução teste na detecção do $\mathrm{CO}_{2}$ em análise de 
COT. Na maioria dos casos não é necessário tempo de recuperação para uma amostra com alto teor de COT, permitindo assim uma análise mais rápida, que pode traduzir-se numa validação de limpeza mais rápida do processo de fabricação e aumento da produtividade (Shimadzu Corporation, 2010), apresentando ainda a vantagem da alta sensibilidade e baixos limites de detecção quando comparada a outras técnicas relacionadas na TAB. 9 (BISUTTI; HILKE; RAESSLER, 2004; BENEDETTI, 2012).

TABELA 9 - Técnicas de detecção/quantificação de $\mathrm{CO}^{2}$

\begin{tabular}{cl}
\hline Técnica & Propriedades \\
\hline IVND & Determina $\mathrm{CO}_{2}$ diretamente e possui alta sensibilidade. \\
\hline Condutividade & Método indireto medindo a diferença de resistência entre $\mathrm{CO}_{2} \mathrm{e}$ \\
Térmica & um gás referência. Pode sofrer interferência por haletos. \\
\hline Titulação & $\mathrm{CO}_{2}$ deve estar preso a uma base forte. Detecção do COT \\
& somente em concentrações acima de 200 ugL ${ }^{-1}$. \\
\hline \multirow{2}{*}{ Gravimetria } & Utilizando bulbos de adsorção. A concentração de $\mathrm{CO}_{2}$ é \\
& concentrada pelo ganho de peso. Detecção do COT somente em \\
\hline Fonte: BISUTTI; HILKE; RAESSLER, 2004.
\end{tabular}

\subsubsection{Validação de métodos analíticos}

A validação de métodos pode ser definida como o processo utilizado para confirmar, mediante estudos experimentais, que o procedimento analítico utilizado para um teste específico é adequado para o uso pretendido. Tais estudos constituem uma ferramenta fundamental na implantação e manutenção de BPF em indústrias farmacêuticas, bem como em sistemas de gestão da qualidade de laboratórios de diversas áreas analíticas, sendo pautados em guias e documentos orientadores publicados nacional e internacionalmente (BERNARDES, SOUZA, 2011).

Os resultados da validação do método podem ser usados na avaliação da qualidade, confiabilidade e consistência dos resultados analíticos, sendo uma parte integrante de qualquer boa prática analítica (ANVISA, 2003; SHARMA; SHARMA, 2012). 
Dependendo da sua aplicação, significa dizer que o método funciona de forma reprodutível quando realizado pelas mesmas ou diferentes pessoas, nos mesmos ou diferentes laboratórios, utilizando diferentes reagentes químicos ou utilizando diferentes equipamentos em diferentes condições ou ambientes (SHARMA; SHARMA, 2012).

A metodologia analítica deve ser validada anteriormente à sua utilização nos testes de rotina, quando ocorre transferência para outro laboratório, bem como na utilização de novas técnicas ou equipamentos (SHARMA; SHARMA, 2012; ICH, 2005).

A revalidação deve ocorrer nas seguintes circunstâncias: caso ocorra mudanças na síntese ou composição de um produto, mudança no procedimento analítico, e sempre que houver alterações nos parâmetros ou condições do método (ANVISA, 2003; SHARMA; SHARMA, 2012).

O desempenho de um método analítico depende de dois principais parâmetros: a qualidade do instrumental de análise e a confiabilidade dos cálculos estatísticos utilizados no processamento de dados (FERREIRA et al., 2008).

Existe uma diversidade de parâmetros de desempenho utilizados nos processos de validação. A TAB. 10 apresenta os parâmetros recomendados para validação intralaboratorial pelos Guias da AOAC Internacional, ISO e IUPAC, INMETRO e ANVISA.

TABELA 10 - Parâmetros de desempenho previstos no guia harmonizado pela AOAC Internacional, ISO e IUPAC, no documento orientativo do INMETRO e no guia da ANVISA

\begin{tabular}{cccc}
\hline $\begin{array}{c}\text { Parâmetro de } \\
\text { desempenho }\end{array}$ & $\begin{array}{c}\text { Guia harmonizada pela } \\
\text { AOAC Internacional, } \\
\text { ISO e IUPAC (2002) }\end{array}$ & $\begin{array}{c}\text { Documento } \\
\text { orientativo do } \\
\text { INMETRO (2007) }\end{array}$ & $\begin{array}{c}\text { Guia da } \\
\text { ANVISA } \\
(2003)\end{array}$ \\
\hline Aplicabilidade & Sim & Não & Não \\
Seletividade & Sim & Sim & Sim \\
Linearidade $^{2}$ & Sim & Sim & Sim \\
Exatidão $^{3}$ & Sim & Sim & Sim \\
Precisão & Sim & Sim & Sim \\
Faixa ou intervalo & Sim & Sim & Sim
\end{tabular}


TABELA 10 - Parâmetros de desempenho previstos no guia harmonizado pela AOAC

Internacional, ISO e IUPAC, no documento orientativo do INMETRO e no guia da ANVISA

\begin{tabular}{|c|c|c|c|}
\hline $\begin{array}{l}\text { Parâmetro de } \\
\text { desempenho }\end{array}$ & $\begin{array}{l}\text { Guia harmonizada pela } \\
\text { AOAC Internacional, } \\
\text { ISO e IUPAC (2002) }\end{array}$ & $\begin{array}{c}\text { Documento } \\
\text { orientativo do } \\
\text { INMETRO (2007) }\end{array}$ & $\begin{array}{c}\text { Guia da } \\
\text { ANVISA } \\
(2003)\end{array}$ \\
\hline $\begin{array}{c}\text { Limite de detecção } \\
\text { (LD) }\end{array}$ & Sim & Sim & Sim \\
\hline $\begin{array}{c}\text { Limite de } \\
\text { quantificação }{ }^{5}(\mathrm{LQ})\end{array}$ & Sim & Sim & Sim \\
\hline Sensibilidade $^{6}$ & Sim & Sim & Sim \\
\hline Robustez & Sim & Sim & Sim \\
\hline $\begin{array}{c}\text { Adequação ao } \\
\text { propósito }\end{array}$ & Sim & Não & Não \\
\hline Variação de matriz & Sim & Não & Não \\
\hline Incerteza de medição & Sim & Não & Não \\
\hline
\end{tabular}

\footnotetext{
${ }^{1}$ No guia da ANVISA, os termos seletividade e especificidade são tratados de forma inapropriada como sinônimos. Neste documento o termo especificidade é utilizado erroneamente no contexto da validação.

${ }^{2}$ No guia internacional, este parâmetro é tratado como linearidade e calibração.

${ }^{3}$ No documento do INMETRO, os termos utilizados são tendência/recuperação com a nota que a exatidão é avaliada numericamente pela tendência. Os três documentos tratam recuperação em conjunto com a estimativa da exatidão, embora o guia internacional destaque esse parâmetro.

${ }^{4}$ No guia da ANVISA, o termo adotado é intervalo, enquanto no do INMETRO são apresentados faixa de trabalho e faixa linear, devidamente distinguidos.

${ }^{5}$ No guia internacional, este parâmetro também é tratado como limite de determinação.

${ }^{6}$ No guia da ANVISA, o termo sensibilidade é tratado como sinônimo de limite de detecção e não como um parâmetro independente. No documento do INMETRO, este parâmetro é adequadamente associado ao parâmetro linearidade.
}

Fonte: Bernardes, 2011.

Na TAB. 11 estão representados os parâmetros de desempenho com suas respectivas definições estabelecidos na Resolução - RE n 899/2003 da ANVISA. 
TABELA 11 - Parâmetros de desempenho e definições apresentados na RE nº 899/2003

\begin{tabular}{|c|c|}
\hline $\begin{array}{l}\text { Parâmetro de } \\
\text { desempenho }\end{array}$ & Definição \\
\hline Linearidade & $\begin{array}{l}\text { Capacidade de uma metodologia analítica de demonstrar que os } \\
\text { resultados obtidos são diretamente proporcionais à concentração do } \\
\text { analito na amostra, dentro de um intervalo especificado. }\end{array}$ \\
\hline Intervalo & $\begin{array}{l}\text { Faixa entre os LQ superior e inferior de um método analítico. } \\
\text { Normalmente é derivado do estudo de linearidade e depende da } \\
\text { aplicação pretendida do método. É estabelecido pela confirmação de } \\
\text { que o método apresenta exatidão, precisão e linearidade adequados } \\
\text { quando aplicados às amostras contendo quantidades de substâncias } \\
\text { dentro do intervalo especificado. }\end{array}$ \\
\hline $\begin{array}{l}\text { Especificidade/ } \\
\text { seletividade }^{1}\end{array}$ & $\begin{array}{l}\text { Capacidade que o método possui de medir exatamente um composto } \\
\text { em presença de outros componentes tais como impurezas, produtos de } \\
\text { degradação e componentes da matriz. }\end{array}$ \\
\hline Exatidão & $\begin{array}{l}\text { Proximidade dos resultados obtidos pelo método em estudo em relação } \\
\text { ao valor verdadeiro. }\end{array}$ \\
\hline $\begin{array}{l}\text { Precisão } \\
\text { (repetibilidade } \\
\text { ou intra- } \\
\text { corrida) }\end{array}$ & $\begin{array}{l}\text { Avaliação da proximidade dos resultados obtidos em uma série de } \\
\text { medidas de uma amostragem múltipla de uma mesma amostra. } \\
\text { Concordância entre os resultados dentro de um curto período de tempo } \\
\text { com o mesmo analista e mesma instrumentação. }\end{array}$ \\
\hline $\begin{array}{l}\text { Precisão } \\
\text { (intermediária } \\
\quad \text { ou } \\
\text { intercorridas) }\end{array}$ & $\begin{array}{l}\text { Avaliação da proximidade dos resultados obtidos em uma série de } \\
\text { medidas de uma amostragem múltipla de uma mesma amostra. } \\
\text { Concordância entre os resultados do mesmo laboratório, mas obtidos } \\
\text { em dias diferentes, com analistas diferentes e/ou equipamentos } \\
\text { diferentes. }\end{array}$ \\
\hline $\begin{array}{l}\text { Limite de } \\
\text { detecção/sensi } \\
\text { bilidade }^{2}\end{array}$ & $\begin{array}{l}\text { Menor quantidade do analito presente em uma amostra que pode ser } \\
\text { detectado, porém não necessariamente quantificado, sob as condições } \\
\text { experimentais estabelecidas. }\end{array}$ \\
\hline $\begin{array}{c}\text { Limite de } \\
\text { quantificação }\end{array}$ & $\begin{array}{l}\text { Menor quantidade do analito em uma amostra que pode ser } \\
\text { determinada com precisão e exatidão aceitáveis sob as condições } \\
\text { experimentais estabelecidas. }\end{array}$ \\
\hline
\end{tabular}


TABELA 11 - Parâmetros de desempenho e definições apresentados na RE nº 899/2003

\begin{tabular}{ll}
\hline $\begin{array}{l}\text { Parâmetro de } \\
\text { desempenho }\end{array}$ & Definição \\
\hline
\end{tabular}

A medida da capacidade de um método em resistir a pequenas e

Robustez deliberadas variações dos parâmetros analíticos. Indica sua confiança durante o uso normal.

\footnotetext{
${ }^{1}$ Os termos seletividade e especificidade são tratados, equivocadamente, como sinônimos.

${ }^{2} \mathrm{O}$ termo sensibilidade é tratado, equivocadamente, como sinônimo de limite de detecção.

Fonte: Bernardes, 2011.
}

\subsection{Conformidade do sistema (System Suitability)}

O teste de conformidade ou adequação do sistema é uma parte integrante de muitos procedimentos/metodologias analíticos, sendo realizado para garantir que o equipamento utilizado está apto a gerar resultados de exatidão e precisão aceitáveis (BOTTOLI et al., 2004; $\mathrm{ICH}, 2005)$.

Parâmetros de teste de adequação do sistema a serem estabelecidos para um determinado procedimento/método dependem do tipo de procedimento que está sendo validado, seguindo-se um determinado compêndio farmacopeico (BENEDETTI, 2012).

Nas análises de COT, o teste de conformidade do sistema estabelece que se proceda à recuperação de uma substância teste (1,4-benzoquinona) frente a uma substância de referência (sacarose) (ICH, 2005).

\subsection{Robustez}

A robustez de um método analítico é definida como a capacidade de manter-se inalterado frente a pequenas variações nos parâmetros analíticos, e deve ser avaliada durante o desenvolvimento da metodologia. Caso a suscetibilidade do método seja constatada, as condições analíticas deverão ser controladas ou precauções deverão ser incluídas no procedimento (ANVISA, 2003; BOTTOLI et al., 2004).

Quanto maior for a robustez de um método, maior será a confiança desse em relação à sua precisão (INMETRO, 2010). 
Para determinar a robustez de um método, o INMETRO recomenda o teste de Youden, que permite não só avaliar a robustez do método, como também ordenar a influência de cada uma das variações nos resultados finais (BOTTOLI et al., 2004; INMETRO, 2010).

\subsection{Linearidade}

A linearidade corresponde à capacidade do método em fornecer resultados diretamente proporcionais à concentração da substância em análise, dentro de uma determinada faixa de aplicação pré-estabelecida (BOTTOLI et al., 2004; ICH, 2005).

Para sabermos se determinado método é linear, a correlação entre o sinal medido (área ou altura do pico) e a massa ou concentração da espécie de interesse deve ser determinada empiricamente, a partir de sinais medidos para massas ou concentrações conhecidas dessa espécie, podendo essa relação matemática ser expressa como uma equação de reta conhecida como curva analítica. Dessa forma, obtêm-se a equação da reta (Eq. 11) e os coeficientes de regressão, e, a partir destes, calcula-se o coeficiente de correlação linear (r) e a soma residual dos quadrados mínimos da regressão linear $\left(\mathrm{r}^{2}\right)$. O (r) e o $\left(\mathrm{r}^{2}\right)$ são obtidos através das Eq. 12 e Eq. 13 (BOTTOLI et al., 2004; FERREIRA et al., 2008). O coeficiente de correlação linear (r) e a soma residual dos mínimos quadrados da regressão linear $\left(\mathrm{r}^{2}\right)$ permitem uma estimativa da qualidade da curva obtida, pois quanto mais próximo de 1,0 , menor a dispersão do conjunto de pontos experimentais e menor a incerteza dos coeficientes de regressão estimados.

$$
\begin{gathered}
\mathrm{y}=a x+\mathrm{b} \\
r=\frac{\sum(x-\bar{x})(y-\bar{y})}{\sqrt{\left(\sum(x-\bar{x})^{2} \sum(y-\bar{y})^{2}\right)}} \\
r^{2}=\frac{\sum x \cdot y-\left(\sum x\right)\left(\sum y\right)}{\sqrt{\left[n \sum x^{2}-\left(\sum x\right)^{2}\right]\left[n \sum y^{2}-\left(\sum y\right)^{2}\right]}}
\end{gathered}
$$

Onde:

$\mathbf{x}$ - concentração do analito;

y - intensidade do sinal analítico;

a - coeficiente angular; 
b - coeficiente linear;

n - número de pontos de curva.

A ANVISA recomenda um coeficiente de correlação igual a 0,99 e o INMETRO um valor acima de 0,90 (BOTTOLI et al., 2004; INMETRO, 2010).

\subsection{Limite de Deteç̧ão - LD}

O limite de detecção (LD) é definido como a menor concentração do analito que pode ser detectada pela técnica instrumental, mas não necessariamente quantificada (ANVISA, 2003; ICH, 2005).

O limite de detecção (LD) pode ser calculado por três diferentes métodos: método visual, método da relação sinal-ruído, e método baseado em parâmetros da curva analítica (ANVISA, 2003; BOTTOLI et al., 2004; USP, 2015).

O método é realizado mediante análise de amostras contendo baixas concentrações conhecidas do analito de interesse, considerando-se o LD como a menor concentração que pode ser detectada e que seja distinta do sinal analítico do ruído (FERREIRA et al., 2008).

Este método pode ser aplicado em procedimentos analíticos que apresentam sinal/ruído da linha de base e é estimado por meio da comparação do sinal analítico obtido para uma amostra contendo baixas concentrações do analito de interesse com o sinal de uma amostra do branco, estabelecendo-se assim a concentração mínima na qual o analito pode ser detectado. Geralmente a razão sinal/ruído com valor 3:1 ou 2:1 é considerada aceitável para estimativa do LD (FERREIRA et al., 2008).

No método baseado em parâmetros da curva analítica o LD pode ser definido como a concentração mínima de uma substância que pode ser medida e informada com 99\% ou 95\% de confiança. Tal metodologia fornece uma maior confiabilidade estatística, pois leva em consideração o intervalo de confiança da regressão (FERREIRA et al., 2008).

A estimativa do LD pode ser feita com base na relação de 3 vezes o ruído da linha de base, conforme a Eq. 14 (ANVISA, 2003; BOTTOLI et al., 2004).

$$
\mathrm{LD}=\frac{\left(3 \times \mathrm{DP}_{\mathrm{a}}\right)}{\mathrm{IC}}
$$


Onde:

LD - limite de detecção;

DPa - desvio padrão do coeficiente de regressão linear;

IC - média de coeficiente angular.

\subsection{Limite de Quantificação - LQ}

O limite de quantificação (LQ) representa a menor concentração do analito que pode ser determinada em uma amostra dentro dos limites de exatidão e precisão do método, e pode ser expresso pela Eq. 15 (ANVISA, 2003; BOTTOLI et al., 2004).

$$
\mathrm{LQ}=\frac{\left(10 \times \mathrm{DP} \mathrm{a}_{\mathrm{a}}\right)}{\mathrm{IC}}
$$

A exemplo do LD, o LQ também pode ser calculado pelos métodos visual, relação sinal-ruído e parâmetros da curva analítica (BOTTOLI et al., 2004). A determinação de LQ é realizada principalmente para ensaios quantitativos de impurezas, produtos de degradação em fármacos e produtos de degradação em formas farmacêuticas, sendo tal parâmetro expresso como concentração do analito (ANVISA, 2003).

\subsection{Precisão}

A precisão de um método analítico é o parâmetro que representa a dispersão de resultados entre ensaios independentes, repetidos de uma mesma amostra, amostras semelhantes ou padrões, sob condições definidas (BOTTOLI et al., 2004).

A precisão pode ser estimada em três níveis: repetibilidade, precisão intermediária e reprodutibilidade (ANVISA, 2003).

A repetibilidade (precisão intracorrida) corresponde à concordância entre os resultados realizados pelo mesmo analista, utilizando os mesmos instrumentos, num curto período de tempo, devendo ser verificada por no mínimo 9 (nove) determinações contemplando o intervalo linear do método, ou seja, 3 (três) concentrações (baixa, média e alta), com 3 (três) réplicas cada ou mínimo de 6 determinações a 100\% da concentração do teste (ANVISA, 2003). 
A precisão intermediária (precisão inter-corridas) corresponde à concordância entre os resultados do mesmo laboratório, obtidos em dias diferentes, com analistas diferentes e/ou equipamentos diferentes, recomendando-se um mínimo de 2 (dois) dias (ANVISA, 2003).

Reprodutibilidade (precisão inter-laboratorial) corresponde à concordância entre os resultados obtidos em laboratórios diferentes como em estudos colaborativos, geralmente aplicados à padronização de metodologia analítica, por exemplo, para inclusão de metodologia em farmacopeias (ANVISA, 2003).

A precisão de um método analítico pode ser expressa como o desvio padrão (DP) ou desvio padrão relativo (DPR) -também referido como coeficiente de variação (CV\%) - de uma série de medidas. Os cálculos matemáticos do DP e DPR (ANVISA, 2003) são realizados conforme as Eq. 16 e Eq. 17.

$$
\begin{aligned}
& \mathrm{DP}=\mathrm{S}=\sqrt{\frac{\sum_{\mathrm{i}}^{\mathrm{n}}(\mathrm{X}-\overline{\mathrm{X}})^{2}}{\mathrm{n}-1}} \\
& \operatorname{DPR}(\%)=\frac{(\mathrm{DP} \times 100)}{\mathrm{CMD}}
\end{aligned}
$$

Onde:

DPR - desvio padrão relativo;

DP - desvio padrão;

CMD - concentração média determinada.

\subsection{Exatidão}

A exatidão de um método analítico representa a proximidade dos resultados (grau de concordância) obtidos no método em estudo em relação a um dado valor de referência aceito como verdadeiro (ANVISA, 2003; BOTTOLI et al., 2004), e relaciona-se com o erro absoluto de uma medida (ANVISA, 2003; BOTTOLI et al., 2004; Q3).

A exatidão do método deve ser determinada após o estabelecimento da linearidade, do intervalo linear e da especificidade do mesmo, sendo verificada a partir de, no mínimo, 9 (nove) determinações contemplando o intervalo linear do procedimento, ou seja, 3 (três) replicatas em (três) amostras de concentrações conhecida, sendo expressa pela relação entre a 
CMD experimentalmente e a concentração teórica correspondente, de acordo com a Eq. 18 (ANVISA, 2003).

$$
\text { Exatidão }(\%)=\frac{(\mathrm{CMD} \times 100)}{\mathrm{CT}_{1}}
$$

Onde:

CMD - concentração média determinada;

CT1 - concentração teórica. 


\section{MATERIAIS E MÉTODOS}

\subsection{Equipamentos}

Todos os ensaios foram realizados utilizando-se um analisador de carbono modelo TOC-Vwp acoplado a um amostrador automático modelo ASI-V, ambos da marca Shimadzu ${ }^{\circledR}$ e controlados por software TOC Control-V Shimadzu ${ }^{\circledR}$. Foi utilizado como gás de arraste o nitrogênio $\left(\mathrm{N}_{2}\right)$, grau 5.0 analítico (White Martins). A análise de dados foi realizada através dos softwares TOC Control-V Shimadzu ${ }^{\circledR}$, OriginPro 8 (Microcal ${ }^{\circledR}$ ) e Microsoft Excel.

Foi utilizada balança analítica da marca Mettler Toledo ${ }^{\circledR}$, modelo XS205 com precisão de $10^{-5}$ g para pesagem dos padrões utilizados e fármacos utilizados nas análises.

Agitador magnético da marca Eletrolab ${ }^{\circledR}$, modelo Macro 303.

Purificador Elix-10 acoplado a um reservatório de 30L, da Millipore ${ }^{\circledR}$.

\subsubsection{Princípio de funcionamento do analisador de carbono}

$\mathrm{O}$ analisador de carbono utilizado neste trabalho utilizou o método direto para quantificação do carbono orgânico não purgável/volátil (CONP), relacionando-o com a concentração de COT.

Após acidificação da amostra a um pH entre 2-3 pela adição de ácido fosfórico $\left(\mathrm{H}_{3} \mathrm{PO}_{4}\right)$, os carbonatos e hidrogeno-carbonatos foram convertidos em dióxido de carbono $\left(\mathrm{CO}_{2}\right)$, e o gás de aspersão $\left(\mathrm{N}_{2}\right)$ foi borbulhado na amostra para remoção de todo CI. Posteriormente, o conteúdo de CT remanescente na amostra após a aspersão foi submetido à oxidação química com persulfato $\left(\mathrm{Na}_{2} \mathrm{~S}_{2} \mathrm{O}_{8}\right)$ e luz UV em um reator úmido aquecido a 80,0 \pm $0,5^{\circ} \mathrm{C}$, e o $\mathrm{CO}_{2}$ foi então mensurado para determinar o carbono orgânico total, sendo o resultado geralmente referido como COT. No equipamento TOC-V, este valor de análise é expresso como CONP para distingui-lo do valor de COT obtido pela diferença entre CT e CI (método indireto). CONP significa carbono orgânico não-purgável e refere-se ao carbono orgânico não-volátil.

\subsubsection{Descrição das etapas para determinação de CONP}

As amostras foram colocadas em frascos dentro do amostrador automático (Autoamostrador - ASI-V da Shimadzu), conforme FIG.8, com posterior injeção das alíquotas no 
aparelho de análise, seguindo-se 3 etapas: Acidificação com sparging, oxidação com $\mathrm{Na}_{2} \mathrm{~S}_{2} \mathrm{O}_{8}$ e luz UV, e detecção e quantificação com IVND.

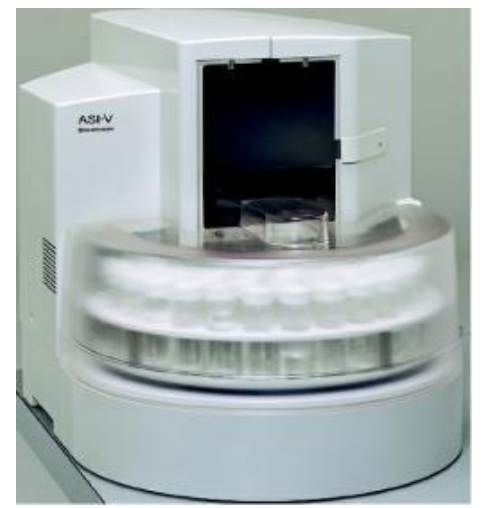

FIGURA 8 - Autoamostrador - ASI-V da Shimadzu.

(Fonte: SHIMADZU CORPORATION, 2004.)

- Acidificação com sparging

A amostra foi succionada por uma agulha de dentro de frasco próprio posicionado no amostrador automático, e injetada na seringa dentro do equipamento analisador de carbono. Posteriormente a alíquota da amostra foi injetada no tubo reator de CI, sendo então acrescentada a solução acidificante $\left(\mathrm{H}_{3} \mathrm{PO}_{4}\right)$, e na sequência o gás $\mathrm{N}_{2}$ foi borrifado (sparging).

$\mathrm{O} \mathrm{N}_{2}$ foi borbulhado nesta solução, havendo a conversão do $\mathrm{CI}$ em $\mathrm{CO}_{2}$ e posterior remoção (purga) da solução.

- Oxidação com $\mathrm{Na}_{2} \mathrm{~S}_{2} \mathrm{O}_{8}$ e luz UV

Após eliminação do CI, o CONP remanescente na solução foi coletado, retornando à seringa, de onde foi injetado até o reator de CT e submetido à oxidação química com persulfato $\left(\mathrm{Na}_{2} \mathrm{~S}_{2} \mathrm{O}_{8}\right)$ e luz UV.

A reação de oxidação do CONP com produção de $\mathrm{CO}_{2}$ é descrita pela Eq. 19.

$$
\mathrm{C}_{8} \mathrm{O}_{4} \mathrm{H}_{5} \mathrm{~K}+\mathrm{Na}_{2} \mathrm{~S}_{2} \mathrm{O}_{8} \rightarrow \mathrm{CO}_{2}+\text { subprodutos }
$$

$\Delta$

$\mathrm{O} \mathrm{CO}_{2}$ gerado pela combustão foi encaminhado até um desumidificador (para resfriamento e extração da umidade) e um depurador de halógenos (scrubber, para remoção de 
possíveis impurezas que pudessem interferir na mensuração), seguindo até uma membrana filtrante.

- Detecção e quantificação

O CONP na forma de $\mathrm{CO}_{2}$ foi direcionado para o interior da célula do detector IVND, onde ocorreu a adsorção de luz infravermelha com produção de um sinal. Este sinal foi medido em função do tempo que o gás fluiu pelo detector de forma continua, resultando em picos. A área do pico foi proporcional à concentração de $\mathrm{CO}_{2}$, ou seja, de CONP presente na amostra (considerando que as concentrações de CONP e de CT, são iguais no método direto). A FIG. 9 apresenta o diagrama de fluxo do analisador de carbono.

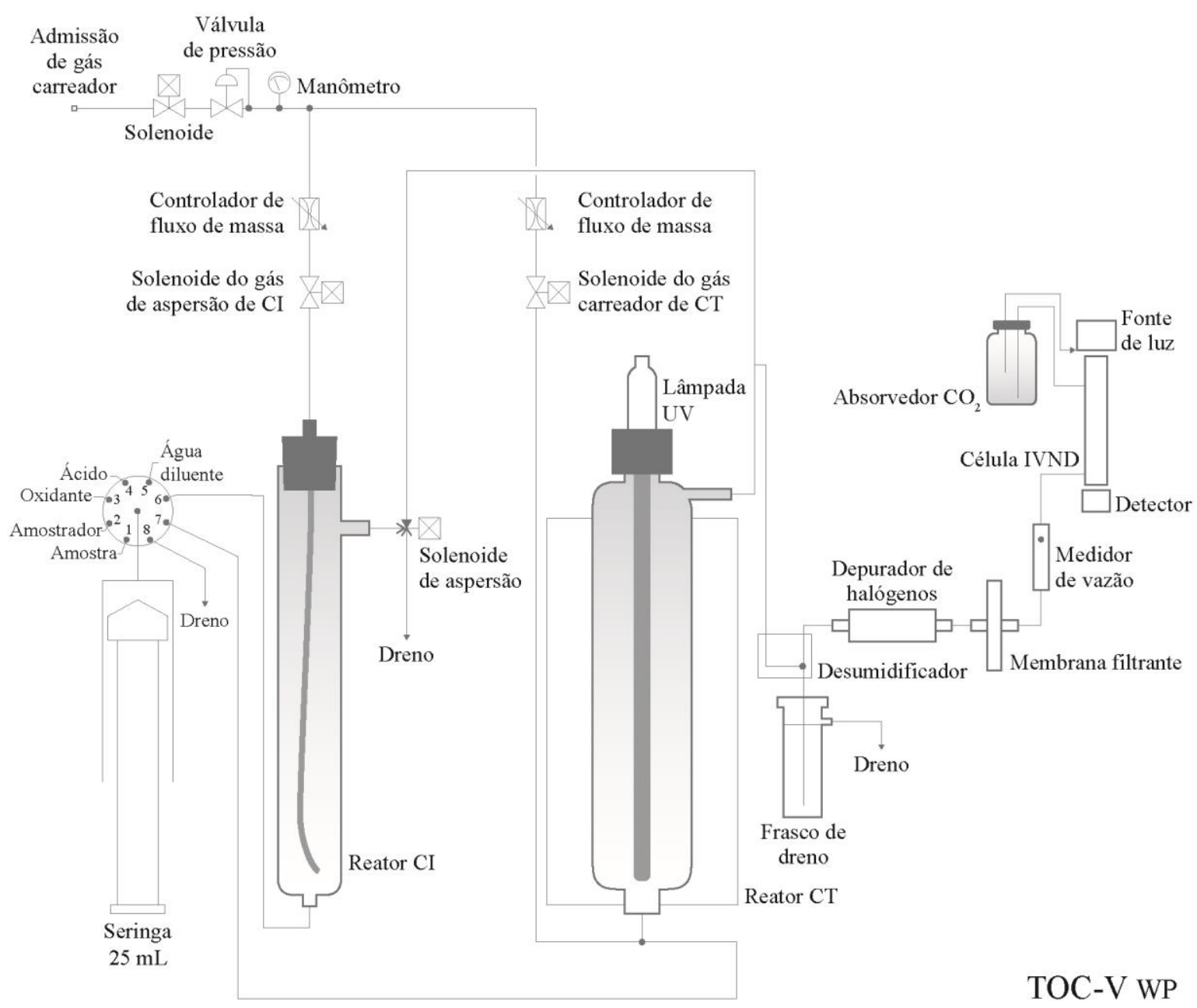

FIGURA 9 - Diagrama de fluxo do analisador de carbono

(Fonte: Adaptado de SHIMADZU CORPORATION, 2004.) 


\subsection{Materiais e reagentes}

\subsubsection{Preparo e coleta das amostras}

Toda a vidraria utilizada foi separada e exclusivamente utilizada nas análises de COT / CONP. Para coleta das amostras e análises de COT / CONP foram utilizados frascos de $40 \mathrm{~mL}$ específicos para o analisador de carbono modelo TOC-Vwp. Para o preparo das soluções padrão foram utilizados balões volumétricos calibrados de 100, 200, 500 e $1.000 \mathrm{~mL}$.

Toda a vidaria foi previamente lavada com água purificada (AP) e mantidos em ácido nítrico $\left(\mathrm{HNO}_{3}\right) 30 \%$ por 24 horas. A vidraria volumétrica calibrada foi seca em temperatura ambiente, com o devido cuidado para que não houvesse contaminação por carbono. Todo o material não volumétrico foi submetido à secagem e aquecimento em estufa a $60-80^{\circ}$ C até o momento de sua utilização.

As soluções de reagente oxidante (solução de $\mathrm{Na}_{2} \mathrm{~S}_{2} \mathrm{O}_{8} 0,5 \mathrm{~mol} \mathrm{~L}^{-1}$ ) e acidificante (solução de $\mathrm{H}_{3} \mathrm{PO}_{4}$ 3,0 mol L-1) foram preparadas conforme recomendações do fabricante do analisador de carbono (Shimadzu), utilizando-se reagentes PA (Merck).

As soluções padrão de COT/CONP utilizadas nas curvas de calibração (concentrações 40-1000 $\mu \mathrm{gL}^{-1}$ ) foram obtidas a partir de solução estoque de COT/CONP na concentração de $20 \mathrm{mg} \mathrm{L}^{-1}$, utilizando a substância química referência biftalato de potássio $\left(\mathrm{C}_{8} \mathrm{H}_{5} \mathrm{O}_{4} \mathrm{~K}\right)$ da Nakalai Tesque ${ }^{\circledR}$.

A AP utilizada no preparo e diluição das soluções padrão, "branco" e diluente foi obtida de purificador Elix-10 acoplado a um reservatório de 30L, da Millipore ${ }^{\circledR}$, com sistema de iluminação UV acionado a cada 24 horas durante 30 minutos.

\subsubsection{Preparo da solução estoque COT /CONP $20 \mathrm{mg} \mathrm{L}^{-1}$}

Foi pesado exatamente $21,2 \mathrm{mg}$ de biftalato de potássio, previamente seco a 105 $120^{\circ} \mathrm{C}$ por uma hora e seco no dessecador. Posteriormente transferiu-se esse conteúdo para um balão de $500 \mathrm{~mL}$ e completou-se com AP, obtendo-se uma solução de concentração de carbono de $20 \mathrm{mg} \mathrm{L}^{-1}$.

\subsubsection{Conformidade do sistema (System Suitability)}

Foram preparadas soluções de sacarose $\left(\mathrm{C}_{12} \mathrm{H}_{22} \mathrm{O}_{11}\right)$ e de 1,4-benzoquinona $\left(\mathrm{C}_{6} \mathrm{H}_{4} \mathrm{O}_{2}\right)$ na concentração de $500 \mu \mathrm{gL}^{-1}$ a partir de padrões USP. 
O preparo das soluções seguiu as recomendações da Farmacopeia Americana USP 38(USP, 2015). Para a solução de $\mathrm{C}_{12} \mathrm{H}_{22} \mathrm{O}_{11}$ foram pesados exatamente 1,20 mg do padrão USP que posteriormente foi transferido para um balão de $1 \mathrm{~L}$ e completado com AP até o volume final desejado, obtendo-se $500 \mu \mathrm{g} \mathrm{L}^{-1}$ de carbono em sacarose.

Para a solução de $\mathrm{C}_{6} \mathrm{H}_{4} \mathrm{O}$ foram pesados exatamente $0,75 \mathrm{mg}$ do padrão USP que posteriormente foi transferido para um balão de $1 \mathrm{~L}$ e completado com AP, obtendo-se $500 \mu \mathrm{g}$ $\mathrm{L}^{-1}$ de carbono em 1,4-benzoquinona.

\subsection{Métodos}

\subsubsection{Análise do teor de COT nos equipamentos de produção de RL}

\subsubsection{Análise do teor de COT antes da limpeza dos equipamentos de produção de RL}

Após produção de alguns RL, o béquer utilizado no processo foi preenchido com $500 \mathrm{~mL}$ de AP. Posteriormente, foi introduzida uma barra magnética no béquer e procedeu-se a agitação por 2 minutos em agitador magnético da marca Eletrolab ${ }^{\circledR}$, modelo Macro 303. A água de primeira lavagem (rinsagem) foi transferida para frascos de $40 \mathrm{~mL}$ (específicos para análise em COT) e foi realizada análise do teor de COT utilizando analisador de carbono.

O mesmo procedimento foi realizado por mais duas vezes, para a segunda e terceira águas de lavagem (rinsagem).

Foram realizadas análises em triplicata do teor de COT da primeira, segunda e terceira águas de rinsagem nas diluições $1 / 50$ e 1/100.

O resultado do teor de COT do "branco" foi subtraído em cada um dos experimentos realizados.

\subsubsection{Análise do teor COT após limpeza dos equipamentos de produção de RL}

Após produção de alguns RL e execução dos procedimentos de limpeza do béquer utilizado no processo, foram realizadas análises em triplicata do teor de COT nas águas de lavagem (rinsagem), seguindo-se os procedimentos adotados nas análises realizadas antes da limpeza dos equipamentos de produção de RL. 


\subsubsection{Cálculo do Pior Caso para Validação de Limpeza}

Para determinar o pior caso para a validação de limpeza dos equipamentos utilizados na linha de produção de RL realizou-se o cálculo denominado "índice para pior caso" (WCI, do inglês Worst Case Index), conforme Eq. 20:

$$
\text { WCI }=\frac{f_{S} \times f_{D}}{f_{S}}
$$

Onde:

fs - Fator de Solubilidade do fármaco em água expresso em ppm (partes por milhão);

fD - Fator representando o grau de dificuldade de limpeza dos equipamentos;

fo - Fator de ocupação de um determinado medicamento na linha de produção.

\subsubsection{Fator de Solubilidade - fs}

Os dados de solubilidade em água dos fármacos foram obtidos das fichas com informações sobre produtos químicos, bancos de dados contendo informações sobre substâncias químicas e compostos (Chemical; Chemspider; Pubchem), Ficha de Informações de Segurança de Produtos Químicos - FISPQ (do inglês, Material Safety Data Sheet-MSDS), Merck Index e laudos de análises dos fornecedores de matéria prima contendo as especificações dos fármacos. Foram realizados cálculos para que a solubilidade pudesse ser expressa em ppm.

Nas fontes consultadas, as informações sobre solubilidade nem sempre estiveram disponíveis na forma numérica para alguns dos fármacos utilizados no estudo. Os dados numéricos obtidos foram transformados em ppm (partes por milhão).

Para uniformizar números e expressões descritas para solubilidade foi realizado um enquadramento, sendo então definida e estabelecida uma tabela de referência, para que se pudesse realizar uma classificação e posterior aplicação de pontuação, a qual correspondeu ao fator de solubilidade - fs. O enquadramento dos termos descritivos para solubilidade e seu significado foi realizado com base na Farmacopeia Brasileira (ANVISA, 2010c). Posteriormente, utilizou-se o fs para aplicação no cálculo de WCI. 


\subsubsection{Fator de dificuldade de limpeza - fD}

O fator $\mathbf{f}_{\mathbf{D}}$ foi obtido das respostas em entrevistas com os operadores da linha de produção dos RL, que realizam a limpeza dos equipamentos, sendo por estes atribuída uma pontuação relativa à dificuldade de limpeza, considerando a produção de todos os reagentes liofilizados (RL). As entrevistas foram realizadas aplicando-se um questionário fechado aos operadores de limpeza, com três opções de resposta (fácil de limpar, dificuldade média de limpar e difícil de limpar).

\subsubsection{Fator de ocupação - fo}

Para o cálculo do fo foi realizado um levantamento de dados junto ao Controle de Qualidade do IPEN (Indicadores de Qualidade) do número de lotes/ano produzidos para cada um dos RL, tendo como referência o ano de 2013. Os dados foram agrupados em faixas (intervalos), sendo aplicada a cada uma das faixas (intervalos) uma pontuação. A pontuação correspondeu ao fator de ocupação fo.

\subsubsection{Validação de Método Analítico para Determinação de COT - CONP}

\subsubsection{Conformidade do sistema (System Suitability)}

A avaliação da conformidade do sistema foi realizada pela análise de soluções padrão de sacarose e de 1,4-benzoquinona preparadas na concentração de $500 \mu \mathrm{gL}^{-1}$ a partir de padrões USP, sendo posteriormente aplicados os resultados obtidos de CONP na Eq. 21 para obtenção da porcentagem SS\%:

$$
\mathrm{SS} \%=100 \frac{\mathrm{Rbz}-\mathrm{Rb}}{\mathrm{Rs}-\mathrm{Rb}}
$$

Onde:

Rbz - Concentração da solução de 1,4 - benzoquinona;

Rb - Concentração da solução branco;

Rs - Concentração da solução de sacarose. 


\subsubsection{Robustez}

Nos ensaios de robustez foram avaliados quatro parâmetros do método de análise, a saber: volumes de solução oxidante (solução de $\mathrm{Na}_{2} \mathrm{~S}_{2} \mathrm{O}_{8} \mathrm{em} \mathrm{mL}$ ), volumes de solução acidificante (solução de $\mathrm{H}_{3} \mathrm{PO}_{4}$ em \%), tempo de integração da área para o cálculo de CONP e tempo de sparge.

Foi utilizada solução padrão de COT/CONP (biftalato de potássio - $\mathrm{C}_{8} \mathrm{H}_{5} \mathrm{O}_{4} \mathrm{~K}$ ) na concentração de $100 \mu \mathrm{gL}^{-1}$ para avaliação dos parâmetros, sendo a análise realizada em triplicata.

Para obtenção da solução padrão de $100 \mu \mathrm{gL}^{-1}$ foram transferidos $500 \mu \mathrm{L}$ da solução estoque CT /CONP $20 \mathrm{mg} \mathrm{L}^{-1}$ para um balão volumétrico de $100 \mathrm{~mL}$, completando-se com AP até o volume final desejado.

A AP utilizada no preparo das soluções referida como "branco" foi subtraída de cada um dos experimentos no estudo de robustez.

O volume de solução oxidante e volume de solução acidificante avaliados foram 0,$5 ; 1,0 ; 1,5 ; 2,0$ e $2,5 \mathrm{~mL}$ e 1,$0 ; 3,0 ; 4,0 ; 5,0$ e $6,0 \%$, respectivamente.

Os tempos utilizados na avaliação do tempo de integração da área para cálculo de CONP foram 2,$0 ; 2,5 ; 3,0 ; 3,5 ; 4,0$ e 4,5 minutos e para sparge time foram $2,3,5,9$ e 10 minutos.

\subsubsection{Linearidade}

Três curvas analíticas foram obtidas utilizando-se soluções padrão de COT/CONP nas concentrações zero (água), 40, 100, 200, 400 e $1000 \mu \mathrm{g} \mathrm{L}^{-1}$ (n=6), obtidas a partir da solução estoque COT/CONP $20 \mathrm{mg} \mathrm{L}^{-1}$.

Para obtenção das soluções padrão de 40, 100, 200, 400 e $1.000 \mu \mathrm{gL}^{-1}$ foram transferidos 200, 500, 1.000, 2.000 e $5.000 \mu \mathrm{L}$ da solução estoque COT /CONP $20 \mathrm{mg} \mathrm{L}^{-1}$ para balões volumétricos de $100 \mathrm{~mL}$, completando-se com AP.

Cada uma das amostras foi analisada no mínimo em triplicata $(5<\mathrm{n}<3)$. Após subtração do valor de área obtido para a água utilizada no preparo das soluções, a equação da reta com 5 concentrações, o coeficiente de correlação (r) e a soma residual dos mínimos quadrados $\left(\mathrm{r}^{2}\right)$ foram calculados pelo software OriginPro 8, conforme representado nas Eq. 11, Eq. 12 e Eq. 13 (pág. 70). 


\subsubsection{Limite de deteç̧ão (LD) e limite de quantificação (LQ)}

Para cálculo dos limites de detecção e quantificação foram utilizados os valores da média dos coeficientes angulares (a) e o desvio padrão dos coeficientes lineares (DPa) das curvas de calibração $(n=3)$ obtidas no ensaio de linearidade, conforme representado nas Eq. 14 e Eq.15 (págs. 71 e 72).

\subsubsection{Precisão: Repetibilidade e precisão intermediária}

Para avaliação de repetibilidade (intradia) e precisão intermediária (interdia) foram utilizadas soluções padrão de COT/CONP nas concentrações 100, 400 e $800 \mu \mathrm{g} \mathrm{L}^{-1}$. As soluções padrão de 100, 400 e $800 \mu \mathrm{gL}^{-1}$ foram obtidas pela adição de 500, 2.000 e $4.000 \mu \mathrm{L}$ da solução estoque CT /CONP $20 \mathrm{mg} \mathrm{L}^{-1}$ em balões volumétricos de $100 \mathrm{~mL}$, completando-se com AP.

Cada solução foi analisada em triplicata por dois dias seguidos.

A repetibilidade e a precisão intermediária foram obtidas pelo cálculo do desvio padrão (DP) e o desvio padrão relativo (DPR) entre as triplicatas utilizando-se as Eq. 16 e Eq. 17 (pág. 73), respectivamente.

\subsubsection{Exatidão: recuperação}

A exatidão do método foi calculada com experimentos de recuperação com amostras de solução padrão de COT/CONP nas concentrações 100, 400 e $800 \mu \mathrm{g} \mathrm{L}^{-1}$, contempladas na faixa de linearidade do método, acrescidas de $100 \mu \mathrm{g} \mathrm{L}^{-1}$ do fármaco tetrafluorborato tetramibi cuproso, representado pela sigla Mibi (matéria-prima utilizada na fabricação do RL MIBI-TEC).

As soluções padrão de CT/CONP nas concentrações 100, 400 e $800 \mu \mathrm{gL}^{-1}$ foram obtidas a partir da solução estoque COT/CONP $20 \mathrm{mg} \mathrm{L}^{-1}$. Foram transferidos 500, 2.000 e $4.000 \mu \mathrm{L}$ da solução estoque CT /CONP $20 \mathrm{mg} \mathrm{L}^{-1}$ para balões volumétricos de $100 \mathrm{~mL}$, completando-se com AP.

Para obtenção da solução estoque de Mibi foram pesadas exatamente 20,9 mg de Mibi, e posteriormente transferiu-se esse conteúdo para um balão de $500 \mathrm{~mL}$, completando-se com AP até o volume final desejado, obtendo-se uma solução de concentração de carbono de $20 \mathrm{ppm}$.

Foram transferidas alíquotas das soluções padrão de COT/CONP e de Mibi para um balão volumétrico e completou-se com AP. 
A recuperação foi calculada conforme a Eq. 22.

$$
\text { Recuperação }(\%)=\frac{(\mathrm{Ca}-\mathrm{Cna})}{\mathrm{CT}}
$$

Ca - Área encontrada na amostra adicionada de padrão;

Cna - Área encontrada na amostra não adicionada de padrão;

CT - Concentração teórica.

Foram obtidas três curvas de calibração de Mibi utilizando-se soluções padrão de Mibi nas concentrações "branco", 100, 400 e $800 \mu \mathrm{gL}^{-1} \quad(\mathrm{n}=3)$, preparadas a partir de solução estoque de Mibi $20 \mathrm{mg} \mathrm{L}^{-1}$.

Para obtenção das soluções padrão de 100, 400 e $800 \mu \mathrm{gL}^{-1}$ foram transferidos 500, 2.000 e $4.000 \mu \mathrm{L}$ da solução estoque Mibi $20 \mathrm{mg} \mathrm{L}^{-1}$ para balões volumétricos de $100 \mathrm{~mL}$, completando-se com AP até o volume final desejado.

Cada uma das amostras foi analisada no mínimo em triplicata $(5<\mathrm{n}<3)$. Após subtração do valor de área obtido para a água utilizada no preparo das soluções, a equação da reta com 3 concentrações, o coeficiente de correlação (r) e a soma residual dos mínimos quadrados $\left(\mathrm{r}^{2}\right)$ foram calculados pelo software OriginPro 8, conforme representado nas Eq. 11, Eq. 12 e Eq. 13 (pág. 70). 


\section{RESULTADOS E DISCUSSÃO}

\subsection{Recuperação de COT em vidraria utilizada na produção de RL: prévia e posteriormente ao procedimento de limpeza}

Inicialmente fez-se uma análise do teor de COT nos equipamentos utilizados na produção dos RL.

A produção dos produtos (RL) na radiofarmácia é diferenciada sob o ponto de vista do processo farmacêutico. Isto porque os radiofármacos são produzidos em lotes pequenos, que variam entre 200 a $700 \mathrm{~mL}$, e, diferentemente da indústria farmacêutica tradicional, os equipamentos utilizados na produção são béqueres.

Dessa forma, para verificar a eficiência da execução dos procedimentos de limpeza nesses equipamentos, foram realizadas análises do teor de COT nas águas de lavagem (rinsagem) antes e após a realização dos procedimentos de limpeza. Para esta análise, foi utilizado o método direto de determinação de COT, o qual já estava validado e consolidado no monitoramento do teor de COT da AP e API.

Os resultados das análises do teor de COT nas águas de lavagem (rinsagem) antes da execução dos procedimentos de limpeza dos equipamentos (béqueres) estão expressos na TAB. 12.

TABELA 12 - Dados da análise do teor de COT antes da execução dos procedimentos de limpeza dos equipamentos utilizados na produção dos RL

\begin{tabular}{ccccc}
\hline$N^{\circ}$ Lote & Produto & $\begin{array}{l}\text { Lavagem/ } \\
\text { Rinsagem }\end{array}$ & Diluição & COT $\left(\boldsymbol{\mu g L} \mathbf{-}^{-1}\right)$ \\
\hline \multirow{2}{*}{ L 276} & MDP-TEC & $1^{\mathrm{a}}$ & & $6.440,58$ \\
& $1^{\mathrm{a}}$ & $1 / 100$ & 115,58 \\
& $2^{\mathrm{a}}$ & & 388,68
\end{tabular}


TABELA 12 - Dados da análise do teor de COT antes da execução dos procedimentos de limpeza dos equipamentos utilizados na produção dos RL

\begin{tabular}{|c|c|c|c|c|}
\hline$N^{\circ}$ Lote & Produto & $\begin{array}{l}\text { Lavagem/ } \\
\text { Rinsagem }\end{array}$ & Diluição & $\operatorname{COT}\left(\mu g L^{-1}\right)$ \\
\hline & & $2^{a}$ & $1 / 100$ & 49,28 \\
\hline & & $3^{\mathrm{a}}$ & & 310,08 \\
\hline & & $3^{\mathrm{a}}$ & $1 / 100$ & *ND \\
\hline \multirow{6}{*}{ L 279} & \multirow{6}{*}{ MDP-TEC } & $1^{\mathrm{a}}$ & & $5.135,7$ \\
\hline & & $1^{\mathrm{a}}$ & $1 / 100$ & 164,0 \\
\hline & & $2^{\mathrm{a}}$ & & 757,5 \\
\hline & & $2^{a}$ & $1 / 100$ & 73,9 \\
\hline & & $3^{\mathrm{a}}$ & & 663,7 \\
\hline & & $3^{\mathrm{a}}$ & $1 / 100$ & *ND \\
\hline \multirow{7}{*}{ L830 } & \multirow{7}{*}{ DTPA-TEC } & $1^{\mathrm{a}}$ & & $7.469,89$ \\
\hline & & $1^{\mathrm{a}}$ & $1 / 50$ & 122,59 \\
\hline & & $1^{\mathrm{a}}$ & $1 / 100$ & 67,79 \\
\hline & & $2^{a}$ & & 83,39 \\
\hline & & $2^{\mathrm{a}}$ & $1 / 50$ & 104,69 \\
\hline & & $2^{\mathrm{a}}$ & $1 / 100$ & $* N D$ \\
\hline & & $3^{\mathrm{a}}$ & & 42,99 \\
\hline \multirow{4}{*}{ L 284} & \multirow{4}{*}{ MDP-TEC } & $1^{\mathrm{a}}$ & & $3.958,7$ \\
\hline & & $1^{\mathrm{a}}$ & $1 / 50$ & 108,3 \\
\hline & & $1^{\mathrm{a}}$ & $1 / 100$ & 73,87 \\
\hline & & $2^{\mathrm{a}}$ & & 99,4 \\
\hline
\end{tabular}


TABELA 12 - Dados da análise do teor de COT antes da execução dos procedimentos de limpeza dos equipamentos utilizados na produção dos RL

\begin{tabular}{|c|c|c|c|c|}
\hline $\mathrm{N}^{\circ}$ Lote & Produto & $\begin{array}{l}\text { Lavagem/ } \\
\text { Rinsagem }\end{array}$ & Diluição & $\operatorname{COT}\left(\mu g L^{-1}\right)$ \\
\hline & & $2^{a}$ & $1 / 50$ & 11,77 \\
\hline & & $3^{\mathrm{a}}$ & & 100,5 \\
\hline & & $3^{\mathrm{a}}$ & $1 / 50$ & 23,64 \\
\hline
\end{tabular}

*ND - Não detectado

Conforme TAB. 12 os resultados apontaram uma variação no teor de COT antes da execução dos procedimentos de limpeza entre 7.469,89 $\mu \mathrm{gL}^{-1}$ e 3.958,7 $\mu \mathrm{gL}^{-1}$. Após a segunda rinsagem o teor de COT variou entre $757,5 \mu \mathrm{gL}^{-1}$ e $83,39 \mu \mathrm{gL}^{-1}$. O teor de COT para a $3^{\mathrm{a}}$ rinsagem ficou entre $664,7 \mu \mathrm{gL}^{-1}$ e $43,0 \mu \mathrm{gL}^{-1}$. O maior teor de COT antes da execução dos procedimentos de limpeza nos equipamentos de produção foi obtido para o RL DTPA-TEC. Muito embora o maior teor de COT tenha sido obtido para o DTPA-TEC, após a segunda e terceira rinsagens o teor diminui consideravelmente, ficando em 83,39 e 42,99 $\mu \mathrm{gL}^{-1}$ respectivamente. Para o produto MDP-TEC, a comparação entre os resultados de COT obtidos para três lotes analisados de limpeza mostrou considerável variação para a primeira rinsagem $\left(6.440,58 ; 5.135,7\right.$ e $\left.3.958,7 \mu \mathrm{gL}^{-1}\right)$, o mesmo ocorrendo para a segunda $(388,68 ; 757,5$ e 99,4 $\left.\mu \mathrm{gL}^{-1}\right)$ e terceira rinsagem $\left(310,08 ; 663,7\right.$ e $\left.100,5 \mu \mathrm{gL}^{-1}\right)$.

Na TAB. 13 estão compilados os resultados das análises do teor de COT nas águas de lavagem (rinsagem) após a execução dos procedimentos de limpeza dos equipamentos (béqueres).

TABELA 13 - Dados da análise do teor de COT após execução dos procedimentos de limpeza dos equipamentos utilizados na produção dos RL

\begin{tabular}{ccccc}
\hline $\mathrm{N}^{\circ}$ Lote & Produto & $\begin{array}{l}\text { Lavagem/ } \\
\text { Rinsagem }\end{array}$ & Diluição & COT $\left(\mu \mathrm{gL}^{-1}\right)$ \\
\hline L 827 & DTPA-TEC & $1^{\mathrm{a}}$ & & 227,21
\end{tabular}


TABELA 13 - Dados da análise do teor de COT após execução dos procedimentos de limpeza dos equipamentos utilizados na produção dos RL

\begin{tabular}{|c|c|c|c|c|}
\hline $\mathrm{N}^{\circ}$ Lote & Produto & $\begin{array}{l}\text { Lavagem/ } \\
\text { Rinsagem }\end{array}$ & Diluição & $\operatorname{COT}\left(\mu g L^{-1}\right)$ \\
\hline & & $2^{a}$ & & 84,41 \\
\hline & & $3^{\mathrm{a}}$ & & 17,96 \\
\hline \multirow{4}{*}{ L 275} & & $1^{\mathrm{a}}$ & & 96,61 \\
\hline & MDP-TEC & & & \\
\hline & & $2^{a}$ & & 63,11 \\
\hline & & $1^{\mathrm{a}}$ & & 301,56 \\
\hline \multirow[t]{3}{*}{ L828 } & DTPA-TEC & $2^{a}$ & & 225,16 \\
\hline & & $3^{\mathrm{a}}$ & & 211,56 \\
\hline & & $1^{\mathrm{a}}$ & & 144,46 \\
\hline \multirow[t]{3}{*}{ L288 } & PUL-TEC & $2^{\mathrm{a}}$ & & 99,06 \\
\hline & & $3^{a}$ & & 67,36 \\
\hline & & $1^{\mathrm{a}}$ & & 534,57 \\
\hline \multirow[t]{5}{*}{ L281 } & MDP-TEC & $2^{\mathrm{a}}$ & & 413,77 \\
\hline & & $3^{\mathrm{a}}$ & & 77,47 \\
\hline & & $1^{\mathrm{a}}$ & & 902,25 \\
\hline & & $1^{\mathrm{a}}$ & $1 / 50$ & 39,04 \\
\hline & & $1^{\mathrm{a}}$ & $1 / 100$ & 12,0 \\
\hline \multirow[t]{4}{*}{ L289 } & PUL-TEC & $2^{\mathrm{a}}$ & & 353,35 \\
\hline & & $2^{\mathrm{a}}$ & $1 / 50$ & 49,92 \\
\hline & & $2^{\mathrm{a}}$ & $1 / 100$ & 202,65 \\
\hline & & $3^{\mathrm{a}}$ & & 244,25 \\
\hline
\end{tabular}


TABELA 13 - Dados da análise do teor de COT após execução dos procedimentos de limpeza dos equipamentos utilizados na produção dos RL

\begin{tabular}{|c|c|c|c|c|}
\hline $\mathrm{N}^{\circ}$ Lote & Produto & $\begin{array}{l}\text { Lavagem/ } \\
\text { Rinsagem }\end{array}$ & Diluição & $\operatorname{COT}\left(\mu g L^{-1}\right)$ \\
\hline & & $3^{\mathrm{a}}$ & $1 / 50$ & 24,35 \\
\hline & & $3^{\mathrm{a}}$ & $1 / 100$ & 85,1 \\
\hline \multirow{3}{*}{ L290 } & & $1^{\mathrm{a}}$ & & 812,1 \\
\hline & PUL-TEC & $2^{\mathrm{a}}$ & & 98,0 \\
\hline & & $3^{a}$ & & 141,4 \\
\hline \multirow[b]{2}{*}{ L832 } & & $1^{\mathrm{a}}$ & & 67,6 \\
\hline & DTPA-TEC & $1^{\mathrm{a}}$ & $1 / 50$ & 11.19 \\
\hline \multirow{10}{*}{ L291 } & & $1^{\mathrm{a}}$ & & 296,12 \\
\hline & & $1^{\mathrm{a}}$ & $1 / 50$ & 127,72 \\
\hline & & $1^{\mathrm{a}}$ & $1 / 100$ & 140,62 \\
\hline & & $2^{a}$ & & 202,52 \\
\hline & MDP-TEC & $2^{a}$ & $1 / 50$ & 94,32 \\
\hline & & $2^{\mathrm{a}}$ & $1 / 100$ & 95,32 \\
\hline & & $3^{\mathrm{a}}$ & & 188,42 \\
\hline & & $3^{\mathrm{a}}$ & $1 / 50$ & 132,92 \\
\hline & & $3^{\mathrm{a}}$ & $1 / 100$ & 118,22 \\
\hline & & $1^{\mathrm{a}}$ & & 56,40 \\
\hline \multirow[t]{2}{*}{ L294 } & PUL-TEC & $2^{a}$ & & 36,22 \\
\hline & & $3^{a}$ & & 14,32 \\
\hline L292 & MDP-TEC & $1^{\mathrm{a}}$ & & 30,64 \\
\hline
\end{tabular}


TABELA 13 - Dados da análise do teor de COT após execução dos procedimentos de limpeza dos equipamentos utilizados na produção dos RL

\begin{tabular}{|c|c|c|c|c|}
\hline $\mathrm{N}^{\circ}$ Lote & Produto & $\begin{array}{l}\text { Lavagem/ } \\
\text { Rinsagem }\end{array}$ & Diluição & $\operatorname{COT}\left(\mu g L^{-1}\right)$ \\
\hline & & $1^{\mathrm{a}}$ & $1 / 50$ & 11,31 \\
\hline & & $2^{\mathrm{a}}$ & & 6,9 \\
\hline & & $2^{\mathrm{a}}$ & $1 / 50$ & 4,25 \\
\hline \multirow{9}{*}{ L294 } & \multirow{9}{*}{ MDP-TEC } & $1^{\mathrm{a}}$ & & 191,03 \\
\hline & & $1^{\mathrm{a}}$ & $1 / 50$ & 47,79 \\
\hline & & $1^{\mathrm{a}}$ & $1 / 100$ & 27,63 \\
\hline & & $2^{a}$ & & 173,73 \\
\hline & & & & \\
\hline & & $2^{\mathrm{a}}$ & $1 / 50$ & 20,12 \\
\hline & & $2^{\mathrm{a}}$ & $1 / 100$ & 11,93 \\
\hline & & $3^{\mathrm{a}}$ & & 133,83 \\
\hline & & $3^{\mathrm{a}}$ & $1 / 50$ & 11,5 \\
\hline \multirow{9}{*}{ L295 } & \multirow{9}{*}{ PUL-TEC } & $1^{\mathrm{a}}$ & & 848,19 \\
\hline & & $1^{\mathrm{a}}$ & $1 / 50$ & 120,89 \\
\hline & & $1^{\mathrm{a}}$ & $1 / 100$ & 98,39 \\
\hline & & $2^{\mathrm{a}}$ & & 687,59 \\
\hline & & $2^{a}$ & $1 / 50$ & 60,11 \\
\hline & & $2^{\mathrm{a}}$ & $1 / 100$ & 68,16 \\
\hline & & $3^{\mathrm{a}}$ & & 409,09 \\
\hline & & $3^{\mathrm{a}}$ & $1 / 50$ & 51,1 \\
\hline & & $3^{\mathrm{a}}$ & $1 / 100$ & 74,59 \\
\hline
\end{tabular}


TABELA 13 - Dados da análise do teor de COT após execução dos procedimentos de limpeza dos equipamentos utilizados na produção dos RL

\begin{tabular}{|c|c|c|c|c|}
\hline $\mathrm{N}^{\circ}$ Lote & Produto & $\begin{array}{l}\text { Lavagem/ } \\
\text { Rinsagem }\end{array}$ & Diluição & $\operatorname{COT}\left(\mu \mathrm{gL}^{-1}\right)$ \\
\hline \multirow{8}{*}{ L271 } & \multirow{8}{*}{ DEX 500-TEC } & $1^{\mathrm{a}}$ & & 186,15 \\
\hline & & $1^{\mathrm{a}}$ & $1 / 50$ & 49,09 \\
\hline & & $1^{\mathrm{a}}$ & $1 / 100$ & 37,68 \\
\hline & & $2^{\mathrm{a}}$ & & 122,85 \\
\hline & & $2^{a}$ & $1 / 50$ & 53,76 \\
\hline & & $2^{\mathrm{a}}$ & $1 / 100$ & 49,18 \\
\hline & & $3^{\mathrm{a}}$ & & 74,32 \\
\hline & & $3^{\mathrm{a}}$ & $1 / 50$ & 7,137 \\
\hline \multirow{8}{*}{ L315 } & \multirow{8}{*}{ MDP-TEC } & $1^{\mathrm{a}}$ & & 340,15 \\
\hline & & $1^{\mathrm{a}}$ & $1 / 50$ & 178,65 \\
\hline & & $1^{\mathrm{a}}$ & $1 / 100$ & 66,98 \\
\hline & & $2^{\mathrm{a}}$ & & 210,75 \\
\hline & & $2^{a}$ & $1 / 50$ & 57.76 \\
\hline & & $2^{\mathrm{a}}$ & $1 / 100$ & 27,88 \\
\hline & & $3^{\mathrm{a}}$ & & 177,65 \\
\hline & & $3^{\mathrm{a}}$ & $1 / 50$ & 46,9 \\
\hline \multirow{2}{*}{ L272 } & DEX 500 - & $1^{a}$ & & 52,8 \\
\hline & TEC & $2^{a}$ & & 14,2 \\
\hline \multirow{2}{*}{ L105 } & & $1^{\mathrm{a}}$ & & 78,62 \\
\hline & DE & $2^{\mathrm{a}}$ & & 60,95 \\
\hline
\end{tabular}


TABELA 13 - Dados da análise do teor de COT após execução dos procedimentos de limpeza dos equipamentos utilizados na produção dos RL

\begin{tabular}{|c|c|c|c|c|}
\hline $\mathrm{N}^{\circ}$ Lote & Produto & $\begin{array}{l}\text { Lavagem/ } \\
\text { Rinsagem }\end{array}$ & Diluição & $\operatorname{COT}\left(\mu g L^{-1}\right)$ \\
\hline & & $3^{\mathrm{a}}$ & & 16,43 \\
\hline \multirow{9}{*}{ L303 } & \multirow{9}{*}{ PUL - TEC } & $1^{\mathrm{a}}$ & & 471,72 \\
\hline & & $1^{\mathrm{a}}$ & $1 / 50$ & 79,62 \\
\hline & & $1^{\mathrm{a}}$ & $1 / 100$ & 75,61 \\
\hline & & $2^{\mathrm{a}}$ & & 390,02 \\
\hline & & $2^{\mathrm{a}}$ & $1 / 50$ & 121,72 \\
\hline & & $2^{\mathrm{a}}$ & $1 / 100$ & 49,18 \\
\hline & & $3^{\mathrm{a}}$ & & 255,72 \\
\hline & & $3^{\mathrm{a}}$ & $1 / 50$ & 96,52 \\
\hline & & $3^{\mathrm{a}}$ & $1 / 100$ & 69,5 \\
\hline
\end{tabular}

A primeira rinsagem para os três lotes de DTPA - TEC analisados após a execução dos procedimentos de limpeza dos equipamentos apresentou teor de COT com uma variação entre 227,$21 ; 301,56$ e $67,6 \mu \mathrm{gL}^{-1}$. Para a segunda e terceira rinsagens houve variação entre 84,41 e $225,16 \mu \mathrm{gL}^{-1}$, e 211,56 e $17,96 \mu \mathrm{gL}^{-1}$, respectivamente.

O produto MDP - TEC apresentou para a primeira rinsagem diferenças significativas no teor de COT para os seis lotes analisados, com maior teor em $534,57 \mu \mathrm{gL}^{-1} \mathrm{e}$ menor teor em 30,64 $\mu \mathrm{gL}^{-1}$. O mesmo efeito foi obtido na segunda rinsagem, com variação entre 413,77 e $6,9 \mu \mathrm{gL}^{-1}$. A análise do teor de COT na terceira rinsagem ficou na faixa entre 100,0 e $188,0 \mu \mathrm{gL}^{-1}$.

Os maiores teores de COT nas análises realizadas após execução dos procedimentos de limpeza dos equipamentos de produção foram obtidos para o produto PUL - TEC, com uma magnitude em torno de 800,0 a $900,0 \mu \mathrm{gL}^{-1}$ para a primeira rinsagem. Para dois dos seis lotes 
analisados, a primeira rinsagem apresentou um baixo teor de COT, de 144,46 e $56,40 \mu \mathrm{gL}^{-1}$. A segunda rinsagem apresentou teor de COT entre 687,59 e 36,22 $\mu \mathrm{gL}^{-1}$, indicando considerável variabilidade. Na análise da terceira rinsagem foram obtidos valores para COT entre 409,09 e $14,32 \mu \mathrm{gL}^{-1}$, também com considerável variabilidade.

Foram obtidos baixos teores de COT para os produtos DEX 70-TEC e DEX 500TEC. O único lote de DEX 70 - TEC analisado apresentou resultados de 78,62, 60,95 e 16,43 $\mu \mathrm{gL}^{-1}$ para a primeira, segunda e terceira rinsagens, respectivamente. Para o DEX 500-TEC, os resultados variaram entre 52,8 e $186,15 \mu \mathrm{gL}^{-1}$ para primeira rinsagem, 14,2 e $122,85 \mu \mathrm{gL}^{-1}$ para a segunda rinsagem. Para terceira rinsagem obteve-se um valor de $74,32 \mu \mathrm{gL}^{-1}$.

De acordo com os resultados apresentados, conclui-se que a melhor eficiência na execução dos procedimentos de limpeza dos equipamentos utilizados na produção dos RL pode ser obtida após realização de três ciclos de limpeza, com teor máximo de COT em torno de 400 $\mu \mathrm{g} \mathrm{L} \mathrm{L}^{-1}$.

Foram realizadas análises do teor de CONP em água de lavagem (rinsagem) após a execução dos procedimentos de limpeza dos equipamentos (béqueres) utilizados na produção de alguns RL, de forma a confirmar a eficiência do método direto de determinação de COT. Os resultados obtidos para análise do teor de CONP estão referenciados na TAB. 14.

TABELA 14 - Dados da análise de CONP após execução dos procedimentos de limpeza dos equipamentos utilizados na produção dos RL

\begin{tabular}{ccccc}
\hline Lote & Produto & $\begin{array}{l}\text { Lavagem/ } \\
\text { Rinsagem }\end{array}$ & Diluição & CONP $\left(\mu \mathrm{gL}^{-1}\right)$ \\
\hline \multirow{2}{*}{ L106 } & DEX 70 - TEC & $2^{\mathrm{a}}$ & 170,9 \\
& $3^{\mathrm{a}}$ & 56,7 \\
& & $1^{\mathrm{a}}$ & 25,2 \\
\hline L314 & $1^{\mathrm{a}}$ & $1 / 50$ & 572,6 \\
& & $1^{\mathrm{a}}$ & $1 / 100$ & 58,9 \\
& & & & 17,1
\end{tabular}


TABELA 14 - Dados da análise de CONP após execução dos procedimentos de limpeza dos equipamentos utilizados na produção dos RL

\begin{tabular}{|c|c|c|c|c|}
\hline Lote & Produto & $\begin{array}{l}\text { Lavagem/ } \\
\text { Rinsagem }\end{array}$ & Diluição & $\operatorname{CONP}\left(\mu \mathrm{gL}^{-1}\right)$ \\
\hline & & $2^{a}$ & & 169,5 \\
\hline & & $2^{\mathrm{a}}$ & $1 / 50$ & 47,0 \\
\hline & & $2^{\mathrm{a}}$ & $1 / 100$ & 33,4 \\
\hline & & $3^{\mathrm{a}}$ & & 167,1 \\
\hline & & $3^{\mathrm{a}}$ & $1 / 50$ & 129,1 \\
\hline & & $3^{\mathrm{a}}$ & $1 / 100$ & 10,6 \\
\hline \multirow{3}{*}{ L315 } & & $1^{\mathrm{a}}$ & & 649,02 \\
\hline & PUL - TEC & $1^{\mathrm{a}}$ & $1 / 50$ & 74,93 \\
\hline & & $1^{\mathrm{a}}$ & $1 / 100$ & 43,96 \\
\hline L190 & SAH - TEC & $1^{\mathrm{a}}$ & & 29,2 \\
\hline L854 & DTPA - TEC & $1^{\mathrm{a}}$ & & 23,4 \\
\hline
\end{tabular}

Os resultados obtidos nas análises do teor de CONP nas rinsagens efetuadas após execução dos procedimentos de limpeza confirmaram os maiores valores obtidos para o produto PUL - TEC, bem como a considerável diminuição no teor após a segunda e terceira rinsagens. Concluiu-se que a obtenção de eficiência nos procedimentos de limpeza pode ser alcançada após realização de três ciclos de limpeza. 


\subsection{Estabelecimento do pior caso para validação de limpeza dos equipamentos}

O ponto de partida para iniciar uma validação de limpeza é fazer a análise das situações críticas ou piores casos entre os produtos ou processos produtivos representativos para um grupo similar. Há orientações de que é preferível a utilização de dados toxicológicos ou terapêuticos, porém, no caso dos radiofármacos, a obtenção destas informações foi um fator complicador, pois o princípio ativo ou é um material radioativo ou é uma matéria-prima não usual para a indústria farmacêutica tradicional, e, portanto, na maior parte não estão disponíveis.

Alguns trabalhos têm sido realizados com enfoque na metodologia de validação de limpeza de equipamentos (ALENCAR et al., 2004; ALENCAR; CLEMENTINO; NETO, 2006; ANDRADE, 2012; BAGO, 2010). Muitas indústrias buscam um denominador comum para que produtos similares possam ser agrupados, e através deste processo tentam converter uma situação complexa num projeto gerenciável. Cada uma tem desenvolvido seus próprios critérios e metodologias para a escolha do produto que representa o "pior caso" (AGALLOCO, 1992).

A determinação do pior caso para a validação de limpeza dos equipamentos utilizados na linha de produção de RL do IPEN pautou-se no trabalho realizado por Alencar (ALENCAR; CLEMENTINO; NETO, 2006), que adotou a estratégia para escolha do produto pior caso para validação de limpeza no Laboratório Farmacêutico de Pernambuco - LAFEPE mediante estabelecimento de um índice, usando simultaneamente informações de toxicidade, solubilidade, dificuldade de limpeza além da taxa de ocupação de cada produto em cada unidade do laboratório.

Alencar por sua vez baseou-se na ideia de Rodricks (1984), que propôs em seu trabalho uma classificação para gerenciamento de riscos na utilização de substâncias químicas mediante criação de um índice, o qual se apoiou num sistema de pontos que classifica as substâncias químicas de acordo com os seguintes fatores de avaliação: toxicidade aguda, carcinogenicidade, mutagenicidade, teratogenicidade, persistência no meio ambiente, bioacumulação, efeitos estéticos e efeitos adversos crônicos. Rodricks atribuiu uma escala de pontos para cada um desses fatores, de acordo com a importância do fator e a sua repercussão no cálculo do índice de risco final. Dessa forma, o Índice de risco foi calculado pela multiplicação dos pontos obtidos nas escalas, sendo o potencial de dano maior quanto maior o valor numérico obtido, fornecendo assim uma base para a classificação, o e o estabelecimento de medidas prioritárias de controle (ALENCAR; CLEMENTINO; NETO, 2006).

Para realização do presente trabalho foram escolhidos fatores julgados importantes na validação de limpeza dos equipamentos utilizados na produção dos RL, sendo atribuída uma 
escala de pontos a cada um destes fatores. Os fatores julgados importantes foram: solubilidade do fármaco, dificuldade de limpeza dos equipamentos e ocupação do produto na linha de produção. Os fatores foram reunidos em torno de um índice para pior caso (WCI, do inglês Worst Case Index), cuja magnitude do resultado numérico pode indicar a escolha do produto pior caso representativo para utilização na validação de limpeza dos equipamentos de fabricação dos RL.

A solubilidade do fármaco tem grande impacto na validação de limpeza dos equipamentos de produção, visto que quanto menos solúvel em água, maior a capacidade de aderência deste ao equipamento, e, portanto, maior a dificuldade na execução dos procedimentos de limpeza. Dessa forma, atribuiu-se um fs maior para os fármacos mais solúveis e um $f_{\mathrm{S}}$ menor para os menos solúveis, ou seja, quanto menos solúvel for o fármaco, maior será sua contribuição no índice "WCI”.

Normalmente as solubilidades dos fármacos são expressas de forma descritiva e em função da quantidade de solvente necessário à solubilização de uma dada massa do soluto, e são expressas nas farmacopeias. No presente trabalho, foram consultados os compêndios Farmacopeia Brasileira (ANVISA, 2010c) e Farmacopeia Americana USP 38 (USP, 2015). Porém, tais compêndios não dispunham de tal informação para os fármacos utilizados na produção da classe de produtos analisados (RL para marcação com ${ }^{99 \mathrm{~m}} \mathrm{Tc}$ ). Assim outras fontes de informação foram consultadas. Nas fontes consultadas, as informações sobre solubilidade nem sempre estiveram disponíveis na forma numérica para alguns dos fármacos utilizados no estudo.

Os dados numéricos obtidos foram transformados em ppm (partes por milhão).

Os dados de solubilidade em água e as respectivas referências utilizadas nos cálculos para que esta pudesse ser expressa em ppm, estão dispostos na TAB. 15. 
TABELA 15 - Dados de Solubilidade dos RL produzidos no IPEN-CNEN/SP

\begin{tabular}{|c|c|c|c|c|}
\hline $\begin{array}{l}\text { Produto - } \\
\text { RL }\end{array}$ & Fármaco & $\begin{array}{c}\text { Solubilidade em } \\
\text { Água }\end{array}$ & $\begin{array}{l}\text { Solubilidade } \\
\text { em Água em } \\
\text { ppm }\end{array}$ & Referência \\
\hline CIS - TEC & etilenodicisteína & $4,712 \times 10^{5} \mathrm{mg} / \mathrm{L}$ & 471.200 & Chemspider \\
\hline $\begin{array}{c}\text { DEX -500 } \\
\text { TEC }\end{array}$ & dextrana 500 & $* * *$ Sol & & $\begin{array}{l}\text { Pharmacosmos } \\
\text { (FISPQ/MSDS) }\end{array}$ \\
\hline $\begin{array}{c}\text { DEX - } 70 \\
\text { TEC }\end{array}$ & dextrana 70 & $* * *$ Sol & & $\begin{array}{l}\text { Pharmacosmos } \\
\text { (FISPQ/MSDS) }\end{array}$ \\
\hline DISI-TEC & disofenina & 52,751 & 52,751 & Chemspider \\
\hline $\begin{array}{l}\text { DMSA- } \\
\text { TEC }\end{array}$ & succímer & $2,88 \times 10^{5} \mathrm{mg} / \mathrm{mL}$ & 288.000 .000 & Pubchem \\
\hline DTPA-TEC & ácido pentético & $4,8 \mathrm{~g} / \mathrm{L}$ & 4.800 & Merck Index \\
\hline ECD-TEC & $\begin{array}{l}\text { dicloridrato de } \\
\text { etilenodicisteína } \\
\text { dietiléster }\end{array}$ & \multicolumn{2}{|c|}{ ***Solúvel $\mathrm{H} 2 \mathrm{O} / \mathrm{HCl}$} & $\mathrm{ABX}$ \\
\hline FITA -TEC & ácido fítico & \multicolumn{2}{|l|}{ Solúvel } & $\begin{array}{l}\text { Merck Index } \\
\text { Chemspider }\end{array}$ \\
\hline MDP-TEC & ácido medrônico & $50 \mathrm{mg} / \mathrm{mL}$ & 50.000 & Sigma-Aldrich \\
\hline MIBI-TEC & $\begin{array}{l}\text { tetrafluorborato } \\
\text { tetramibi cuproso }\end{array}$ & $25 \mathrm{~g} / \mathrm{L}$ & 25.000 & $\begin{array}{c}\text { Lantheus Medical } \\
\text { Imaging }\end{array}$ \\
\hline PIRO-TEC & $\begin{array}{c}\text { pirofosfato } \\
\text { tetrassódico } \\
\text { decahidratado }\end{array}$ & $\begin{array}{c}8,14 \mathrm{~g} / 100 \mathrm{~mL} \\
\text { Solúvel }\end{array}$ & 81.400 & $\begin{array}{l}\text { Merck Index } \\
\text { Chemspider }\end{array}$ \\
\hline
\end{tabular}




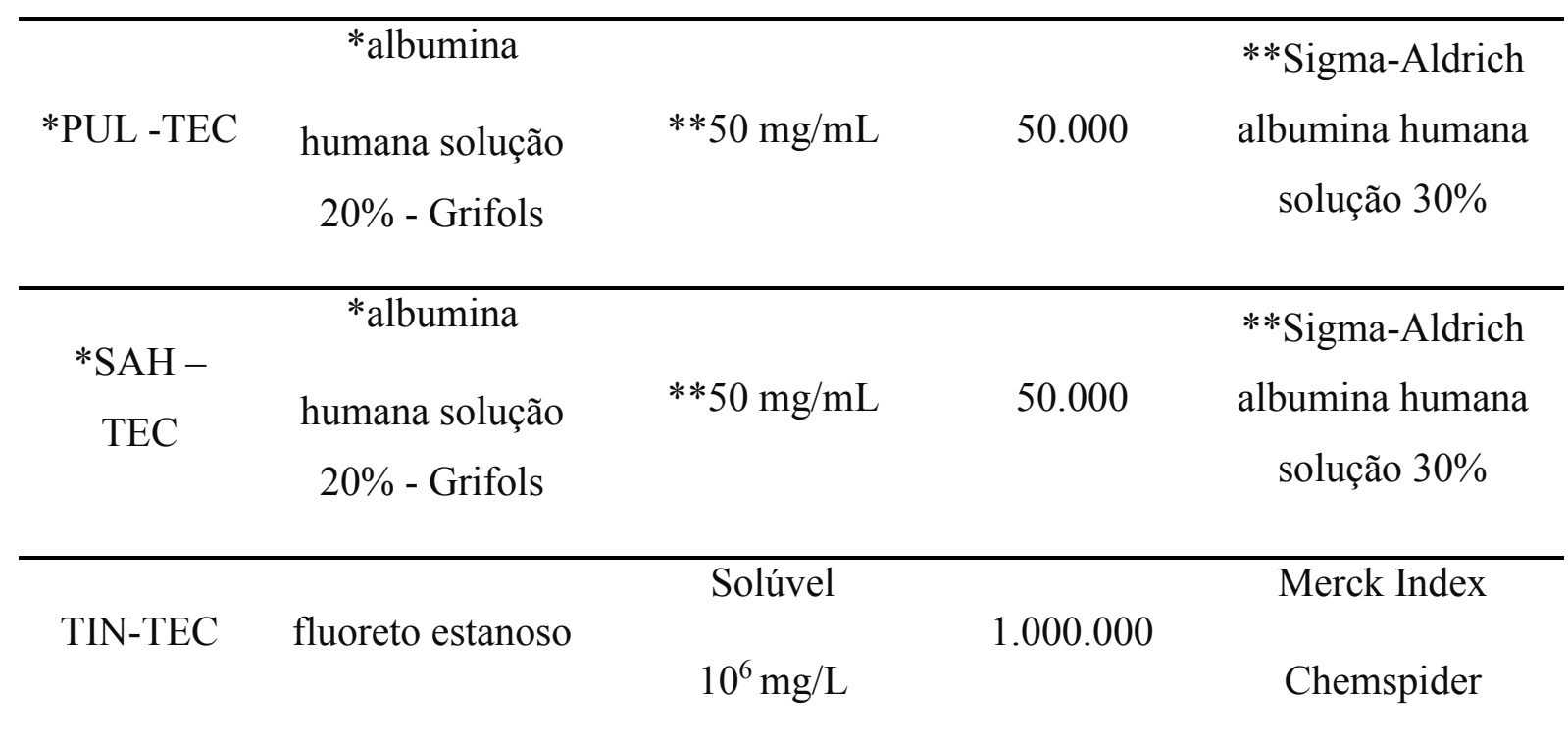

* Na produção dos RL SAH-TEC e PUL-TEC utiliza-se como princípio ativo/fármaco o medicamento acabado Albumina Humana Solução 20\% da Grifols, cujos dados de solubilidade não constam do Certificado de Análise do fabricante. Em outras fontes também não foi encontrada nenhuma referência sobre solubilidade do referido produto.

** Foi utilizado o dado de solubilidade da Albumina Humana Solução 30\%, da Sigma-Aldrich.

*** Não foi encontrada nenhuma referência numérica de solubilidade para os fármacos dicloridrato de etilenodicisteína dietiléster, dextrana 70 e dextrana 500.

Para uniformizar números e expressões descritas para solubilidade, foi realizado um enquadramento, sendo então definida e estabelecida uma tabela de referência (TAB. 16), para que se pudesse realizar uma classificação e posterior aplicação de pontuação, a qual correspondeu ao fator de solubilidade - fs. O enquadramento dos termos descritivos para solubilidade e seu significado foi realizado com base na Farmacopeia Brasileira (ANVISA, 2010c). Posteriormente, utilizou-se o fs para aplicação no cálculo de WCI.

TABELA 16 -Tabela de Referência com respectivo Fator de Solubilidade em água - $\mathrm{fS}_{\mathrm{S}}$

\begin{tabular}{cccc}
\hline Termo Descritivo & $\begin{array}{c}\text { Solubilidade }(\mathrm{S}) \\
\text { em água }(\mathrm{ppm})\end{array}$ & Classificação & Pontos fs \\
\hline Muito solúvel & $\mathrm{S}>1.000 .000$ & Alta & 3 \\
Facilmente & $100.000<\mathrm{S}<1.000 .000$ & solubilidade & \\
solúvel & $33.000<\mathrm{S}<100.000$ & & \\
Solúvel & & & \\
\hline
\end{tabular}


TABELA 16 -Tabela de Referência com respectivo Fator de Solubilidade em água - $\mathrm{f}_{\mathrm{S}}$

\begin{tabular}{lccc}
\hline Termo Descritivo & $\begin{array}{c}\text { Solubilidade }(\mathrm{S}) \\
\text { em água }(\mathrm{ppm})\end{array}$ & Classificação & Pontos fs \\
\hline $\begin{array}{c}\text { Ligeiramente } \\
\text { solúvel }\end{array}$ & $10.000<\mathrm{S}<33.000$ & Moderada & 2 \\
Pouco solúvel & $1.000<\mathrm{S}<10.000$ & solubilidade & \\
\hline $\begin{array}{c}\text { Muito pouco } \\
\text { solúvel }\end{array}$ & $100<\mathrm{S}<1.000$ & Baixa & 1 \\
Praticamente & & solubilidade & \\
insolúvel ou & & & \\
insolúvel & $\mathrm{S}<100$ & & \\
\hline
\end{tabular}

Fonte: Adaptada de ANVISA, 2010c.

O fator de dificuldade de limpeza - fo foi obtido das respostas em entrevistas com os operadores de produção dos RL, que também realizam a limpeza dos equipamentos, sendo por estes atribuída uma pontuação. A pontuação atribuída ao fD está descrita na TAB. 17, sendo esta maior quanto maior a dificuldade operacional de se executar os procedimentos de limpeza para determinado produto (RL). No estabelecimento da pontuação, quando da ocorrência de discordância nas respostas obtidas nas entrevistas, pesou a resposta do operador de limpeza com maior experiência.

TABELA 17 - Fator de dificuldade de limpeza - $f_{D}$

\begin{tabular}{cc}
\hline Pontos $-f_{D}$ & Dificuldade de Limpar \\
\hline 3 & Difícil de limpar \\
2 & Dificuldade média de limpar \\
1 & Fácil de limpar \\
\hline
\end{tabular}

A TAB. 18 referencia os dados compilados para o número de lotes dos RL produzidos no ano de 2013, e a TAB. 19 a respectiva pontuação atribuída ao fator de ocupação - fo para cada faixa (intervalo) de número de lotes. O fator fo está relacionado com o quanto um produto ocupa a linha de produção. A lógica assumida para escolha deste fator baseou-se no 
número de procedimentos de limpeza que foram executados para cada um dos RL, e na possibilidade da ocorrência de contaminação cruzada, sendo maior a probabilidade de um produto fabricado em maior frequência contaminar outros produtos, que aqueles cuja frequência é menor.

TABELA 18 - Número de lotes de RL produzidos no IPEN - CNEN/SP em 2013

\begin{tabular}{ccc}
\hline Produto & Fármaco & Número de Lotes/Ano \\
\hline CIS-TEC & etilenodicisteína & 12 \\
DEX 500-TEC & dextrana 500 & 11 \\
DEX 70-TEC & dextrana 70 & 11 \\
DISI-TEC & disofenina & 11 \\
DMSA-TEC & succímer & 17 \\
DTPA-TEC & ácido pentético & 23 \\
ECD-TEC & dicloridrato de etilenodicisteína dietiléster & 15 \\
FITA-TEC & ácido fítico & 15 \\
MDP-TEC & ácido medrônico & 53 \\
MIBI-TEC & tetrafluorborato tetramibi cuproso & 25 \\
PIRO-TEC & pirofosfato tetrassódico & 19 \\
PUL-TEC & albumina humana solução 20\% & 26 \\
SAH-TEC & albumina humana solução 20\% - Grifols & 6 \\
TIN-TEC & fluoreto estanoso & 9 \\
\hline Fonte: Indicadores do Controle de Qualidade - IPEN &
\end{tabular}

TABELA 19 - Fator de Ocupação - fo

\begin{tabular}{cl}
\hline Pontos - fo & Quantidade (lotes/ano) \\
\hline 5 & Acima de 50 lotes \\
4 & Entre 31 e 50 lotes \\
3 & Entre 21 e 30 lotes \\
2 & Entre 11 e 20 lotes
\end{tabular}


TABELA 19 - Fator de Ocupação - fo

\begin{tabular}{cc}
\hline Pontos - fo & Quantidade (lotes/ano) \\
\hline 1 & Até 10 lotes \\
\hline
\end{tabular}

Após o enquadramento dos dados levantados, cada fator $\mathbf{f}_{\mathbf{S}}, \mathbf{f} \mathbf{D}$ e forelacionado a um produto assumiu um valor. Os valores de cada fator e o valor obtido para o índice WCI para cada um dos produtos estão descritos na TAB. 20. O WCI dos produtos está em ordem decrescente, do maior para o menor valor.

TABELA 20 - Valores dos fatores $f_{O}, f_{D}$, $f_{S}$ e cálculo do WCI para cada RL produzido no IPEN-CNEN/SP

\begin{tabular}{ccccc}
\hline Produto & $f_{\mathrm{O}}$ & $\mathrm{f}_{\mathrm{D}}$ & $\mathrm{f}_{\mathrm{S}}$ & WCI \\
\hline PUL-TEC & 3 & 3 & $3^{*}$ & 3 \\
MIBI-TEC & 3 & 2 & 2 & 3 \\
MDP-TEC & 5 & 1 & 2 & 2,5 \\
DISI-TEC & 2 & 1 & 1 & 2,0 \\
DEX 500-TEC & 2 & 3 & 3 & 2,0 \\
DTPA-TEC & 3 & 1 & 2 & 1,5 \\
DEX 70-TEC & 2 & 2 & 3 & 1,33 \\
DMSA-TEC & 2 & 2 & 3 & 1,33 \\
FITA-TEC & 2 & 2 & 3 & 1,33 \\
SAH-TEC & 1 & 2 & $3 *$ & 0,66 \\
CIS-TEC & 2 & 1 & 3 & 0,66 \\
PIRO-TEC & 2 & 1 & 3 & 0,66 \\
ECD-TEC & 2 & 1 & 3 & 0,66 \\
TIN-TEC & 1 & 1 & 3 & 0,33
\end{tabular}

*O Fator de solubilidade - $\mathrm{f}_{\mathrm{S}}$ utilizado no cálculo do WCI foi obtido com dados de solubilidade da Albumina Humana Solução 30\%, da Sigma-Aldrich. 
Os produtos PUL-TEC e MIBI-TEC apresentaram o maior índice WCI, com mesmo valor numérico $(3,0)$.

O índice WCI do PUL-TEC pode ser creditado à sua alta solubilidade, bem como à limpeza difícil, conforme experiência dos operadores da área, além de uma taxa de ocupação relativamente média (acima de 20 lotes).

Algumas considerações devem ser feitas em relação à obtenção do índice WCI para o PUL-TEC, levando-se em conta aspectos do processo produtivo e características do fármaco albumina, e que podem elucidar a divergência entre alta solubilidade creditada ao fármaco e alta dificuldade de limpeza relatada pelos operadores. A albumina é a mais abundante proteína plasmática, e quando comparada a outras proteínas, ela é uma molécula relativamente pequena, formada por uma cadeia de 584 aminoácidos, com um peso molecular em torno de 69.000 Daltons (CUPPARI et al., 2004).

As proteínas são macromoléculas extremamente complexas formadas por polímeros de aminoácidos, e possuem quatro diferentes níveis de estrutura - primária, secundária, terciária e quaternária. Embora a sequência de aminoácidos corresponda à estrutura primária da proteína, as propriedades químico-biológicas da proteína são muito dependentes da estrutura tridimensional ou terciária (FOOD INGREDIENTS BRASIL, 2012; PARTICLE SCIENCES, 2009). As proteínas podem ser classificadas de acordo com sua solubilidade e composição, função, e sua forma e tamanho. A classificação baseada na solubilidade e composição divide as proteínas em três grupos principais: proteínas simples, conjugadas e derivadas. As proteínas simples fornecem por hidrólise apenas aminoácidos e coagulam pela ação do calor. As albuminas podem ser classificadas como proteínas simples e que apresentam como principal propriedade, que as distingue de todas as outras proteínas, a sua solubilidade em água (FOOD INGREDIENTS BRASIL, 2012). Masuelli (2013) relata que a solubilidade das albuminas está relacionada com sua alta carga elétrica total, com correspondente forte hidrofilia e atração para as moléculas de água. Quando próximas da neutralidade, as albuminas são extremamente solúveis em água, $35 \%$ em peso em soluções salinas diluídas, e $50 \%$ em peso em soluções puras de água (MASUELLI, 2013).

Um fato a ser ressaltado é que as proteínas podem ter sua estrutura e propriedades modificadas pela ação de vários agentes, como por exemplo, o aquecimento. Tal fenômeno é conhecido como desnaturação proteica e consiste na quebra das estruturas secundária e terciária das proteínas. Como resultado dessa desnaturação ocorre mudança na conformação da proteína, 
com rompimento de ligações de hidrogênio (responsáveis pela estabilidade da conformação) e consequente desenrolamento das cadeias peptídicas, tornando-as mais esticadas, o que causa uma diminuição da solubilidade e aumento da viscosidade da proteína (Food Ingredients Brasil, 2012). No processo de produção do PUL-TEC, a albumina humana é aquecida a $100^{\circ} \mathrm{C}$, havendo sua desnaturação, diminuição da solubilidade e aumento da viscosidade, o que explica a divergências nas informações obtidas para o cálculo do índice WCI para o PUL-TEC. Outro fator que contribui para a diminuição da solubilidade e aumento da viscosidade é a utilização de uma base forte, hidróxido de sódio $(\mathrm{NaOH})$ no processo de produção do PUL-TEC.

Para produto MIBI-TEC, que também apresentou uma taxa de ocupação relativamente média, a dificuldade média de limpeza e principalmente a moderada solubilidade, impactaram no valor do índice WCI obtido $(3,0)$.

O produto MDP-TEC apresentou um WCI $(2,5)$ próximo aos produtos MIBI-TEC e PUL-TEC, com moderada solubilidade, fácil limpeza e um alto fator de ocupação (o maior dentre todos os RL), o que refletiu no índice WCI.

O índice WCI obtido para o DISI-TEC e o DEX 500-TEC foi exatamente igual $(2,0)$, ambos os produtos apresentando o mesmo fator de ocupação (11 lotes), relativamente baixo. Para o DISI-TEC pesaram no cálculo do WCI a fácil limpeza e baixa solubilidade, enquanto que para o DEX 500-TEC a alta solubilidade foi determinante para obtenção do WCI. Muito embora os operadores de limpeza tenham classificado o produto DEX 500-TEC como de difícil limpeza, a empresa Pharmacosmos, especializada na síntese de dextranas, assinala que as frações de dextrana são facilmente solúveis em água e soluções de eletrólitos, e formam soluções límpidas e estáveis, podendo ocorrer formação de soluções turvas (quando em repouso) apenas quando são usadas soluções concentradas das frações de dextrana de baixo peso molecular (5000 e 10000).

Os produtos, DEX 70-TEC, DMSA-TEC e FITA-TEC apresentaram exatamente os mesmos valores numéricos para WCI $(1,33)$, próximo ao obtido para o DTPA-TEC, pesando no cálculo a alta solubilidade, média dificuldade de limpeza e fator de ocupação relativamente baixo.

Os produtos SAH-TEC, CIS-TEC, PIRO-TEC e ECD-TEC apresentaram índice WCI iguais $(0,66)$, e distantes dos primeiro colocados, PUL-TEC e MIBI-TEC. A alta solubilidade dos quatro produtos e a baixa ocupação (a menor entre todos os produtos) do 
primeiro foram fatores decisivos na obtenção do WCI. O produto que apresentou menor valor para WCI foi o TIN-TEC.

De posse da eleição dos produtos com maiores índices WCI, obteve-se como potencial referência para validação dos processos de limpeza dos equipamentos de produção de RL os produtos PUL-TEC e MIBI-TEC.

\subsection{Validação de Método Analítico para Determinação de COT/CONP}

O objetivo da validação consiste em demonstrar que o método analítico é adequado para o seu propósito, assegurando assim a confiabilidade dos resultados.

A validação do método analítico para determinação de COT/CONP realizada no presente trabalho seguiu as determinações estabelecidas no "Guia para validação de métodos analíticos e bioanalíticos, publicado pela Resolução - RE n 899/2003, da ANVISA (ANVISA, 2003).

Para tanto, seguiu-se a classificação para categoria II estabelecida por esta resolução, a saber: Testes quantitativos ou ensaio limite para a determinação de impurezas e produtos de degradação em produtos farmacêuticos e matérias-primas.

Os parâmetros avaliados foram: conformidade do sistema, robustez, linearidade, limite de detecção (LD) e limite de quantificação (LQ), precisão (repetibilidade e precisão intermediária), e exatidão (recuperação).

Todas as soluções reagentes utilizadas nos ensaios foram preparadas com AP com teor de COT inferior a $100 \mathrm{ug} \mathrm{\textrm {L } ^ { - 1 }}$.

\subsubsection{Conformidade do sistema (System Suitability)}

A inclusão de um teste de adequação do sistema em uma corrida analítica tem como objetivo garantir a todo o tempo a validade do método analítico e o seu bom desempenho. Caso as medições sejam suscetíveis a variações nas condições analíticas, estas devem ser adequadamente controladas ou uma recomendação de prudência deve ser incluída no procedimento. São exemplos de variações típicas: estabilidade das soluções analíticas e tempo de extração (ICH, 2005; USP, 2015). 
Dessa forma, procedeu-se o teste de adequação do sistema com o intuito de averiguar a capacidade do método proposto em quantificar a concentração de soluções com diferentes complexidade e estabilidade.

A sacarose é um dissacarídeo solúvel em água, estável em solução, de fácil oxidação, e é utilizada como padrão para obtenção do pico na curva de calibração. A 1,4 benzoquinona $\left(\mathrm{C}_{6} \mathrm{H}_{4} \mathrm{O}_{2}\right)$ é instável em solução e fotossensível. É utilizada como padrão para verificar a eficiência do sistema por ser uma substância de difícil oxidação, o que é creditado ao fato de conter anéis aromáticos em sua fórmula estrutural (CLEMENTINO, 2006). As estruturas moleculares da sacarose e da 1,4-benzoquinona estão representadas na FIG. 10 e 11.

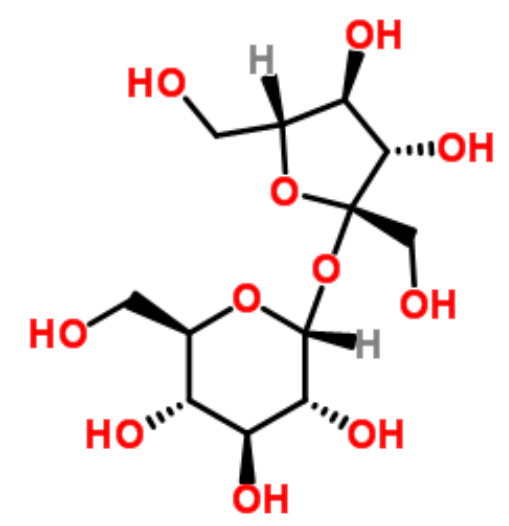

FIGURA 10 - Estrutura molecular da sacarose

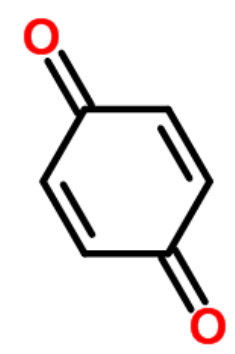

FIGURA 11 - Estrutura molecular da 1,4-benzoquinona

O resultado do ensaio de conformidade do sistema (System Suitability) foi obtido a partir da Eq. 21 (pág. 81) e está descrito abaixo:

$$
\mathrm{SS} \%=100 \frac{549-55,99}{552,9-55,99}
$$




$$
\mathrm{SS} \%=99,215 \%
$$

$\mathrm{O}$ resultado de $\mathrm{SS} \%$ atendeu à faixa aceitável estabelecida pela Farmacopeia Americana USP - 38, que correspode a 85-115\%.

\subsubsection{Robustez}

Para mensuração de CONP é necessário definir alguns parâmetros no analisador de carbono. No ensaio de robustez esses parâmetros foram alterados a fim de verificar a influência da variação de cada um destes na obtenção dos resultados do teor de CONP a partir de solução de concentração conhecida. A recomendação do fabricante para cada um desses parâmetros é: volume de solução acidificante $3 \%, 1,5 \mathrm{~mL}$ de solução oxidante, tempo de integração da área da curva de aproximadamente 5,0 minutos.

Cada parâmetro foi avaliado separadamente e os resultados estão representados em figuras e tabelas.

\subsubsection{Volume de solução acidificante}

$\mathrm{O}$ efeito da variação do volume de solução acidificante $\mathrm{H}_{3} \mathrm{PO}_{4} 3,0 \mathrm{~mol} \mathrm{~L}^{-1}$ na análise da mensuração do teor de carbono de uma solução com concentração de COT/CONP $100 \mu \mathrm{gL}^{-1}$ é apresentado na FIG. 12. 


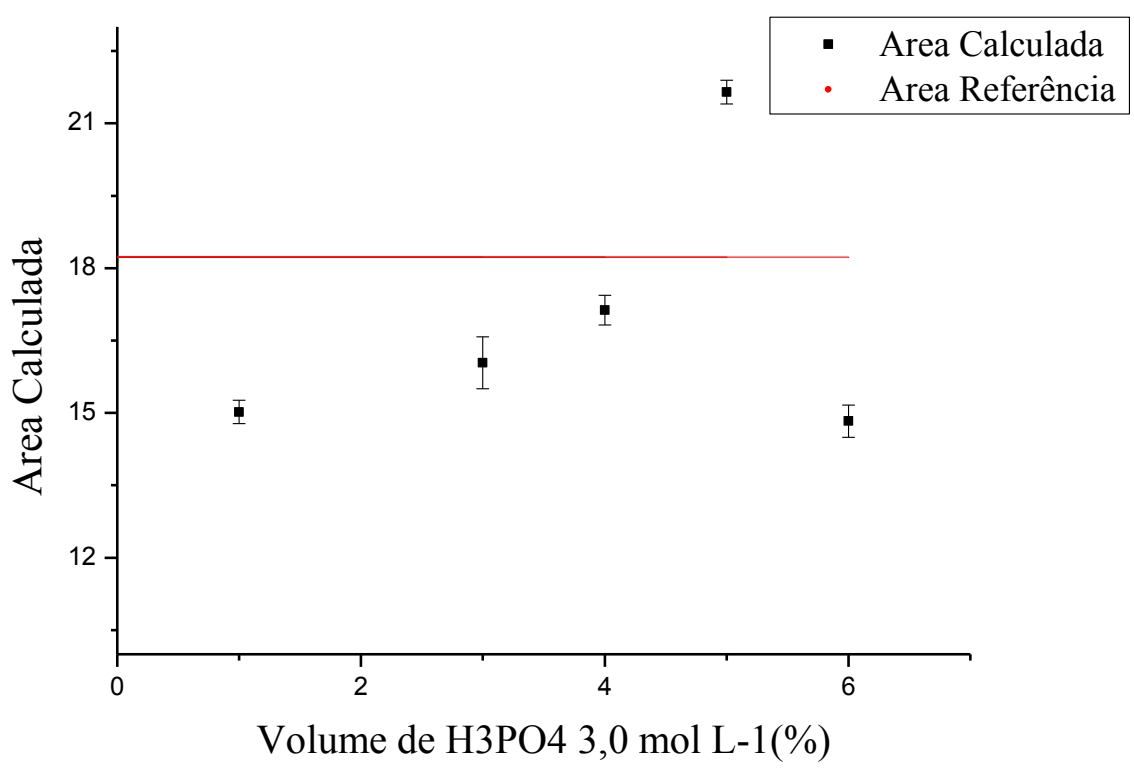

FIGURA 12 - Efeito da variação do volume de solução acidificante na análise de padrão de CONP $100 \mu \mathrm{gL}^{-1}$

Conforme representado na FIG.12 observou-se que os resultados de área mais próximos do valor nominal da área de referência $(18,23)$ do padrão foram obtidos com os volumes de solução acidificante de 3,0 e 4,0\%. O menor DP $(0,30)$ foi obtido com volume de solução acidificante de $4,0 \%$.

Acredita-se que 4,0\% de solução acidificante seja suficiente e a melhor concentração para eliminar todo o carbono inorgânico presente no padrão de $100 \mu \mathrm{g} \mathrm{L}^{-1}$, e, portanto, este foi o volume escolhido para compor o método de análise de CONP.

\subsubsection{Volume de solução oxidante}

Os resultados da mensuração do teor de carbono em solução padrão com concentração de COT/CONP $100 \mu \mathrm{gL}^{-1}$ após variação do volume de solução oxidante $\mathrm{Na}_{2} \mathrm{~S}_{2} \mathrm{O}_{8}$ 0,5 mol L ${ }^{-1}$ estão dispostos na FIG. 13. 


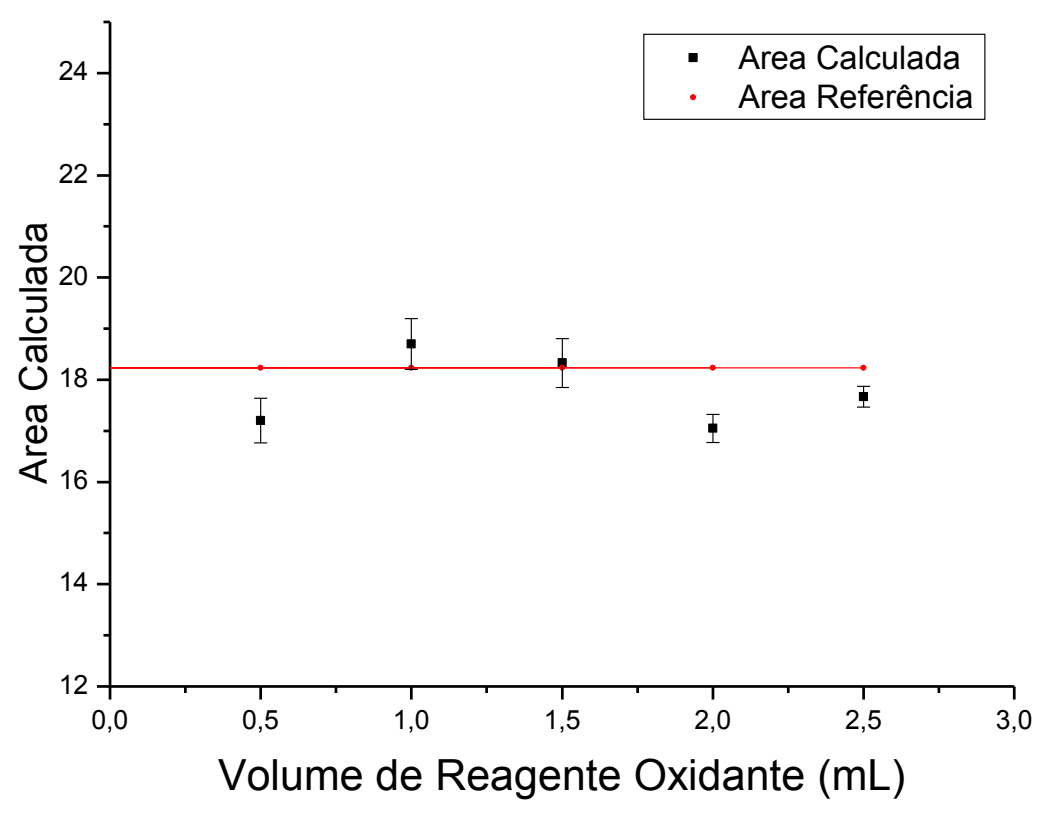

FIGURA 13 - Efeito da variação do volume de oxidante na análise de padrão de CONP $100 \mu \mathrm{gL}^{-1}$

Foi constatado que os resultados de área mais próximos do valor nominal da área de referência $(18,23)$ do padrão foram obtidos com os volumes de oxidante 1, 1,5 e 2,5 mL(18,7, 18,33 e 17,67 , respectivamente. Os resultados mostraram que o menor DP $(0,20)$ foi obtido com volume de oxidante de $2,5 \mathrm{~mL}$, e portanto, optou-se pela escolha de deste volume de oxidante.

\subsubsection{Tempo de integração da área da curva de COT/NPOC}

A reação de oxidação do carbono orgânico catalisada pelo $\mathrm{Na}_{2} \mathrm{~S}_{2} \mathrm{O}_{8}$ tem como consequência a formação de $\mathrm{CO}_{2}$, que posteriormente é quantificado após captação por detectores IVND. A análise realizada neste quesito foi a variação do tempo necessário para integração da área da curva de reposta do detector para $\mathrm{CO}_{2}$ frente a solução padrão COT/CONP $100 \mu \mathrm{gL}^{-1}$. 


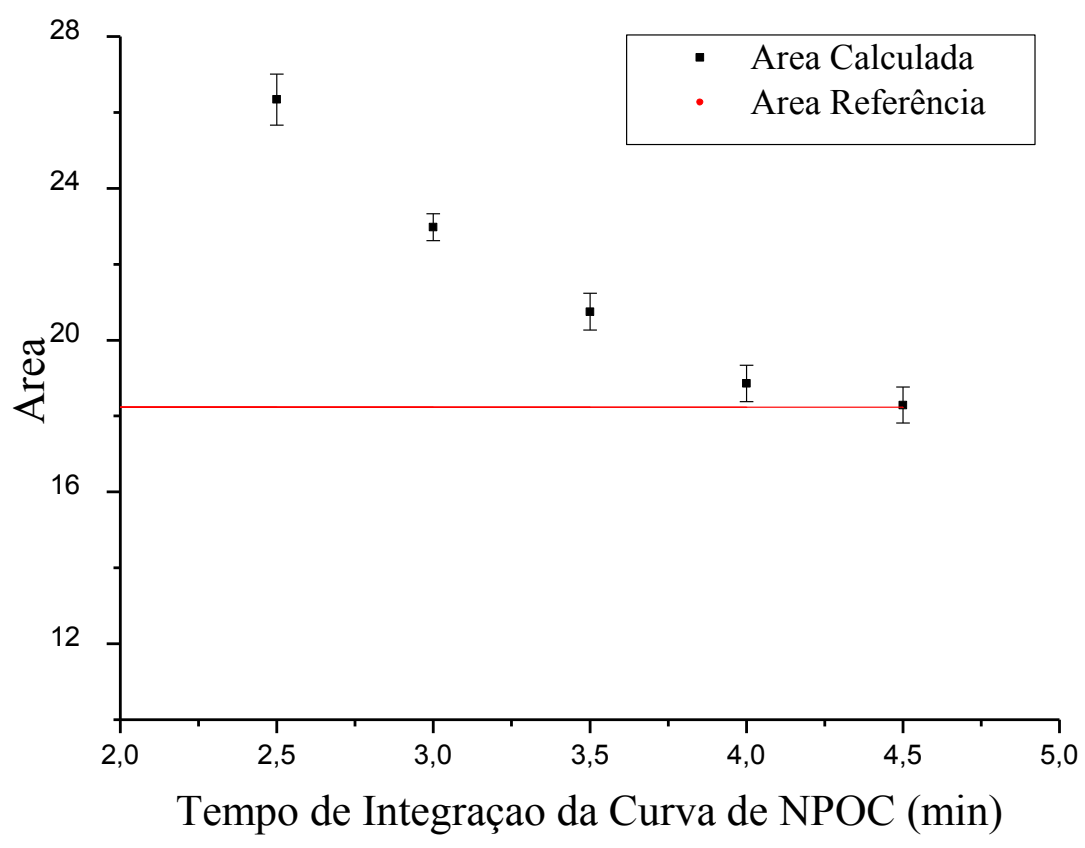

FIGURA 14 - Efeito da variação do tempo de integração na análise de padrão de CONP $100 \mu \mathrm{gL}^{-1}$

Conforme demonstrado na FIG. 14 observou-se que houve uma melhor integração da área referente à leitura de $\mathrm{CO}_{2}$ resultante da reação de oxidação do biftalato de potássio para 4 e 4,5 minutos, com resultados mais próximos do valor nominal da área de referência $(18,23)$ do padrão. O menor DP $(0,47)$ encontrado nesta faixa de tempo foi obtido para 4,5 minutos, associado ao melhor valor nominal de área obtido $(18,29)$. Portanto, o tempo de integração de CT de 4,5 minutos foi escolhido para compor o método de análise. O tempo escolhido assemelhou-se à recomendação do fabricante, que é de aproximadamente 5,0 minutos após a injeção da amostra.

\subsubsection{Tempo de Sparge}

$\mathrm{Na}$ etapa de acidificação com sparging todo o conteúdo de CI é convertido em $\mathrm{CO}_{2}$ e o gás de aspersão $\left(\mathrm{N}_{2}\right)$ é então borbulhado através da amostra para remoção de todo componente de CI.

Neste ensaio verificou-se a influência da variação do tempo de borbulhamento do gás $\mathrm{N}_{2}$ após acidificação de uma solução padrão COT/CONP de $100 \mu \mathrm{gL}^{-1}$, para posterior análise da mensuração do teor de carbono. 


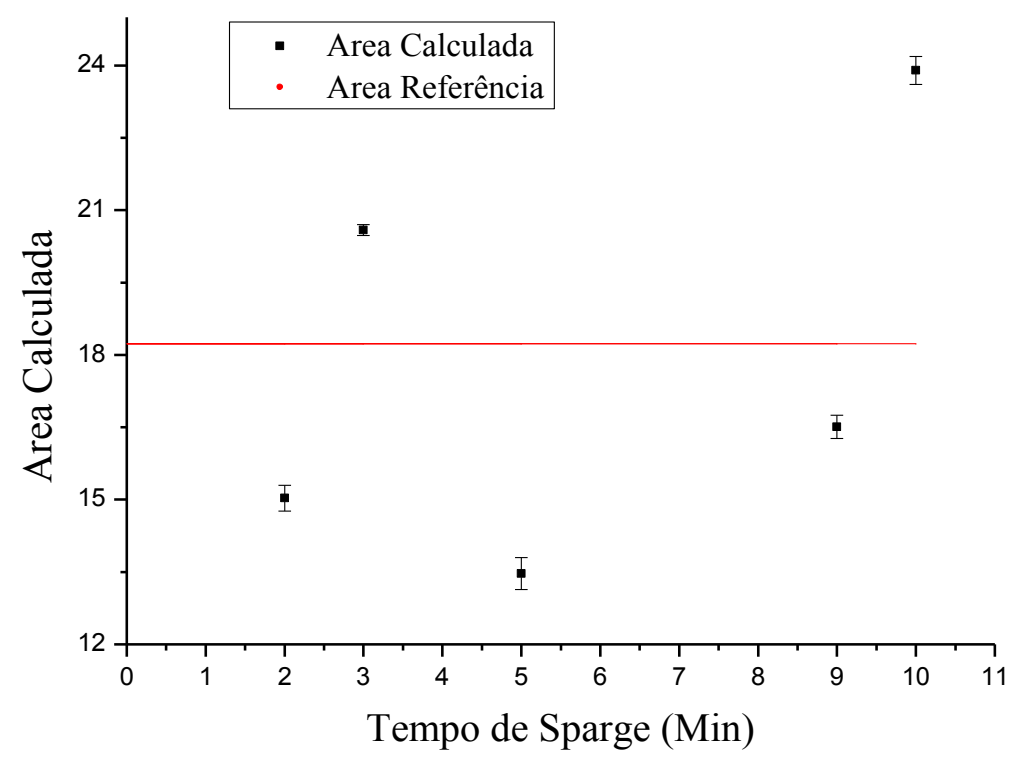

FIGURA 15 - Efeito da variação do tempo de sparge na análise de padrão de CONP $100 \mu \mathrm{gL}^{-1}$

Na FIG.15 pode-se observar que os resultados de área mais próximos do valor nominal da área de referência $(18,23)$ do padrão foram obtidos com os tempos de sparge de 3 e 9 minutos (20,59 e 16,51 respectivamente). Os resultados mostraram que o menor DP $(0,11)$ foi obtido para o tempo de sparge de 3 minutos, suficiente para eliminação de todo componente de CI, e este foi escolhido para compor o método de análise.

Após conclusão dos ensaios de robustez os parâmetros definidos para compor o método analítico de determinação do CONP foram: volume de solução acidificante 4\%, volume de solução oxidante $2,5 \mathrm{~mL}$, tempo de integração da curva 4,5 minutos e tempo de sparge 3,0 minutos.

\subsubsection{Linearidade}

As curvas de calibração obtidas na avaliação de linearidade para CONP estão dispostas na TAB. 21 e FIG. 16.

TABELA 21 - Curvas de calibração obtidas para CONP

\begin{tabular}{cccc}
\hline $\mathrm{N}$ & Eq. da reta: $\mathrm{y}=\mathrm{ax}+\mathrm{b}$ & $\mathrm{r}^{2}$ & $\mathrm{r}$ \\
\hline 1 & Área $=0,15471[\mathrm{CONP}]+1,08459$ & 0,99996 & 0,99
\end{tabular}


TABELA 21 - Curvas de calibração obtidas para CONP

\begin{tabular}{cccc}
\hline $\mathrm{N}$ & Eq. da reta: $\mathrm{y}=\mathrm{ax}+\mathrm{b}$ & $\mathrm{r}^{2}$ & $\mathrm{r}$ \\
\hline 2 & Área $=0,15267[\mathrm{CONP}]+2,18216$ & 0,99922 & 0,99 \\
3 & Área $=0,15809[\mathrm{CONP}]+0,7597$ & 0,99592 & 0,99 \\
\hline
\end{tabular}

De acordo com os resultados expressos na TAB. 21 e FIG. 16, a faixa linear para determinação de CONP foi de 40-1000 $\mu \mathrm{gL}^{-1}$ com $\mathrm{r}$ e $\mathrm{r}^{2}>0,99$, atendendo assim o critério mínimo aceitável estabelecido pela ANVISA.

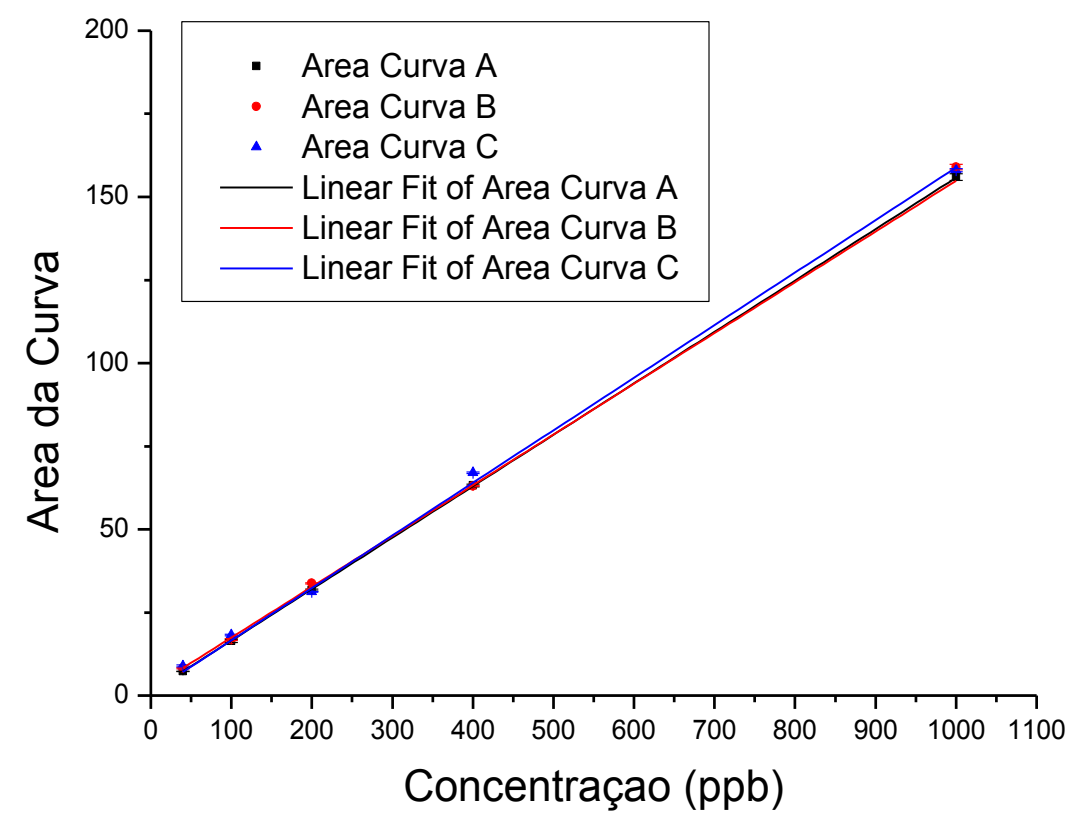

FIGURA 16 - Curvas de Calibração de CONP

\subsubsection{Limite de detecção (LD) e limite de quantificação (LQ)}

Os limites de detecção e quantificação obtidos para CONP foram 14,258 $\mu \mathrm{g} \mathrm{L}^{-1} \mathrm{e}$ $47,528 \mu \mathrm{g} \mathrm{L}^{-1}$ respectivamente.

\subsubsection{Precisão: repetibilidade e precisão intermediária}

Os resultados dos ensaios de repetibilidade (intradia) e precisão intermediária (interdia) para as soluções padrão de COT / CONP 100, 400 e $800 \mu \mathrm{gL}^{-1}$ foram obtidos a partir 
dos cálculos do DP (Eq. 16, pág. 73) e DPR (Eq. 17, pág. 73), e estão expressos nas TAB. 22, 23 e 24.

TABELA 22 - Precisão e Exatidão intradia - $1^{\circ}$ dia de análise

\begin{tabular}{cccc}
\hline CONP $\left(\mu \mathrm{g} \mathrm{L}^{-1}\right)$ & CMD \pm DP $\left(\mu \mathrm{g} \mathrm{L}^{-1}\right)$ & DPR (\%) & Exatidão (\%) \\
\hline & & & \\
\hline 100 & $102,90 \pm 4,60$ & 4,47 & 102,90 \\
400 & $397,07 \pm 4,34$ & 1,09 & 99,26 \\
800 & $796,04 \pm 0,94$ & 0,11 & 99,50 \\
\hline $\mathrm{n}=3$ & & & \\
& & &
\end{tabular}

TABELA 23 - Precisão e Exatidão intradia de CONP - $2^{\circ}$ dia de análise

\begin{tabular}{cccc}
\hline CONP $\left(\mu \mathrm{g} \mathrm{L}^{-1}\right)$ & $\mathrm{CMD} \pm \mathrm{DP}\left(\mu \mathrm{g} \mathrm{L}^{-1}\right)$ & $\mathrm{DPR}(\%)$ & Exatidão (\%) \\
\hline 100 & $98,35 \pm 1,85$ & 1,88 & 98,35 \\
400 & $392,35 \pm 2,46$ & 0,62 & 98,08 \\
& & & \\
& & &
\end{tabular}

A precisão intradia (repetibilidade) e a exatidão do método, avaliados com padrão de COT/CONP para as três concentrações apresentaram resultados dentro dos limites aceitáveis (DPR $\leq 5 \%$ e exatidão entre $80-120 \%$ ).

Os resultados para precisão interdia (precisão intermediária) para CONP estão demonstrados na TAB.24.

TABELA 24 - Precisão intermediária de CONP

\begin{tabular}{ccc}
\hline $\operatorname{CONP}\left(\mu \mathrm{g} \mathrm{L}^{-1}\right)$ & $\mathrm{CMD} \pm \mathrm{DP}\left(\mu \mathrm{g} \mathrm{L}^{-1}\right)$ & $\mathrm{DPR}(\%)$ \\
\hline 100 & $99,13 \pm 3,77$ & 3,80 \\
400 & $394,71 \pm 2,36$ & 0,59 \\
800 & $786,25 \pm 9,7$ & 1,23 \\
\hline
\end{tabular}


TABELA 24 - Precisão intermediária de CONP

\begin{tabular}{lll}
\hline $\operatorname{CONP}\left(\mu \mathrm{g} \mathrm{L}^{-1}\right)$ & $\mathrm{CMD} \pm \mathrm{DP}\left(\mu \mathrm{g} \mathrm{L}^{-1}\right)$ & $\mathrm{DPR}(\%)$ \\
\hline $\mathrm{n}=3$
\end{tabular}

A precisão intermediária para CONP apresentou-se dentro dos limites especificados $(\mathrm{DPR} \leq 5 \%)$.

\subsubsection{Ensaios de Recuperação}

Nas TAB. 25, 26 e 27 estão dispostos os resultados obtidos para a recuperação com amostras de solução padrão de $\mathrm{CT} / \mathrm{CONP}$ (biftalato de potássio - $\mathrm{C}_{8} \mathrm{H}_{5} \mathrm{O}_{4} \mathrm{~K}$ ) nas concentrações

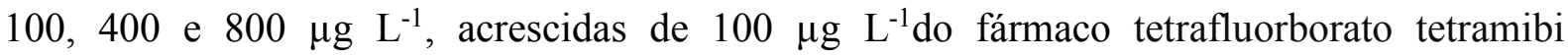
cuproso(representado pela sigla Mibi).

TABELA 25 - Porcentagem de Recuperação - $1^{\circ}$ dia de análise

\begin{tabular}{ccc}
\hline Analito & Área & Recuperação (\%) \\
\hline CONP $100 \mu \mathrm{g} \mathrm{L}^{-1}$ & 19,596 & \\
CONP $400 \mu \mathrm{g} \mathrm{L}^{-1}$ & 64,096 & \\
CONP $800 \mu \mathrm{g} \mathrm{L}^{-1}$ & 127,996 & \\
Mibi $100 \mu \mathrm{g} \mathrm{L}^{-1}$ & 16,536 & \\
CONP 100 $\mu \mathrm{g} \mathrm{L}^{-1}+$ Mibi $100 \mu \mathrm{g} \mathrm{L}^{-1}$ & 35,616 & 97,37 \\
CONP $400 \mu \mathrm{g} \mathrm{L}^{-1}+$ Mibi $100 \mu \mathrm{g} \mathrm{L}^{-1}$ & 77,726 & 95,47 \\
CONP $800 \mu \mathrm{g} \mathrm{L}^{-1}+$ Mibi $100 \mu \mathrm{g} \mathrm{L}^{-1}$ & 139,096 & 95,75 \\
\hline
\end{tabular}

TABELA 26 - Porcentagem de Recuperação - $2^{\circ}$ dia de análise

\begin{tabular}{|c|c|c|}
\hline Analito & Área & Recuperação (\%) \\
\hline CONP $100 \mu \mathrm{g} \mathrm{L}^{-1}$ & 32,37 & \\
\hline CONP $400 \mu \mathrm{g} \mathrm{L}^{-1}$ & 68,81 & \\
\hline CONP $800 \mu \mathrm{g} \mathrm{L}^{-1}$ & 131,75 & \\
\hline
\end{tabular}


TABELA 26 - Porcentagem de Recuperação - $2^{\circ}$ dia de análise

\begin{tabular}{ccc}
\hline Analito & Área & Recuperação (\%) \\
\hline Mibi 100 $\mu \mathrm{g} \mathrm{L}^{-1}$ & 19,77 & \\
CONP 100 $\mu \mathrm{g} \mathrm{L}^{-1}+$ Mibi $100 \mu \mathrm{g} \mathrm{L}^{-1}$ & 50,93 & 96,26 \\
CONP $400 \mu \mathrm{g} \mathrm{L}^{-1}+$ Mibi $100 \mu \mathrm{g} \mathrm{L}^{-1}$ & 85,85 & 96,03 \\
CONP $800 \mu \mathrm{g} \mathrm{L}^{-1}+$ Mibi $100 \mu \mathrm{g} \mathrm{L}^{-1}$ & 146,05 & 95,84 \\
\hline
\end{tabular}

TABELA 27 - Porcentagem de Recuperação - $3^{\circ}$ dia de análise

\begin{tabular}{ccc}
\hline Analito & Área & Recuperação (\%) \\
\hline CONP $100 \mu \mathrm{g} \mathrm{L}^{-1}$ & 16,26 & \\
CONP $400 \mu \mathrm{g} \mathrm{L}^{-1}$ & 59,66 & \\
CONP $800 \mu \mathrm{g} \mathrm{L}^{-1}$ & 122,18 & \\
Mibi $100 \mu \mathrm{g} \mathrm{L}^{-1}$ & 13,29 & \\
CONP $100 \mu \mathrm{g} \mathrm{L} \mathrm{L}^{-1}+$ Mibi $100 \mu \mathrm{g} \mathrm{L}^{-1}$ & 31,29 & 110,7 \\
CONP $400 \mu \mathrm{g} \mathrm{L}^{-1}+$ Mibi $100 \mu \mathrm{g} \mathrm{L}^{-1}$ & 75,17 & 103,72 \\
CONP $800 \mu \mathrm{g} \mathrm{L}^{-1}+$ Mibi $100 \mu \mathrm{g} \mathrm{L}^{-1}$ & 134,88 & 99,52 \\
\hline
\end{tabular}

De acordo com resultados apontados demonstrou-se que a porcentagem de recuperação variou entre 95,4 e 110,7 \%, indicando que o Mibi na concentração de $100 \mu \mathrm{g} \mathrm{L}{ }^{-1}$ não interfere na análise de CONP. O guia de validação da ANVISA não estabelece critérios de aceitabilidade para \% de recuperação, porém a AOAC Internacional prevê limites entre 70 e 125\% (BERNARDES; SOUZA, 2011).

A FIG. 17 e a TAB. 28 apresentam as curvas de calibração obtidas na avaliação de linearidade para CONP/Mibi. 


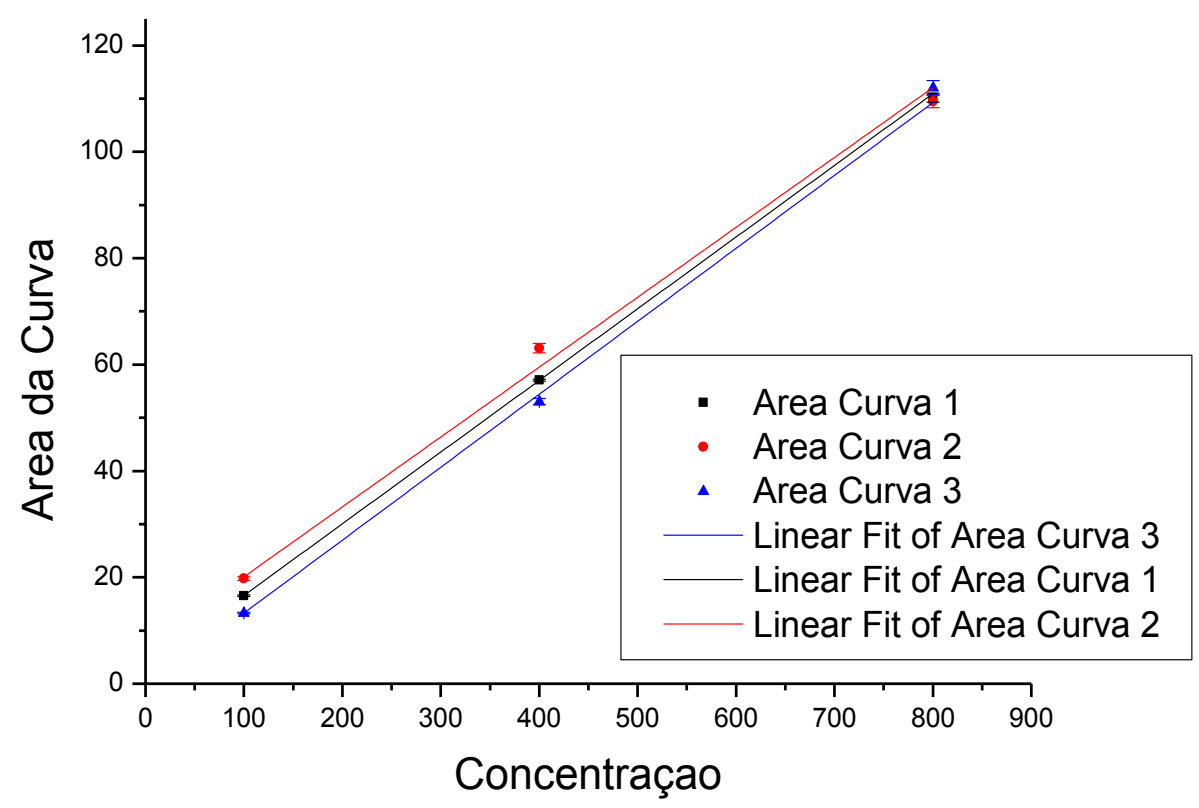

FIGURA 17 - Curvas de Calibração obtidas para CONP/Mibi

TABELA 28 - Curvas de calibração obtidas para Mibi

\begin{tabular}{cccc}
\hline $\mathrm{N}$ & Eq. da reta: $\mathrm{y}=\mathrm{a}+\mathrm{bx}$ & $\mathrm{r}^{2}$ & $\mathrm{r}$ \\
\hline 1 & Área $=0,13483[\mathrm{CONP}]+3,08663$ & 0,99995 & 0,99 \\
2 & Área $=0,13147[\mathrm{CONP}]+6,93024$ & 0,99352 & 0,99 \\
3 & Área $=0,13721[\mathrm{CONP}]+0,46733$ & 0,99796 & 0,99 \\
\hline
\end{tabular}

Conforme demonstrado na FIG.17 pode-se inferir que na faixa de $100-800$ $\mu \mathrm{g} \mathrm{L}^{-1}$ a área do carbono presente no Mibi responde linearmente com a concentração.

A equação da reta para determinação de Mibi apresenta parâmetros similares aos da curva padrão obtida com o biftalato. O coeficiente de correlação e a soma dos mínimos quadrados, $\mathrm{r}_{\text {e }}{ }^{2}>0,99$, atenderam ao critério mínimo aceitável estabelecido pela ANVISA. 


\section{CONCLUSÃO}

A estratégia de propor um índice de pior caso para validação dos processos de limpeza dos equipamentos de produção de RL considerando fatores de solubilidade dos reagentes, dificuldade de limpeza dos equipamentos e taxa de ocupação se mostrou adequada. Não foi incluído o fator de toxicidade devido à falta de dados para os reagentes. Os fatores que se mostraram mais críticos para a escolha dos produtos pior caso foram a solubilidade e a dificuldade de limpeza e os produtos definidos pior caso foram PUL-TEC e MIBI-TEC, com WCI 3,0. Considerando que são fabricados 14 RL na área de produção, a abordagem adotada neste trabalho permite uma simplificação do processo de validação e redução no tempo e nos custos das atividades envolvidas.

Análises de água de rinsagem de béqueres utilizados na fabricação de RL indicaram que do teor de COT (método indireto) inicial encontrou-se acima de $7.000 \mu \mathrm{g} \mathrm{mL}^{-1}$. A quantificação de COT após o procedimento de limpeza dos mesmos indicou redução até cerca de $6.500 \mu \mathrm{g} \mathrm{mL}^{-1}$. Para a quantificação do teor de COT foi necessária a utilização de três ciclos de rinsagem com agitação com $500 \mathrm{~mL}$ de água purificada. Resultados similares de CONP (método direto) foram observados. A variabilidade dos resultados de teor de COT e CONP na água de rinsagem após a realização dos procedimentos de limpeza nos equipamentos de produção de RL, efetuadas para diferentes lotes de produção de um mesmo produto, apontou para a necessidade de revisão e melhor padronização dos procedimentos de limpeza, de forma a obter-se maior eficiência na limpeza e remoção dos resíduos.

Os ensaios de validação do método direto de quantificação do CONP foram realizados de forma a atender às exigências preconizadas pela Resolução - RE n 899/2003 da ANVISA, avaliando-se os parâmetros de conformidade do sistema, robustez, linearidade, limite de detecção (LD) e limite de quantificação (LQ), precisão (repetibilidade e precisão intermediária), e exatidão (recuperação). A curva analítica para Mibi apresentou parâmetros similares aos das curvas analíticas de CONP. Os resultados apontados nos ensaios de recuperação com o produto pior caso demonstraram que a \% recuperação variou entre 95,4 e $111 \%$, indicando que o Mibi na concentração de $100 \mu \mathrm{g} \mathrm{L}^{-1}$ não interfere na análise de CONP. Todos os resultados obtidos nos ensaios de validação atenderam as exigências e especificações preconizadas pela referida norma para considerar a metodologia validada. A metodologia analítica de quantificação do CONP mostrou ser uma técnica de baixo nível de detecção e capaz 
de detectar compostos orgânicos de natureza diversa, podendo desta forma ser adaptada para radiofármacos, sem necessidade de desenvolvimento de método específico para cada um dos RL.

O trabalho desenvolvido mostrou a importância de se ter procedimentos de limpeza bem definidos e detalhados que permitam aos operadores a adequada limpeza dos equipamentos de produção, de uma forma reprodutível e eficaz. A validação da metodologia analítica de quantificação do CONP em amostras resultantes do processo de limpeza de equipamentos de produção possibilitará ao CR do IPEN proceder a validação de limpeza dos equipamentos, atendendo assim a um requisito regulatório, e diminuindo o risco de desvio de qualidade pela contaminação cruzada. 


\section{REFERÊNCIAS BIBLIOGRÁFICAS}

ACTIVE PHARMACEUTICAL INGREDIENTS COMMITTEE (APIC). Cleaning validation in active pharmaceutical ingredient manufacturing plants. Bruxelas, p. 2-25, set. 1999.

ACTIVE PHARMACEUTICAL INGREDIENTS COMMITTEE (APIC). Guidance on aspects of cleaning validation in active pharmaceutical ingredient plants. Bruxelas, p. 1646, dez. 2000.

AGALLOCO, J. "Points to Consider" in the validation of equipment cleaning procedures. $\boldsymbol{J}$ Parent Sci Techn, EUA, v. 46, n. 5, p. 163-168, 1992.

AGENCIA ESPAÑOLA DE MEDICAMENTO. Normas sobre medicamentos de la unión europea: normas de correcta fabricación, medicamentos de uso humano y medicamentos veterinarios. Madrid: Ministerio de Sanidad y Consumo, 2002.

AGÊNCIA NACIONAL DE VIGILÂNCIA SANITÁRIA (ANVISA). Guia de Validação de Limpeza para Farmoquímicas. 2013. Disponível em:

$<$ http://portal.anvisa.gov.br/wps/wcm/connect/2443e9804f1af51ea138bdc88f4b6a31/Guia+de +valida\%C3\%A7\%C3\%A3o+de+limpeza+para+Farmoqu\%C3\%ADmicas.pdf?MOD=AJPER ES>. Acesso em: 29 jun. 2015.

. Guias relacionados à garantia de qualidade. Brasília: ANVISA, 2006.

Resolução da Diretoria Colegiada (RDC) n. 17.Abr. 16, 2010. Brasília: Diário Oficial da União Poder Executivo, Abr. 19, 2010. n. 73, seção 1, p. 94-110.

Resolução da Diretoria Colegiada (RDC) n. 49: Farmacopeia Brasileira. 2010. Brasília: Diário Oficial da União Poder Executivo, Nov. 24, 2010.n. 224, 5 ed., v. 1.

Resolução da Diretoria Colegiada (RDC) n. 63. Dez. 18, 2009. Brasília: Diário

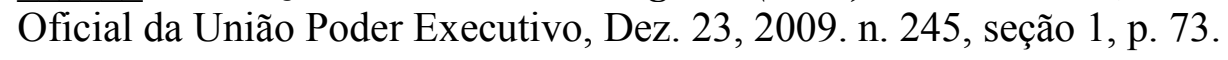

. Resolução da Diretoria Colegiada (RDC) n. 64. Dez. 18, 2009. Brasília: Diário

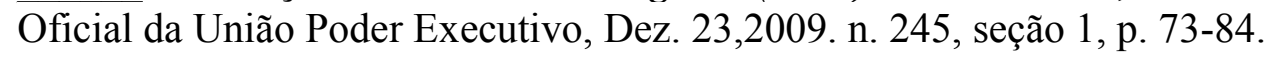

Resolução Específica (RE) n. 899. 2003. Brasília: Diário Oficial da União Poder Executivo, Jun. 02, 2003. n. 104, seção 1, p. 56-59.

ALENCAR, J. R. B.; CLEMENTINO, M. R. A.; NETO, P. J. R. Carbono orgânico total: metodologia analítica e aplicações para indústria farmacêutica. Rev. Bras. Farm., Rio de Janeiro, v. 89, n. 1, p. 74-80, 2008. 
. Validação da limpeza de equipamentos numa indústria de medicamentos: estratégia para escolha do "pior caso". Rev. Bras. Farm., Rio de Janeiro, v. 87, n. 1, p. 13-18, 2006.

ALENCAR, J. R. B.; JIMENEZ, R. C. C.; LIMA, L. G.; NETO, P. J. R.; OLIVEIRA, A. T. C.; OLIVEIRA, M. A. O.; RAMOS, S. V. V.; SANTOS, R. Validação de limpeza de equipamentos multipropósito para formas farmacêuticas líquidas: estudo de caso da zidovudina xarope. Acta Farmacéutica Bonaerense, Buenos Aires, v. 25, n. 1, p. 35-42, 2006.

ALENCAR, J. R. B.; MACHADO, L. B.; MEDEIROS, F. P. M.; MONTEIRO, D. B.; NETO, P. J. R; OLIVEIRA, A. T. C.; RAMOS, S. V. V. Validação de limpeza de zidovudina: estratégia aplicada ao processo de fabricação de medicamentos anti-retrovirais. Rev. Bras. Farm, São Paulo, v. 40, n. 1, p. 1-8, 2004.

ALMEIDA, E. V. Desenvolvimento e validação de metodologia para radiofármacos de tecnécio-99m empregando cromatografia líquida de alta eficiência (CLAE). 2009. Dissertação (Mestrado) - Universidade de São Paulo, São Paulo.

AMOL, D.; GULSHAN, R.; PANKAJ, B. An overview on cleaning validation of API manufacturing plants. International Journal of Pharmaceutical Research and Development. EUA, v. 5, Jul. 2013.

ANDRADE, S. C. I. Validação de limpeza de equipamentos farmacêuticos. 2012.

Dissertação (Mestrado) - Instituto Politécnico de Leiria, Escola Superior de Turismo e Tecnologia do Mar, Portugal.

ARAÚJO, E. B. de. Garantia da qualidade aplicada à produção de radiofármacos. Rev. Bras. Cienc. Farm., São Paulo, v. 44, n. 1, mar. 2008.

ARAYNE, M.S.; SULTANA, N.; SAJID, S.S.; ALI, S.S. Cleaning validation of ofloxacin on pharmaceutical manufacturing equipment and validation of desired HPLC method. PDA $\boldsymbol{J}$ Pharm Sci Tech, EUA, v. 62, p.353-361, 2008.

BAGO, B. C. Validação do processo de limpeza de tanque multiuso utilizado para formulação de vacinas. 2010. Dissertação (Mestrado) - Universidade do Estado do Rio de Janeiro, Rio de Janeiro.

BANERJEE, N.D.; PAWAR, H. A.; PAWAR, P.; PAWAR, S. Current perspectives on cleaning validation in pharmaceutical industry: a scientific and risk based approach. International Journal Of Pharmaceutical And Phytopharmacological Research, England, p. 8-16, 2011.

BANSAL, S. K. Qualification of analytical instruments for use in the pharmaceutical industry: ascientific approach. Aaps Pharmscitech, EUA, v. 5, 2004. 
BATISTA, R. T.; LUIZ, L. C.; MONTEIRO, K. T. S. Os aceleradores de partículas e sua utilização na produção de radiofármacos. Rev. Bras. Farm., Rio de Janeiro, v. 92, n. 3, p. 90 95, 2011.

BENEDETTI, S. Avaliação do teor de carbono orgânico total na qualidade da água: aplicação na radiofarmácia. 2012. Dissertação (Mestrado) - Universidade de São Paulo, São Paulo.

BERNARDES, A.C.M.; SOUZA, S.V.C. Análise comparativa do guia para validação de métodos analíticos proposto pela Anvisa com o documento orientativo do INMETRO e o protocolo internacional harmonizado pela AOAC internacional, ISO e IUPAC. Analytica, São Paulo, v. 51, p.66-77, 2011.

BISUTTI, I.; HILKE, I.; RAESSLER, M. Determination of total organic carbon: an overwiew of current methods. Trac-Trend Anal Chem, v. 23, p.716-726, dez. 2004.

BOONE, J. M.; BUSHBERG, J. T.; JUNIOR, E. M. L.; SEIBERT, J. A. The essential physics of medical imaging. Philadelphia: Lippincott Williams \& Wilkins, 2012.

BOTTOLI, C. B. G.; COLLINS, C. H.; JARDIM, I. C. S. F.; MELO, L. F. C.; RIBANI, M. Validação em métodos cromatográficos e eletroforéticos. Química Nova, São Paulo, v. 27, n. 5, p. 771-780, 2004.

BUCHPIGUEL, C. A.; HIRONAKA, F. H.; LIMA, M. S.; ONO, C. R.; SAPIENZA, M. T. Medicina nuclear: princípios e aplicações. 1. ed. Rio de Janeiro: Atheneu, 2012. v. 1, 490 p.

CHEMICAL Book: banco de dados. Disponível em:

$<$ http://www.chemicalbook.com/CASDetailList_19500_EN.htm>. Acesso em: 01 jun. 2015.

CHEMSPIDER: banco de dados preparado por Royal Society of Chemistry. Disponível em: $<$ http://www.chemspider.com>. Acesso em: 01 jun. 2015.

CHINCHOLE, A. S.; POUL, B. N.; WAGHMARE, P.V. A brief review on cleaning validation and its significance in pharmaceutical industry.International Journal Of Pharmaceutical Sciences, Inglaterra, p. 165-192, set. 2013.

CHINOL, M.; HNATOWICH, D. J. Generator-produced yttrium-90 for radioimmunotherapy. $\boldsymbol{J}$. $\mathbf{N u c l}$. $\mathbf{M e d}$., Reston, p. 1465-1470. 1987.

CLARK, K.A. Total organic carbon analysis for cleaning validation in pharmaceutical manufacturing. Canton: Anatel Corporation, 2000.

CLESCERI, L. S.; EATON, A. D.; GREENBERG, A. E.; RICE, E. W. Standard methods for the examination of water \& wastewater. 21 ed., Maryland: Port City Press, 2005, p. 1-26. 
CLEMENTINO, M.R.A. Determinação do teor de TOC: metodologia analitica e aplicações na indústria farmacêutica. 2006. Dissertação (Mestrado) - Universidade Federal de Pernambuco, Recife.

COELHO, P.; FERREIRA, D.; OLIVEIRA, R.; SANTOS, D.; VEIGA, F. Preparações radiofarmacêuticas e suas aplicações. Rev. Bras. Cienc. Farm., São Paulo, v. 42, n. 2, jun. 2006.

CONSELHO REGIONAL DE FARMÁCIA DO ESTADO DE SÃO PAULO (CRF-SP). Farmácia Hospitalar. Abr., 2013

CUPPARI, L.; DRAIBE, S. A.; KAMIMURA, M. A.; SANTOS, N. S. J. dos. Albumina sérica como marcador nutricional de pacientes em hemodiálise. Rev Nutr, Campinas, v. 17, n. 3, p. 339-349, set. 2004.

FERREIRA, M. M. C.; MORANO, S. C.; RIBEIRO, F. A. L.; SCHNEIDER, R. P.; SILVA, L. R.Planilha de validação: uma ferramenta para estimar figuras de mérito na validação dos métodos analíticos. Química Nova, São Paulo, v. 31, n. 1, p. 164-171, 2008.

FERREIRA, R. M.; MARQUES, F.L.N. Radiofarmácia. In: HIRONAKA, F. H. et al. Medicina nuclear princípios e aplicações. São Paulo: Atheneu, 2012. p. 55-66.

FLETCHER, D. I. Determinação de limites de resíduos visíveis em superfície de equipamento de uma fábrica farmacêutica. Pharmaceutical Technology Brasil, São Paulo, v. 17, n. 5, p. 610, out. 2013.

FOOD AND DRUG ADMNISTRATION (FDA).Guidance for industry, Q7A good manufacturing practice guidance for active pharmaceutical ingredients. Ago. 2001. Disponível em:

$<$ http://www.fda.gov/ICECI/ComplianceManuals/CompliancePolicyGuidanceManual/ucm20 0364.htm>. Acesso em: 01 jun. 2015.

Validation of cleaning processes: guide to inspections validation of cleaning processes. 1993. Disponível em:

$<$ http://www.fda.gov/ICECI/Inspections/InspectionGuides/ucm074922.htm>. Acesso em: 06 jun. 2013.

FOOD INGREDIENTS BRASIL. Dossiê proteínas: proteínas. Food Ingredients Brasil, São Paulo, n.22, p. 60-72, 2012.

FOURMAN, G.L.; MULLEN, M.V. Determining cleaning validation acceptance limits for pharmaceutical manufacturing operations. Pharm Technol, USA, v. 17, n. 4, p.54-60, 1993. 
FURLONG, J.; PURCELL, M.; WALLACE, B. Total organic carbono analysis as a precursor to disinfection by products in potable water: oxidation technique considerations. J. Environ. Monit., Bethesda, v. 4, p. 35-42, 1996.

GOMES, M. C. S. Validação da eficácia dos procedimentos de limpeza, no equipamento de fabric e embalagem, na indústria farmacêutica. 2012. Dissertação (Mestrado) - Instituto Superior de Engenharia de Lisboa, Portugal.

HEALTH PRODUCTS AND FOOD BRANCH INSPECTORATE. Good manufacturing practices: cleaning validation guidelines. Canadá. 2000.

ICH. ICH Harmonized tripartite guideline: validation of analytical procedures: text and methodology Q2 (R1), 2005.

ICH Harmonized tripartite guideline: good manufacturing practice guide for active pharmaceutical ingredients Q7A, 2000.

INSTITUTO NACIONAL DE METROLOGIA, QUALIDADE E TECNOLOGIA (INMETRO). DOQ-CGCRE-008:orientação sobre validação de métodos analíticos DOQCGCRE. 3 ed., Brasília: INMETRO, 2010.

JONES, A. G.; MAHMOOD, A. In: REDVANLY, C. S. (Ed.).; WELCH, M. J (Ed.). Handbook of radiopharmaceuticals: radiochemistry and applications. Nova York: Wiley, 2003. p. 323-362.

KUMAR, V.S.; SANJEEV, T.; SHARMA, P.K. Overview of cleaning validation in pharmaceutical manufacturing unit. International Journal Of Advanced Research In Pharmaceutical \& Bio sciences, p. 154-164, 2012.

LAKSHMANA, S.P.; SURIYAPRAKASH, T.N.K. Cleaning Validation and its importance in Pharmaceutical Industry. Pharma Times, Londres, v. 42, n. 07, jul. 2010.

LEBLANC, D.A. Establishing Scientifically Justified Acceptance Criteria for Cleaning Validation of Finished Drug Products. Pharmaceutical Technology, EUA, 1998. Disponível em: <http://www.pharmanet.com.br/pdf/validalimpeza.pdf >. Acesso em: 06 jun. 2013.

LUGON, M. M. V. Determinação de Sn(II) por polarografia: aplicação no controle de qualidade de reagentes liofilizados para radiodiagnóstico. 2008. Dissertação (Mestrado) Universidade de São Paulo, São Paulo.

MASUELLI, M. A. Study of bovine serum albumin solubility in aqueous solutions by intrinsic viscosity measurements.Advances in Physical Chemistry, Argentina, 2013. 
MATHER, S. J. Innovation in radiopharmacy: progress and constraints? Eur. J. Nucl. Med. p. 405-407, 2001.

MINGORANCE, J. Sistema de Validação de Limpeza (Parte I). Sociedade Brasileira de Controle de Contaminação, 2005. Disponível em:

$<\mathrm{http} / / /$ www.sbcc.com.br/revistas_pdfs/ed\%2019/19validacao_p1.pdf $>$. Acesso em: 05 ago. 2013.

Sistema de Validação de Limpeza (Parte II). Sociedade Brasileira de Controle de

Contaminação, 2005. Disponível em:

$<$ http://www.sbcc.com.br/revistas_pdfs/ed\%2020/20ValidLimp(parte2).pdf $>$. Acesso em: 05 ago. 2013.

NASH, R.A.; WACHTER, A.H. Pharmaceutical process validation. 3 ed. Nova York: Marcel Dekker, 2003, 860p.

O'NEIL, M.J. (Ed.). The Merck Index: an encyclopedia of chemicals, drugs, and biologicals. EUA: Chapman and Hall, 1996.

OSSO, J.; KNAPP, R. Principles and operation of radionuclide generators. In: THEOBALD, T. (Ed.). Sampson's textbook of radiopharmacy Sampson's textbook of radiopharmacy. Inglaterra: Pharmoceutical Press, 2001. 4 ed., p. 339-364.

PARENTERAL DRUG ASSOCIATION (PDA). Technical report n. 29: points to consider for cleaning validation. 29 ed. rev. EUA: PDA, 2012.

PARTICLE SCIENCES. Protein structure. Technical Brief, EUA, v. 8, 2009.

PERES, C.P. Validação dos processos de limpeza na indústria farmacêutica. Fármacos \& Medicamentos, v. 3, n. 13, p. 20-23, 2001.

PHARMACOSMOS: banco de dados preparado por Dextran Chemistry. Disponível em: $<$ http://www.dextran.net/about-dextran/dextran-chemistry.aspx>. Acesso em: 01 jun. 2015.

PUBCHEM Compound: banco de dados preparado por The National Center for Biotechnology Information. Disponível em: <http://www.ncbi.nlm.nih.gov/pccompound $>$. Acesso em: 01 jun. 2015.

PURCELL, M.; STEVENS, R.; WALLACE, B. Implementing total organic carbon analysis for cleaning validation. Pharmaceutical Technology, p. 40-43, 2004.

RAKIAS, F.; ZOLLE, I. Handbook of quality control methods of 99m Tcradiopharmaceuticals in nuclear medicine; COST B3: WG-1; 1996. 
RODRICKS, J.V. Risk assessment at hazardous waste disposal sites. Hazardous Waste, v. 1, n. 3, p. 333-362, jan. 1984.

SAHA, G. B. Fundamentals of nuclear pharmacy. USA: Springer, 1998. p. 34-170.

SANTOS, H. M. M. Validação de Processos Farmacêuticos. In: Faculdade de Farmácia da Universidade de Coimbra, Portugal. Disponível em: $<$ http://pt.slideshare.net/heltonsantos/validaode-processos-farmacuticos>. Acesso em: 01 jun. 2015.

SCHUMACHER, B.A. Methods for the determination of Total Organic Carbon (TOC) in soils and sediments.Las Vegas: U. S. Environmental Protection Agency, 2002.

SHARMA, A.; SHARMA, R. Validation of analytical procedures: a comparison of ICH vs. pharmacopoeia (USP) vs FDA. International Research Journal Of Pharmacy. Índia, mar. 2012.

SHIMADZU CORPORATION. Examining the role of TOC analyzers in the pharmaceutical laboratory. Columbia, 2010.

. Total organic carbon analyzer: TOC-VWP \& TOC-Control V software: user manual. Japão: Analytical \& Measuring Instruments Division, 2004.

Total organic carbon: standard methods committee. 1996. Disponível em:

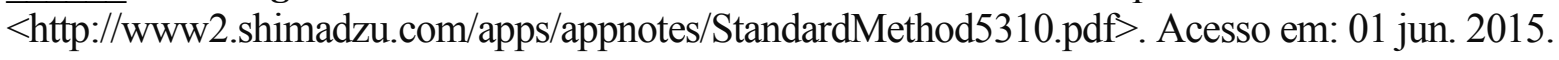

TELEDYNE ANALYTICAL INSTRUMENTS. The pitfalls of process TOC and how to avoid them. USA, s.d.

TUBIS, M.; WOLF, W. Radiopharmacy. Nova York: John Wiley and Sons, 1976. p. 263-265.

UNITED STATES PHARMACOPEIAL CONVENTION (USP). The United States

Pharmacopeia. Rockville, 38 ed., 2015.

VALLABHAJOSULA, S. Molecular imaging: radiopharmaceuticals for PET and SPECT. Nova York: Springer, 2009.

WORLD HEALTH ORGANIZATION (WHO). Expert committee on specifications for pharmaceutical preparation. Geneva, 2006. 461p.

Quality assurance of pharmaceuticals: a compendium of guidelines and related materials. 2 ed. Geneva, 2007. 248 p. 